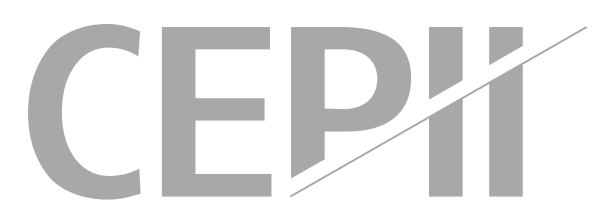

\title{
Product-Level Trade Elasticities: Worth Weighting For*
}

Lionel Fontagné ${ }^{\dagger}$, Houssein Guimbard ${ }^{\dagger \dagger} \&$ Gianluca Orefice ${ }^{\ddagger}$

Highlights

- Trade elasticity is a crucial parameter in evaluating the welfare impacts of trade liberalization.

- We estimate trade elasticities at the product level (6-digit of the Harmonized System) by exploiting the variation in bilateral applied tariffs for each product category. The obtained trade elasticities are centered around -5 .

We show that using homogeneous - instead of product-specific - trade elasticity implies a downward bias in welfare gains from trade in particular for developing countries.

\footnotetext{
* We are grateful to Antoine Bouët, Carsten Eckel, Ben Faber, Robert Feenstra, Lisandra Flach, Christophe Gouel, Mario Larch, Thierry Mayer, Monika Mrazova, Alessandro Nicita, Marcelo Olarreaga, Frédéric Robert-Nicoud, Andres Rodriguez-Clare, John Romalis, Joao Santos-Silva, Ina Simonovska, Alan Taylor and Yoto Yotov for helpful comments. We also thank seminar participants at Berkeley, CEPII (Paris), UC-Davis, Groningen, GTDW (Geneva), LMU (Munich), PSE (Paris) and the World Bank. Gianluca Santoni dispensed particularly shrewd advice regarding the TiVA data. An earlier version of this paper circulated under the title Product-Level

Trade Elasticities and published in December 2019 (updated on August 2020).

† Paris School of Economics - Université Paris I and CEPII - lionel.fontagne@univ-paris1.fr

†† CEPII - houssein.guimbard@cepii.fr.

‡ University Paris-Dauphine, PSL - gianluca.orefice@dauphine.psl.eu
} 


\section{Abstract}

Trade elasticity is a crucial parameter in evaluating the welfare impacts of changes in trade frictions. The value of this parameter varies widely across product categories, however, which is especially important for developing countries' evaluation of the welfare gains from trade. We estimate, and make publicly-available, trade elasticities at the product level (the 6-digit level of the Harmonized System, comprising over 5,000 product categories) by exploiting the variation in bilateral applied tariffs for each product category for the universe of available country pairs over the 2001 to 2016 period. We address potential endogeneity issues, as well as heteroskedasticity and selection bias due to zero trade flows. Homogenous elasticities lead to the underestimation of the welfare impact of trade, in particular for developing economies, and all the more so for those with high import penetration in less-elastic sectors.

\section{Keywords}

Trade Elasticity, International Trade, Tariffs, Welfare Gain.

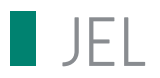

F14, F17.

\section{Working Paper}

CEPII (Centre d'Etudes Prospectives et d'Informations Internationales) is a French institute dedicated to producing independent, policyoriented economic research helpful to understand the international economic environment and challenges in the areas of trade policy, competitiveness, macroeconomics, international finance and growth.
CEPII Working Paper

Contributing to research in international economics

C C CEPII, PARIS, 2019

All rights reserved. Opinions expressed in this publication are those of the author(s) alone.

Editorial Director:
Sébastien Jean
Production: Laure Boivin
Published on 26.08 .20
No ISSN: $1293-2574$

CEPII

20, avenue de Ségur TSA 10726 75334 Paris Cedex 07 +33153685500 www.cepii.fr Press contact: presse@cepii.fr 


\section{Product-Level Trade Elasticities: Worth Weighting For ${ }^{1}$}

Lionel Fontagné (Paris School of Economics - Université Paris I and CEPII)*

Houssein Guimbard (CEPII) ${ }^{\dagger}$

Gianluca Orefice (University Paris-Dauphine, PSL) ${ }^{\ddagger}$

\section{Introduction}

The global economy is currently confronted with an unprecedented resurgence of trade frictions due to the trade war initiated in 2018 and the Covid-19 outbreak crisis of 2020. The quantification of the welfare impacts of these higher trade costs for economies at different levels of economic development, and characterized by different sectoral specialization and degree of openness, requires the sound parametrization of the trade model that is used. Trade elasticity is one of these key parameters, especially when it comes to providing an order of magnitude of the welfare impacts of a change in trade costs: changes in welfare are a function of the change in the share of domestic expenditure and the trade elasticity to variable trade costs (Arkolakis, Costinot \& Rodriguez-Clare 2012). As a tariff is a variable trade cost imposed by the importer country, the elasticity of trade values to changes in tariffs becomes the key parameter for many researchers and practitioners interested in evaluating the welfare effects of trade policies - see the approach coined as "trade theory with numbers"

\footnotetext{
${ }^{1}$ We are grateful to Antoine Bouët, Carsten Eckel, Ben Faber, Robert Feenstra, Lisandra Flach, Christophe Gouel, Mario Larch, Thierry Mayer, Monika Mrazova, Alessandro Nicita, Marcelo Olarreaga, Frédéric RobertNicoud, Andres Rodriguez-Clare, John Romalis, Joao Santos-Silva, Ina Simonovska, Alan Taylor and Yoto Yotov for helpful comments. We also thank seminar participants at Berkeley, CEPII (Paris), UC-Davis, Groningen, GTDW (Geneva), LMU (Munich), PSE (Paris) and the World Bank. Gianluca Santoni dispensed particularly shrewd advice regarding the TiVA data. An earlier version of this paper circulated under the title "Product-Level Trade Elasticities" and published in December 2019 (updated on August 2020).

*lionel.fontagne@univ-paris1.fr

thoussein.guimbard@cepii.fr.

$\ddagger$ gianluca.orefice@dauphine.psl.eu
} 
popularized by Costinot \& Rodriguez-Clare (2014). ${ }^{2}$ A relatively closed economy (typically a large country), or a country in which imports have close domestic substitutes, will suffer little pain from moving to autarky, as the subsequent trade-induced welfare losses are small (Costinot \& Rodriguez-Clare 2018).

But while the first statistic - how much does a country trade with itself as a proportion of its total expenditures - is directly observable, the current estimates of trade elasticities diverge widely. ${ }^{3}$ In their survey of open questions related to the analysis of commercial policies, Goldberg \& Pavcnik (2016) stress that "perhaps surprisingly, estimates of the trade elasticity based on actual trade policy changes are scarce [...] it is surprising that trade policy has not been exploited to a larger extent to identify this crucial parameter". ${ }^{4}$ This paper aims to at least partially fill this gap. By systematically scanning (preferential or MFN) applied tariffs and import flows at the bilateral and product level for 152 importing countries and 189 exporting countries over the 2001-16 period, we provide a set of estimations of theory-consistent trade elasticities at the product level and identify the determinants of heterogeneous productlevel trade elasticities. ${ }^{5}$ Our estimation sample also includes countries at lower levels of development, with only partially-liberalized trade. This is an important contribution with respect to the previous literature, as the trade-elasticity estimates that come from advanced countries, due to the lack of data on developing countries, may not be relevant for the evaluation of welfare changes in developing countries (Simonovska \& Waugh 2014a).

Trade elasticities can be estimated at different levels of disaggregation, ranging from the

\footnotetext{
${ }^{2}$ We consider in what follows that the current tariffs are applied at the date of the trade flow. They may differ from future tariffs to the extent that tariffs are bound above the level that is actually applied on an MFN basis or even not bound at all. Tariffs in advanced countries are fully bound, however.

${ }^{3}$ For example, the trade elasticities estimated by Eaton \& Kortum (2002) range from 3.6 to 12.8, while Caliendo \& Parro (2015) find trade elasticities ranging from 0.49 in the "Auto" sector to 69 in the "Petroleum" sector.

${ }^{4}$ See Goldberg \& Pavcnik (2016), pp. 24-25. Two exceptions are Amiti, Redding \& Weinstein (2019) and Fajgelbaum, Goldberg, Kennedy \& Khandelwal (2020), who take advantage of the large swings in US tariffs and rely on US imports from January 2017 to December 2018 at the origin-month-HS10 level. Amiti et al. (2019) estimate an elasticity of substitution between varieties of 6 (see column 3 of their Table 1). The preferred value for US import-demand elasticity in Fajgelbaum et al. (2020) is 2.47.

${ }^{5}$ With these data at hand, one may also be tempted to estimate (and make publicly-available) product-specific export-supply elasticities by applying the method proposed in Romalis (2007) and Fajgelbaum et al. (2020). However, a lack of complete information on import quantities at the HS 6-digit product level (a large number of missings) would imply very imprecise proxies for before-duty export prices (i.e. import TUV), and considerable measurement-error bias when applying the method in Romalis (2007) and Fajgelbaum et al. (2020). We therefore refrain from the analysis of product-level export-supply elasticities in this paper.
} 
sector to the product or even the variety. In the latter case, it has to be estimated at the level of individual exporters using transaction-level customs data, ${ }^{6}$ with the challenge that export prices and export quantities are endogenous at the firm level. ${ }^{7}$ To overcome this difficulty, and as firm-level export information over multiple countries is rare, ${ }^{8}$ we here rely on the finest grain: the HS 6-digit product level. By doing so, we implicitly aggregate firms (with different levels of productivity) within a given exporting country-product cell; in this case the shape of the distribution of productivity within the cell will affect the observed elasticity (Chaney 2008). ${ }^{9}$ However, we will control for this distribution in our estimations. ${ }^{10}$ Another common concern is that sector-level trade elasticities are (downward-) biased if the elasticity varies sharply across products and/or due to the covariance between the dispersion of tariffs across countries and the sectoral trade elasticities (Imbs \& Mejean 2015): this concern is mitigated here, as we rely on a very disaggregated product classification.

The trade (or Armington) elasticity can be interpreted differently according to the underlying theoretical framework. ${ }^{11}$ Feenstra, Luck, Obstfeld \& Russ (2018) underline the conceptual distinction between the "macro" elasticity between domestic and imported goods, and the "micro" elasticity of substitution between different import suppliers at the core of the current paper (i.e. how bilateral tariffs affect bilateral import flows). While there is no such distinction in the new generation of computable trade models à la Dekle, Eaton \& Kortum (2008), the two elasticities are usually nested in Computable General Equilibrium models with a Constant Elasticity of Substitution (CES) demand system. ${ }^{12}$ Using US data, Feenstra et al. (2018)

\footnotetext{
${ }^{6} \mathrm{~A}$ variety is then defined as the firm-product combination.

${ }^{7}$ Fontagné, Martin \& Orefice (2018) use a firm-level time-varying instrumental variable for export prices, and estimate the firm-level elasticity to tariffs controlling for how exporters absorb tariff shocks in their export prices.

${ }^{8}$ Bas, Mayer \& Thoenig (2017) is an exception, as they are able to combine French and Chinese firm-level exports to estimate trade elasticities.

${ }^{9}$ Using firm-level export data for the universe of French manufacturing firms, Fontagné \& Orefice (2018) estimate trade elasticities at the sector level and - in line with the theory in Chaney (2008) - show that the effect of stringent Non-Tariff Measures in reducing export flows is magnified in sectors with a morehomogeneous distribution of firm productivity (i.e. where a non-negligible share of exports is concentrated among less-productive firms).

${ }^{10}$ In the present paper, the estimations are carried out at the product level with exporter-time fixed effects that control for the distribution of firm productivity in each product-exporter cell.

${ }^{11}$ In a seminal paper, Armington (1969) introduced a preference model in which goods were differentiated by their origin.

${ }^{12}$ See Costinot \& Rodriguez-Clare (2014) for a detailed comparison of the two approaches.
} 
show that the macro elasticity is significantly lower than the micro elasticity for one quarter of goods.

The trade elasticity can be estimated via a demand system (Feenstra 1994, Broda \& Weinstein 2006, Ossa 2015, Soderbery 2018), using the non-arbitrage condition and product-level price data (Simonovska \& Waugh 2014a, Giri, Yi \& Yilmazkuday 2020), considering imports as inputs into the GDP function (Kee, Nicita \& Olarreaga 2008) or in a gravity framework (Caliendo \& Parro 2015). ${ }^{13}$ While Caliendo \& Parro (2015) rely on the multiplicative properties of the gravity equation in order to cancel out unobserved trade costs, in line with the "ratio approach" introduced by Head \& Ries (2001) and systematized as "Tetrads" by Martin, Mayer \& Thoenig (2008) and Head, Mayer \& Ries (2010), ${ }^{14}$ we here take a gravity approach using a strategy of fixed effects, as suggested by Head \& Mayer (2014).

The requirement in terms of observed trade costs therefore depends on the choice of identification strategy. Estimating a demand system implies volume and prices at the finest classification level of traded products (Feenstra 1994) with no explicit consideration of trade policies. The latter are assumed to be fully passed onto the prices at the border. Similarly, in Simonovska \& Waugh (2014a) and Giri et al. (2020), the maximum cross-sectional price difference between countries for detailed price-level data is a proxy for trade frictions. ${ }^{15}$ Unit values are used as a proxy for prices in Kee, Nicita \& Olarreaga (2009), when estimating the import-demand elasticity as the percentage change in the imported quantity, holding the prices of other goods, productivity and the endowment of the importer constant. In contrast, Caliendo \& Parro (2015) rely on the cross-sectional variations in trade shares and applied tariffs in 20 sectors and 30 countries to estimate sectoral trade elasticities.

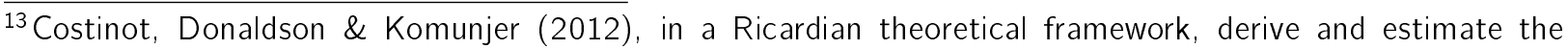
elasticity parameter using trade data and productivity measures for 13 ISIC rev 3.1 sectors in 21 developed countries in 1997. They find an average elasticity of 6.53 .

${ }^{14}$ The triple-difference approach proposed by Caliendo \& Parro (2015) differs, however, from the odds ratio and the "tetrad" approach, as it does not require domestic-sales data (the combination of gross production and trade flows) or a reference country to identify the parameters. The triple-difference approach relies on the assumption that tariffs are the only non-symmetric trade cost (all others are assumed to be symmetric, and so cancel out in the triple difference).

${ }^{15}$ Simonovska \& Waugh (2014a) use disaggregated prices from the International Comparison Programme for 62 product categories in 2004, matched to trade data in a cross-section of 123 countries. Giri et al. (2020) adopt the same strategy for $12 \mathrm{EU}$ countries and 1,410 goods (in 19 traded sectors) in 1990.
} 
In this paper we aim to cover the largest number of importing countries and the finest degree of product disaggregation in our panel estimations, and so rely on actual trade policies. To proceed, we use the most-disaggregated level of information on trade policies and bilateral imports available for the universe of products and importing countries, ${ }^{16}$ which is the 6-digit Harmonized System (HS6 thereafter) that covers over 5,000 different product categories for a sample of 152 importing countries. A typical product category here will be "Trousers, bib and brace overalls, breeches and shorts; men's or boys', of textile materials (other than wool or fine animal hair, cotton or synthetic fibres), knitted or crocheted". As we use bilateral trade data at the product-category level, we do not observe the differentiation of products among firms in a given exporting country. However, given the very-disaggregated product categories, this concern is attenuated here. We calculate the tariff elasticities (and so recover the trade elasticities) comparing the sales of e.g. Indian and Chinese trousers and shorts in importing markets, controlling for any systematic difference in elasticities between importers via destination fixed effects. For each HS6 product category we observe the universe of bilateral trade flows between countries, in value, in a given year, and the tariff (preferential or not) applied to each exporter by each importer of this product. This information is available for 2001, 2004, 2007, 2010, 2013 and 2016. Even though a great deal of the variation in tariffs is cross-sectional, we are able to exploit the panel nature of this dataset, and explain - for a given importer - the cross-country variation in imports via the cross-country variation in tariffs. ${ }^{17}$ We benefit from the fine grain of our data, and estimate not only product-level (HS6) trade elasticities but also sector-level (HS4) trade elasticities by pooling the productlevel observations within each sector. ${ }^{18}$

We show that, when estimated at the HS6 product-category level for the universe of products and country-pairs, and when we replace statistically-insignificant estimates by zero, the distribution of the statistically significant at the $1 \%$ level trade elasticities is centered around

\footnotetext{
${ }^{16}$ Imports can be observed at the tariff line for single countries. This is why US imports have repeatedly been used to estimate trade elasticities. An influential set of elasticities at the tariff-line level for the US (13,972 product categories) and the 1990-2001 period is found in Broda \& Weinstein (2006).

${ }^{17}$ In Section 2.5 we show that the cross-country variation (the between component) in import tariffs is larger than the over-time variation (the within component).

${ }^{18}$ See Section 3.3.2 for a detailed discussion on HS4-specific trade elasticities.
} 
-5 , with an average figure of -5.5 and a median of $-4 .{ }^{19}$ These values are however driven towards zero by our replacement of statistically-insignificant estimates by zeros: when instead these zeros are dropped, the average and median figures in the trade-elasticity distribution become respectively -9.8 and $-7.3 .^{20}$ There is considerable variation around these values, and our results will be useful for a wide set of exercises exploiting the product- (or sector-) level dimension of this elasticity. ${ }^{21}$ These figures are comparable to those found in the trade literature: Romalis (2007) obtains elasticities of substitution of between 6.2 and 10.9 at the HS6 level, while Broda \& Weinstein (2006) find an average value of 6.6 for US imports with 2,715 SITC 5-digit categories, and 12.6 at the tariff-line (13,972 categories) level over the 1990-2001 period. ${ }^{22}$ Using HS6-import data and unit values for 117 importers over the 19882001 period, Kee et al. (2009) obtain a simple average import-demand elasticity of 3.12. The benchmark trade elasticity in Simonovska \& Waugh (2014a), using a simulated method of moments and international differences in individual-price data, is 4.12; Giri et al. (2020) use the same method and find a median trade elasticity of 4.38 (minimum 2.97, maximum 8.94). At the industry level, Ossa (2014) estimates CES elasticities of substitution by pooling the main world importers in cross-section, which produces a mean value of 3.42 (ranging from 1.91 for Other Animal Products to 10.07 for Wheat). By combining GTAP 7 and NBER-UN data for 251 SITC-Rev3 3-digit industries, Ossa (2015) obtains an average elasticity of 3.63 (ranging from 1.54 to 25.05). After controlling for exporter and importer fixed effects in their triple-difference approach, the trade elasticities in Caliendo \& Parro (2015) range from 0.49 in the Auto sector to 69 in the Petroleum sector. ${ }^{23}$ However, other calibration exercises yield higher figures: Hillberry, Anderson, Balistreri \& Fox (2005) show that reproducing vari-

\footnotetext{
${ }^{19}$ Under the usual CES demand system assumption, the trade elasticity $\varepsilon$ is equal to one minus the elasticity of substitution $\sigma ; \sigma$ in turn is equal to the negative of the tariff elasticity when using FOB trade flows (as in this paper). We discuss in Section 3.3.4 whether our estimated elasticities suggest a demand system other than the CES, and in particular whether they are in line with an additive-separable sub-convex system of demand. See Mrázová, Neary \& Carrere (2020) and Section 2.2 for further discussion of this point.

${ }^{20}$ The trade-weighted median figure is -7.5 .

${ }^{21}$ The estimated trade elasticities at different level of aggregation, as well as related additional material, are available on a dedicated web page: https://sites.google.com/view/ product-level-trade-elasticity/home and on the CEPII website: http://www.cepii.fr/CEPII/en/ bdd_modele/presentation.asp?id=35.

${ }^{22}$ Note that the corresponding median figures are much lower, at respectively 2.7 and 3.1. Soderbery (2018) obtains a mean elasticity of 3.4 for 1,243 HS4 product categories over the 1991-2007 period.

${ }^{23}$ See Table A2 in Caliendo \& Parro (2015).
} 
ations in bilateral trade shares with a standard computable general equilibrium model imposes elasticities of substitution of over 15 in half of the sectors. ${ }^{24}$ Even restricting the comparison to the gravity estimates controlling for multilateral resistance terms leads to a wide range of values, as shown by Head \& Mayer (2014) in their review of 435 elasticities from 32 papers: they obtain a median figure of 5.03 with a standard deviation of 9.3.

There is significant trade-elasticity heterogeneity across products, both in the literature and in our work here. Beyond estimating and making publicly-available these product-level trade elasticities, our second contribution is to see what lies behind their magnitude. We find that product differentiation plays a large role, as predicted by theory. We also underline the footprint of firm heterogeneity: the estimated product-level elasticity is sensitive to distance, consistent with the selection of exporters into distant markets.

The third contribution of our work here is to assess the bias in estimating the gains from trade with a homogeneous (instead of industry-specific) trade elasticity for countries at different levels of income per capita. At first sight, heterogeneous elasticities across sectors (and even more so across products) should yield larger gains simply because the average of inverse trade elasticities differs from the inverse of the average trade elasticity (Ossa 2015). However, other dimensions of the problem should also be considered, such as the budget share of the different industries and the openness of each sector (Giri et al. 2020). Even with elasticities that are independent of income and trade values, budget shares and initial specialization may vary substantially along the development ladder. ${ }^{25}$ We compare the welfare gains from trade using heterogeneous vs. average (homogeneous) trade elasticities for countries at different level of development in a standard ACR multi-sector framework (Arkolakis et al. 2012). We confirm that using a homogeneous (instead of heterogeneous) trade elasticity across sectors biases the calculation of the welfare gains from trade. Importantly, this bias is larger for developing countries, and all the more so for those with high import penetration in less-elastic sectors. This is of key interest for both researchers and policy-makers who wish

\footnotetext{
${ }^{24}$ More precisely, in a calibration-as-estimation procedure applied to the GTAP model, this elasticity had to be set at a value above 15 in 21 out of 41 sectors in order to reproduce the actual variation in trade shares. No solution was found in five sectors.

${ }^{25}$ We will show that trade elasticities vary by importer development level.
} 
to evaluate the welfare impacts of trade policies, and is one of the main contributions of this paper. While Giri et al. (2020) argue that the bias from using homogeneous elasticities is only small (between 10 and 20\%), we show that this average figure masks considerable heterogeneity across countries at a given level of development, and that there is an inverse relation between the size of the bias and importer development level. Our findings are related to the generalization of the CES assumption by Adao, Costinot \& Donaldson (2017), in which the demand elasticity varies systematically by observable country characteristics, e.g. income per capita (the "mixed CES" demand system). Last, our argument is related to Fally \& Sayre (2018), who show that a low price elasticity of demand for commodities, if not properly accounted for in calibrated models, leads to the underestimation of the aggregate gains from trade.

The remainder of the paper is structured as follows. We present our theoretical framework and identification strategy in Section 2. Our trade elasticities estimated at the product level appear in Section 3, which also contains a series of robustness checks and tests the accuracy of our estimated elasticities. Section 4 carries out a standard calculation following Arkolakis et al. (2012), and compares the change in welfare from moving to autarky using heterogeneous elasticities versus adopting the average (product-invariant) elasticity for countries at different level of development. Last, Section 4 concludes.

\section{The Identification Strategy}

\subsection{Set-up}

We start from the prior that the coefficient associated with tariffs - a variable trade cost - corresponds to the import-demand elasticity in a structural gravity equation for bilateral trade. Consider a World economy in which every country $i$ can produce the entire spectrum of products $k \in K$ (with traded goods $k$ corresponding to the 6 -digit products in the HS classification). The production of $k$ is differentiated by country of origin $i$ according to the Armington hypothesis. Hence, the set of origins $i \in I$ (for a given product $k$ ) defines the set of varieties available for consumption in country $j$. Let us assume a one-tier CES demand 
system. This implies the separability of the $k$ specific consumption demand functions, which is at the core of our empirical approach since we estimate a structural gravity model for each product $k .^{26}$ Each country $j$ is populated by a representative agent whose consumption of product $k$ maximizes the following CES utility function:

$$
U_{j k, t}=\left(\sum_{i} \alpha_{i k, t}^{\left(1-\sigma_{k}\right) / \sigma_{k}} c_{i j k, t}^{\left(\sigma_{k}-1\right) / \sigma_{k}}\right)^{\sigma_{k} /\left(\sigma_{k}-1\right)} \text { s.t. }=\sum_{i} p_{i j k, t} c_{i j k, t}=E_{j k, t}
$$

where $c_{i j k, t}$ is the demand for good $k$ originating from $i$ at time $t, \sigma_{k}$ (with $\sigma_{k}>1$ ) the product-specific elasticity of substitution across varieties originating from different origins $i, E_{j k, t}$ the expenditure in country $j$ on good $k$ at time $t, p_{i j k, t}$ is the price of product $k$ originating in $i$ and $\alpha_{i k t}$ a positive distribution parameter. The set of origins $i$ also includes the domestic country $j$ as the one-tier structure of demand subsumes an upper nest of the demand system differentiating between domestic and foreign production.

The CIF price is inclusive of the transport cost $t_{i j k}$, whose functional form is $\left(1+t_{i j k}\right)=d_{i j} \rho_{k}$, where $d_{i j}$ is the bilateral distance between $i$ and $j$ and $\rho_{k}$ the elasticity of the shipping cost of good $k$ with respect to distance (Hummels 2007). If the importer country $j$ imposes an (applied) ad valorem tariff $\tau_{i j k t}$ on the CIF price of good $k,{ }^{27}$ and under the assumption of the full pass-through of this tariff to the consumer price $p_{i j k t}$, the price paid by the consumer at destination is: ${ }^{28}$

\footnotetext{
${ }^{26}$ We choose a one-tier CES demand system for the sake of tractability. This implies considering the domestically-produced variety as a consumption option among other foreign-produced varieties at the same level of the consumer's utility function. While this approach has been used repeatedly in the literature (Romalis 2007, Arkolakis et al. 2012), an alternative is to adopt a two- or three-tier CES demand system where the upper nest differentiates between foreign and domestic products, and the lower nest(s) among foreign-produced varieties (Fajgelbaum et al. 2020, Feenstra et al. 2018).

${ }^{27}$ The tariff is charged on CIF values in most countries (the United States is an exception). In what follows we also assume the full use of the preferential tariff rate. Any exporter-specific deviation from this practice is absorbed by exporter-year fixed effects in the empirical specification. In the presence of exporter-importer specific deviations from the full use of the preferential rate, our estimations produce lower-bound elasticities (i.e. an actual tariff cut that is smaller than that which we observe in the tariff data, and the same observed change in bilateral imports). By the same token we also assume the full use of the preferential-tariff rate notwithstanding the Rules of Origin.

${ }^{28}$ Recent empirical evidence suggests the full pass-through of US tariffs into the export prices of Chinese goods (Amiti et al. 2019, Fajgelbaum et al. 2020, Cavallo, Gopinath, Neiman \& Tang 2019). Any exporter-specific deviation from full-pass through is absorbed by the exporter-year fixed effects in our estimations.
} 


$$
p_{i j k, t}=p_{i k, t}\left(1+\tau_{i j k, t}\right)\left(1+t_{i j k}\right)
$$

where $p_{i k t}$ is the before-duty and transport-cost price at country i's border. Import demand (in nominal terms) can be therefore written as:

$$
p_{i j k, t} c_{i j k, t}=\alpha_{i k, t}^{\left(1-\sigma_{k}\right)} p_{i k, t}^{\left(1-\sigma_{k}\right)}\left(1+\tau_{i j k, t}\right)^{\left(1-\sigma_{k}\right)}\left(1+t_{i j k}\right)^{\left(1-\sigma_{k}\right)} P_{j k, t}^{\left(\sigma_{k}-1\right)} E_{j k, t}
$$

where $P_{j k, t}=\left(\sum_{i}\left(\alpha_{i k, t} p_{i j k, t}\right)^{\left(1-\sigma_{k}\right)}\right)^{1 /\left(1-\sigma_{k}\right)}$ is the price index in $j$ of the varieties of product $k$ at time $t$. Our empirical strategy disregards unit values, subject to measurement errors and aggregation issues, ${ }^{29}$ which prevents us from estimating Equation 3 in quantities $c_{i j k t}$. We instead use imports Free On Board (FOB), valued at the before-duty and transport-cost export price $p_{i k t}$. Rewriting Equation 3 in FOB terms, and observing that $\left(1+t_{i j k}\right)=d_{i j}^{\rho_{k}}$, we obtain:

$$
p_{i k, t} c_{i j k, t}=\left(\alpha_{i k, t} p_{i k, t}\right)^{\left(1-\sigma_{k}\right)}\left(1+\tau_{i j k t}\right)^{-\sigma_{k}}\left(d_{i j}\right)^{-\sigma_{k} \rho_{k}} P_{j k, t}^{\left(\sigma_{k}-1\right)} E_{j k, t}
$$

We note immediately that the tariff elasticity can be recovered from the coefficient $-\sigma_{k}$. We can also incidentally recover the elasticity of shipping costs with respect to distance $\rho_{k}$ by dividing the exponent of distance by the estimated $\sigma_{k}$. This last structural interpretation of estimated parameters warns against the use of the elasticity of exports to distance as a trade elasticity. The tariff elasticity is (minus) the elasticity of substitution $\sigma_{k}$ across products coming from different origins $i$. This is at the core of our empirical approach to estimate

\footnotetext{
${ }^{29}$ Unit values are not proper price indices, and suffer from considerablre measurement error as import quantities are very-imprecisely measured (with many missing values) at the HS 6-digit level. Moreover, using unit values would imply the omission of new product varieties from the import-price index (Feenstra 1994). This variety effect acts as a demand shifter that is captured by $\alpha_{i k, t}$ in Equation 3 and by the exporter-time fixed effect in our empirical specification at the product level.
} 
product-specific elasticities of demand, $\epsilon_{k}=1-\sigma_{k}$. This is the average demand elasticity for product $k$, common across importers, over the time period considered. The log-linearized empirical counterpart of Equation 4 is discussed below: exporter-time and importer-time fixed effects will fully capture the terms $\left(\alpha_{i k, t} p_{i k, t}\right)^{\left(1-\sigma_{k}\right)}$ and $P_{j k, t}^{\left(\sigma_{k}-1\right)} E_{j k, t}$ respectively, while tariffs and distance will be used to recover respectively (minus) $\sigma_{k}$ and $\rho_{k}$. The elasticity $\sigma_{k}$ does not change with import demand in the usual CES demand system. However, considering the anomalous prediction of an equalized trade balance in CES-based demand systems, leading to the "mystery of the excess trade balances" highlighted in Davis \& Weinstein (2002), recent work has departed from the CES and adopted non-CES demand systems (Mrázová et al. 2020, Allen, Arkolakis \& Takahashi 2020). In Section 3.3.4 we therefore estimate importdemand elasticities that are consistent with non-CES demand systems, and in particular with an additively-separable demand system.

\subsection{Estimating import-demand elasticities}

To estimate the tariff elasticity for each of the 5,050 HS6 product categories, ${ }^{30}$ we rely on the standard structural-gravity framework with country-time fixed effects. Using the notation $X_{i j k, t}$ for the FOB value $p_{i k, t} c_{i j k, t}$ of the imports in destination $j$ of product $k$ originating in country $i$ in year $t$, the following empirical model is estimated to recover the tariff elasticity at the product level (and is hence estimated 5,050 times, once for each product $k=1, \ldots . K$ ): ${ }^{31}$

$$
X_{i j k, t}=\theta_{i k, t}+\theta_{j k, t}+\beta_{k} \ln \left(1+\tau_{i j k, t}\right)+\gamma_{k} \ln \left(d_{i j}\right)+\mathbf{I}_{k} \mathbf{Z}_{i j}+\epsilon_{i j k, t} \quad \forall k \in K
$$

Here the tariff elasticity is $\beta_{k}=-\sigma_{k}$ in the usual CES framework discussed above, with $\sigma_{k}$ being the elasticity of substitution between varieties of a given HS6 product exported by different countries. The elasticity of the shipping cost with respect to distance for good $k$ is simply $\rho_{k}=\gamma_{k} / \beta_{k}{ }^{32}$

\footnotetext{
${ }^{30}$ The 2007 revision of the HS classification consists of 5052 HS 6-digit products. We disregard positions 710820 (Monetary gold) and 711890 (Coins of legal tender) due to missing information on trade.

${ }^{31}$ Note that we will complement the product-level elasticities with sector-level elasticities by pooling HS6 products within HS4 and other sectoral classifications (GTAP and TiVA sectors).

${ }^{32}$ It should be noted that the interpretation of the tariff elasticity as an elasticity of substitution applies only in
} 
Equation 5 always includes importer-year $\left(\theta_{j k, t}\right)$ and exporter-year $\left(\theta_{i k, t}\right)$ fixed effects to fully control for importer and exporter multilateral-resistance terms. ${ }^{33}$ By doing so, and estimating Equation (5) by product category, we exploit the variation in tariffs imposed by different destinations on a given exporter at different points in time. ${ }^{34}$ Beyond the log-linearization of Equation 4, and notwithstanding the fact that we already control for distance, we also want to control for bilateral-specific geographic-related trade costs: we therefore introduce the set of control variables $\mathbf{Z}_{i j}$, which always includes dummies for (i) a common colony, (ii) a common border, and (iii) a common language. ${ }^{35}$

We combine three main datasets over the 2001-2016 period: (i) bilateral FOB trade flows at the HS6 level from the BACI (CEPII) dataset, (ii) applied bilateral tariffs from the MAcMapHS6 dataset (CEPII-ITC), and (iii) the geographical distance between country pairs and other gravity control variables from CEPII. After merging the three sources, we obtain data for 189 exporters to 152 destinations in each year. The details regarding the sources and construction of the estimation dataset appear in the Data section of Appendix B. To address heteroskedasticity in the error term (and the zero trade-flows problem - missing information), we follow Santos-Silva \& Tenreyro (2006) and adopt (non-linear) Poisson Pseudo Maximum Likelihood - PPML - as the baseline (and preferred) estimator of Equation (5). ${ }^{36}$

models with a CES demand system and homogeneous firms. In other models of trade, in particular those with heterogeneous industries (Eaton \& Kortum 2002) or heterogeneous firms (Chaney 2008), the trade elasticity (i.e the elasticity of trade to changes in variable trade costs) represents the shape parameter of the productivity distribution. See Head \& Mayer (2014) Section 2.3 for a detailed discussion of the economic meaning of trade elasticities across different classes of trade models. Importantly, in the presence of sub-convexity of demand (Mrázová \& Neary 2017), our measured elasticity is the average of the elasticities at different levels of demand (levels of trade volume) across country-pairs for a given HS6 product category. Mrázová et al. (2020) show that the elasticity of trade to distance (for overall trade between country-pairs) falls with the volume of bilateral trade, which is suggestive of sub-convexity of demand. The convexity of the CES is $\left(\frac{\sigma+1}{\sigma}\right)$. We will examine below whether import demand is sub-convex in our sample.

${ }^{33}$ In practice, each $k$-specific regression includes importer-year and exporter-year fixed effects. When applied to product-specific regressions, the country-year terms subsume the country-sector-year fixed effects.

${ }^{34}$ Remember the panel nature of our tariff data available in 2001, 2004, 2007, 2010, 2013 and 2016.

${ }^{35}$ While technically possible, we do not include country-pair fixed effects in our baseline regressions for two reasons. First, because we are also interested in the estimation of distance coefficients to recover the structural parameter $\rho_{k}$. Second, due to the short time horizon in our panel and the small within variation in tariffs (see Table 3). This is underlined by the huge number of zero tariff coefficients (3,548 out of 5,050 HS6 products) when country-pair fixed effects are included in Equation 5. See Section 3.3.3 for robustness checks that include country-pair fixed effects in Equation 5. The inclusion of control variables in $\mathbf{Z}_{i j}$ is key for the correct identification of the tariff elasticity, as it controls for all the other sources of trade costs affecting bilateral imports. Naive specifications that do not control for $\mathbf{Z}_{i j}$ produce an average trade elasticity of -23 .

${ }^{36}$ Note that relying on a strategy of country (or country-time) fixed effects estimated with a PPML is consistent as the sum of fitted export values for each exporter (importer) is equal to its actual output (expenditure): see 
In our baseline set of estimations, Equation (5) is estimated for each HS6 category of product $k$. It can alternatively be estimated by pooling the products $k$ in sector $\kappa \in \mathcal{P}$ (with $\mathcal{P}$ being a partition of $K$ ), thus recovering average parameters for the covariates. We adopt this approach to obtain trade elasticities at the HS4, GTAP and TiVA sector levels: see Sections 3.3.2 and 4. With the product-specific tariff elasticity at hand we can recover the trade elasticity accordingly, i.e. $\varepsilon_{k}=1+\beta_{k} \cdot{ }^{37}$ The distribution of $\varepsilon_{k}$ obtained using a PPML estimator for each HS6 product appears in Figure 1 and discussed in the next section. The comparison between the distribution of the estimated $\varepsilon_{k}$ from PPML and OLS appears in Figure $\mathrm{A} 5$, and illustrates the bias from disregarding the zero trade-flow problem and adopting a log-linear OLS estimator - see Section 3.1 for a detailed discussion of the baseline results.

An additional concern is the composite nature of trade costs: geography, tariffs and nontariff barriers. Our specification controls for the transport costs between the exporter and importer. Although the elasticity of transport cost to distance tends to be sector-specific, our estimation is at the product level, implicitly assuming the elasticity of ad valorem freight costs to distance to be product-specific. Alternatively, we carry out estimation at the sector level, by pooling HS6 products within sectors and so estimating a sector-level elasticity of trade to shipping costs using the TiVA, GTAP or HS 4-digit classifications of sectors. ${ }^{38}$

Beyond the usual third-country effects extensively addressed in the recent literature on structural gravity, the identification of the bilateral tariff elasticity $\beta_{k}$ should control for the strategic reaction of third countries $n=1 \ldots N\left(\right.$ with $n \neq j$ ) to changes in the bilateral tariff $\tau_{i j k, t}$. If a third country $n \neq j$ reacts to a change in the $\tau_{i j k}$ tariff (e.g. to avoid trade diversion), the change in bilateral trade ijk results from two channels: (i) the direct effect of the variation in the bilateral tariff $\tau_{i j k, t}$ and (ii) the indirect effect through the modified relative market access with respect to the third country $n$. Our exporter-year fixed effects (in k-specific regressions) $\theta_{i k, t}$ also capture the average tariff imposed by third countries $n \neq j$ to the exporter country Fally (2015). This property of the PPML has been extensively exploited by Anderson, Larch \& Yotov (2018) to simulate the impact of changes in the trade-cost matrix in full-endowment general equilibrium.

${ }^{37}$ The final database, available at https://sites.google.com/view/product-level-trade-elasticity/ home and on the CEPII website, contains a variable indicating the trade elasticity for each HS6 position.

${ }^{38}$ In a robustness check we estimate trade elasticities at the HS6 level while constraining the elasticity of the other covariates to be constant across products of a given HS 4-digit heading (see Figure A2). 
$i$ on product $k$ (i.e. the tariff faced by exporter country $i$, at time $t$, in exporting to third countries $n) \cdot{ }^{39}$

Two market-access related factors require discussion as potential omitted variables in Equation 5. First, non-tariff measures are not explicitly introduced as control variables in our regressions, and may affect bilateral trade. Although certain regulations convey information on the traded products, and thus facilitate trade, the mere presence of a non-tariff measure may be an obstacle to increasing imports after a tariff cut. However, non-tariff measures are non-discriminatory (see e.g. the WTO agreement on Sanitary and Phyto-Sanitary measures), and their presence is fully captured by the importer-time fixed effects in the product-specific estimations of Equation 5. Second, considering the increasing importance of preferential bilateral tariffs through Preferential Trade Agreements (PTAs) highlighted in Table 2, a robustness check in Section 3.3.3 augments Equation 5 with a dummy for the presence of an active PTA between the importing and exporting countries.

\subsection{Identification Issues}

There are three identification issues that need to be discussed before estimating trade elasticities using tariffs in a gravity framework.

First, the omission of unobserved confounding factors correlated with both tariffs and import demand may introduce bias into our baseline estimation (an omitted-variable bias). The inclusion of country-year fixed effects (controlling for any unobserved country-product-year specific variables in product-specific regressions), along with the geographic controls that capture the bilateral transport cost, sharply reduce omitted-variable concerns in Equation 5. Only unobserved country-pair $x$ product-specific shocks may continue to pose problems in this respect. The use of the lagged tariff variable discussed in Section 3.3.1, the pre-trend test (discussed below), and the Instrumental Variable (IV) strategy presented in Appendix D

\footnotetext{
${ }^{39}$ This strategy is equivalent to the inclusion of the average tariff imposed by third countries $n \neq j$ on exporter $i$, Third Country Tariff $f_{i j, t}=\frac{1}{N-1} \sum_{n \neq j}^{N-1} \tau_{i n, t}$, where $\mathrm{N}$ is the total number of importing countries $n \neq j$. While this variable appears to be $i j, t$ specific, it is a simple combination of the average tariff imposed by third countries $n$ and the bilateral tariff $\tau_{i j, t}$. As such, the inclusion of exporter-year fixed effects and the bilateral tariff subsumes the inclusion of the variable Third Country Tariff $f_{i j, t}$.
} 
further reduce any residual concerns regarding omitted variables.

Second, were tariffs at the product and exporter level to be set in response to a positive import-demand shock, the coefficient on tariffs in Equation 5 would be affected by reverse causality. In the vein of Shapiro (2016), we first rely on the lagged tariff variable to reduce reverse-causality concerns in Equation 5. The use of non-consecutive years (a panel of three-year windows) makes the lagged-tariff strategy reliable. To further reduce concerns about reverse causality, we also follow Fajgelbaum et al. (2020) and provide a pre-trend test in Table 1. The aim here is to exclude the presence of a pre-existing trend in import demand that subsequently affects tariffs. Table 1 correlates the dynamics of import demand prior to the change in the tariff set by country $j$ on product $k$ exported by $i$ in year $\hat{t}$, with the subsequent change in $\tau_{i j k, t}$. In practice we simply calculate the correlation between $\left(\ln \left(/ \operatorname{mport}_{i j k, t}\right)-\ln \left(\operatorname{Import}_{i j k, t-1}\right) \mid t<\hat{t}\right)$ and $\left(\ln \left(1+\tau_{i j k, t}\right)-\ln \left(1+\tau_{i j k, t-1}\right) \mid t>\hat{t}\right)$. The figures in Table 1 suggest little correlation - no matter which fixed effects are included - so that (on average) the varieties $i k$ targeted by a trade policy in country $j$ did not exhibit a different trajectory before the actual tariff change. Given the non-consecutive year nature of our dataset, and considering the results of this pre-existing trend test, we can safely argue that the contemporaneous level of imports is unlikely to affect the tariffs imposed three years beforehand. We therefore do not believe that endogeneity concerns are of first order in our empirical analyses. However, to further alleviate any residual concerns, Appendix D proposes an Instrumental-Variable approach to assess the extent of any endogeneity bias by comparing OLS and 2SLS elasticity estimates: these turn out to be almost identical. ${ }^{40}$

Third, the identification of the import-demand elasticity through the estimation of a tariff coefficient requires that consumers in the importing country base their consumption decisions on the duty-inclusive price $p_{i j k, t}=p_{i k, t}\left(1+\tau_{i j k, t}\right)\left(1+t_{i j k}\right)$. We already noted the assumption of the full pass-through of the tariff in prices at destination. If pass-through is incomplete but common across destinations for a given exporter in a given year, this will be captured

\footnotetext{
${ }^{40}$ In Appendix $\mathrm{D}$ we instrument the observed tariff $\tau_{i j k, t}$ by the average tariff imposed by $j$ on $i$ on other products $s \neq k$ (with $s$ belonging to the same HS 4-digit heading as $k$ ). OLS is the right comparison for 2SLS as both are linear estimators.
} 
Table 1 - Tests for pre-existing trends.

\begin{tabular}{lccccc}
\hline \hline Dep Var: & \multicolumn{4}{c}{ Average import growth before the first change in tariff } \\
\hline Avg tariff growth after change & 0.134 & -0.031 & 0.073 & 0.079 & 0.431 \\
& $(0.252)$ & $(0.265)$ & $(0.134)$ & $(0.137)$ & $(0.384)$ \\
\hline Exporter FE & No & No & Yes & No & No \\
Importer FE & No & No & Yes & No & No \\
Product FE & No & Yes & Yes & Yes & No \\
Exporter x Importer FE & No & No & No & Yes & No \\
Exporter x Product FE & No & No & No & No & Yes \\
Importer x Product FE & No & No & No & No & Yes \\
\hline Observations & $1,130,580$ & $1,130,569$ & $1,130,564$ & $1,129,206$ & $1,005,049$ \\
R-squared & 0.000 & 0.013 & 0.043 & 0.067 & 0.338 \\
\hline
\end{tabular}

Notes: This table shows the pre-trend test for import demand. The dependent variable is the average growth rate of imports (i.e. $\left.\ln (\text { Import })_{i j k, t}-\ln (/ \text { mport })_{i j k, t-1}\right)$ before the first change in the tariff imposed by importer $i$ on variety $j k$. The explanatory variable is the average growth rate in tariffs after the first change in tariff $\left(\ln \left(1+\tau_{i j k, t}\right)\right.$ $\left.-\operatorname{In}\left(1+\tau_{i j k, t-1}\right)\right)$. Source: Authors' calculations.

by the exporter-time fixed effect. Another potential issue is that in some particular developing countries with pervasive corruption, where small bribes can significantly alleviate tariffs, import demand may be insensitive to tariffs (Sequeira 2016). We consider this to be only a minor concern in our empirical framework, where the level of corruption on the importer side is captured by the fixed effects.

\subsection{Estimating Import Elasticities with Sub-Convex Demand}

We motivated our equation to be estimated using a CES demand system. However, CESbased preferences may lead to biased gravity estimations when we estimate gravity at a disaggregated level (Mrázová et al. 2020). The CES-based gravity model predicts a perfectlyequalized bilateral trade balance, which is likely to be rejected once we move away from broadly-aggregated data (Davis \& Weinstein 2002, Allen et al. 2020). Beyond our baseline CES-based estimations, we would therefore want to relax the constant-elasticity assumption, and follow Mrázová et al. (2020) in estimating trade elasticities that are consistent with moregeneral (but still theoretically-tractable) additively-separable preferences. We do this here at the product-category level (HS4 for tractability), instead of on aggregate bilateral trade flows as in Mrázová et al. (2020). It is important to note that, in this demand system (nesting the CES case) and sub- or super-convex preferences structures, the trade-cost elasticity varies 
with the volume of trade. In the case of sub-convex demand, we expect the tariff elasticity to fall (in absolute value) with the volume of bilateral trade for the product category considered. As we rely on values rather than quantities, we adopt a quantile approach and estimate nonCES consistent trade elasticities by the quantiles of trade values. Section 3.3.4 provides a detailed discussion of the quantile approach and the subsequent results.

\subsection{The sources of variation in trade costs in our sample}

At the HS6 level, the worldwide matrix of bilateral trade includes many zeros. However, not all of these zeros convey useful information for our exercise. If country $j$ does not import product $k$ from exporter $i$, this might just reflect that $i$ never exports $k$. In this case, including all of the zeros originating from country $i$ in product $k$ across all destinations $j$ would inflate the dataset with useless information. ${ }^{41}$ We therefore fill in the World-trade matrix only when country $i$ exports product $k$ to at least one destination over the period. We then match all of these non-zero and zero trade flows to the tariffs $\tau_{i j k, t}$. After merging these two datasets, for each of the 5,050 HS6 product categories, we end up with a panel dataset of country pairs (for 2001, 2004, 2007, 2010, 2013 and 2016) that are available in the MAcMap-HS6 tariff data (see Appendix B). The non-consecutive nature of our dataset allows our dependent variable to adjust in the presence of trade-policy changes, i.e. tariff changes in our case (Anderson \& Yotov 2016).

Table 2 columns 2 and 3-5 show respectively the share of non-missing importer-exporter-HS6 combinations with zero applied versus non-zero tariffs. A first observation is that there has been a steady phasing out of tariffs in the 2000s: the share of products (i.e. tariff lines) with zero tariffs almost doubled between 2001 and 2007 (from 18.7\% to 35.6\%), and further rose to reach $40 \%$ in 2016 . This "zeroing" goes beyond the commitments of the Uruguay Round, and mirrors either the phasing out of nuisance tariffs or the phasing-in of PTAs. ${ }^{42}$ The entry into force of new PTAs over the last decades, discussed in detail in Freund \& Ornelas (2010), translates into a lower frequency of both non-zero MFN tariffs (from 13\%

\footnotetext{
${ }^{41}$ More specifically, our baseline PPML estimator would disregard this information, as the dependent variable would be perfectly predicted by exporter-year fixed effects.

${ }^{42}$ Nuisance tariffs are duties close to zero percent that are not worth collecting at the border.
} 
in 2001 to $3.6 \%$ in 2016) and non-zero preferential tariffs (from $67 \%$ in 2001 to $56 \%$ in 2016). Among the non-zero tariffs, preferential tariffs remain extraordinarily present in World trade. ${ }^{43}$ The descriptive evidence in Table 2 calls for a deeper analysis of (i) the coverage of MFN v.s preferential tariffs and (ii) the respective contributions of the within and between changes in product bilateral tariffs.

Table 2 - The share of non-missing importer-exporter-HS6 cells with zero vs. non-zero tariffs (divided into MFN, preferential and non-WTO).

\begin{tabular}{|c|c|c|c|c|}
\hline & \multicolumn{4}{|c|}{ Share of importer-exporter-product cells with: } \\
\hline & Zero Applied & Non-zerc & Applie & Tariffs \\
\hline & Tariffs & Preferential & $M F N$ & Non-WTO \\
\hline 2001 & 18.7 & 67.4 & 13.0 & 1.0 \\
\hline 2004 & 31.0 & 65.6 & 3.3 & 0.1 \\
\hline 2007 & 35.7 & 60.8 & 3.2 & 0.4 \\
\hline 2010 & 37.8 & 58.1 & 3.6 & 0.5 \\
\hline 2013 & 39.5 & 55.9 & 4.1 & 0.5 \\
\hline 2016 & 40.1 & 56.3 & 3.6 & 0.1 \\
\hline
\end{tabular}

Notes: Columns 2 and 3-5 list the share of non-missing importerexporter-HS6 combinations with respectively zero and non-zero tariffs in force. Columns 3-5 show the share of preferential, MFN and non-WTO non-zero tariffs. Source: MAcMap-HS6, authors' calculations.

The characterization of the sources of tariff variation in our data is key in guiding our empirical exercise. Product-level tariffs can vary both within each country pair over time (within variation) and/or across trade partners within a given year (between variation). ${ }^{44}$ Table 3 lists for each HS section the between and within country-pair variances of applied tariffs. Most of the variance for each product occurs between country pairs; we therefore exploit the between pairs variation in bilateral tariffs to estimate tariff elasticities in the next section. The contribution of the within variance is non-negligible in Section XI (corresponding to the phasing out of protection for Textiles and Textile articles). The largest between variation is in Section IV (Prepared Foodstuffs, Beverages and Tobacco); this sector is also that with

\footnotetext{
${ }^{43}$ It should be noted that the vast majority of non-zero tariffs are ad valorem. Specific tariffs or compound tariffs (combining ad valorem and specific elements on the same tariff line) sum up to around one percent of all non-missing importer-exporter-HS6 observations. However, given the potentially high protection they provide, specific or compound tariffs should not be disregarded. We will include the ad valorem equivalent of these specific or compound tariffs in our calculations.

${ }^{44}$ The within variation therefore reflects the variability of tariffs over time, while the between variation reflects the heterogeneity in the tariffs imposed by different countries in a given year on a given product.
} 
the highest average protection among all country pairs (16.9 percent in 2016) as well as the largest variance (38.6), as shown in Tables G1 and G2 in Online Appendix G.

Table 3 - The within vs. between variation in product-level bilateral applied tariffs by HS section, 2001-2016.

\begin{tabular}{llcc}
\hline \hline & & \multicolumn{2}{c}{ Variance } \\
\cline { 3 - 4 } & & Within & Between \\
\hline I & Live Animals and Animal Products & 0.112 & 0.217 \\
II & Vegetable Products & 0.104 & 0.194 \\
III & Animal or vegetable fats and oils & 0.074 & 0.136 \\
IV & Prepared foodstuffs, beverages and tobacco & 0.159 & 0.259 \\
V & Mineral products & 0.033 & 0.060 \\
VI & Products of chemical industries & 0.038 & 0.061 \\
VII & Plastic and articles thereof & 0.043 & 0.079 \\
VIII & Raw hides and skins, leather and article thereof & 0.051 & 0.104 \\
IX & Wood/Cork and articles of Wood/Cork; & 0.063 & 0.101 \\
X & Pulp of wood or other cellulosic materials & 0.040 & 0.075 \\
XI & Textile and textile articles & 0.100 & 0.116 \\
XII & Footwear, Headgear, Umbrellas and prepared feathers & 0.070 & 0.126 \\
XIII & Articles of stone, plaster, ceramic and glass & 0.045 & 0.100 \\
XIV & Natural cultured pearls and precious stones and metals & 0.050 & 0.109 \\
XV & Base metals and articles of base metals & 0.038 & 0.075 \\
XVI & Machinery and mechanical appliances and electrical machinery & 0.037 & 0.067 \\
XVII & Vehicles, Aircraft and transport equipment & 0.050 & 0.092 \\
XVIII & Optical, photographic, precision and medical instruments & 0.042 & 0.079 \\
XIX & Arms and ammunitions & 0.104 & 0.209 \\
XX & Miscellaneous & 0.053 & 0.108 \\
XXI & Works of art & 0.047 & 0.106 \\
\hline
\end{tabular}

Notes: To construct this table we calculated the within and between variance for each HS6 product. The HS6 variances are then aggregated to the HS-section level as simple averages. Source: MAcMap-HS6, authors' calculations.

\section{Disaggregated Trade Elasticities}

This section presents the estimated trade-elasticity parameters $\varepsilon_{k}$ for the 5,050 product categories of the HS 6-digit classification. Section 3.1 first presents our baseline results, focusing on the elasticities that are statistically significant at the $1 \%$ level; ${ }^{45}$ this section

\footnotetext{
${ }^{45}$ The statistical threshold used to define significant trade elasticities does not affect the overall shape of the elasticity distribution. In Figure A3 we compare the distribution of elasticities obtained by keeping coefficients that are significant at the 1\% and 5\% levels: the two are almost identical. Online Appendix Figures G1 and G2 plot the empirical distribution of trade elasticities based on $5 \%$ and $10 \%$ statistically-significant tariff elasticities, while Figure G3 shows the empirical distribution of trade elasticities independent of their underlying statistical significance.
} 
also proposes trade-elasticity estimations by groups of importing countries (developed $v s$. developing) to highlight the different distribution of import elasticities by country development level. This evidence then motivates the welfare-evaluation bias exercise carried out in Section 4. Section 3.2 provides evidence of the accuracy of our $\varepsilon_{k}$ estimates by carrying out an ex-post evaluation of the USA-Chile trade agreement signed in January 2004. The comparison to the elasticities that are found in other papers in the literature appears in Appendix C. Section 3.3 then proposes a battery of robustness checks addressing a number of empirical concerns regarding the estimation of Equation 5 (reverse causality, omitted variables, selection into export markets, and aggregation bias). All of these robustness checks suggest that our baseline estimates are valid.

\subsection{Baseline results}

The empirical distribution of negative and statistically-significant trade elasticities $\varepsilon_{k}$ appears in Figure 1. We characterize in Appendix $F$ the factors lying behind positive $(2.5 \%$ of the estimated elasticities are positive and significant at the $1 \%$ level) or insignificant (at the $1 \%$ level) trade elasticities using a probit regression.

The left tail of the empirical distribution depicted here has been cut at -25 to make the figure more readable, but we only obtain larger trade elasticities for a very-few HS6 products (3\% of the total product lines). ${ }^{46}$ The average trade elasticity after excluding products with a positive tariff elasticity, and setting insignificant $\beta_{k}$ 's to zero, is $-5.5 .{ }^{47}$ If we set the elasticities that are statistically insignificant to the minimum statistically-significant elasticity, the average trade elasticity becomes $-6.0 .{ }^{48}$ If we consider trade elasticities that are significant at the $5 \%$ level, the average figure is -6.2 . Finally, abstracting from the statistical significance of the underlying tariff elasticity (i.e. without replacing insignificant $\beta_{k}$ values by zero), the average trade elasticity is -7.6 .

\footnotetext{
${ }^{46}$ We examine the determinants of the occurrence of very-large estimated trade elasticities later in this section. ${ }^{47}$ This average value may be recovered from the online available dataset by (1) dropping products with positive tariff elasticities (the "positive" dummy in the online dataset), (2) replacing trade elasticities as missing if the "missing" dummy is one in the online dataset (these are products for which the tariff variable has been dropped by STATA due to collinearity with the fixed effects), and (3) replacing the trade elasticity figure by one if the underlying tariff elasticity is zero (i.e. the "zero" dummy is one in the online dataset).

${ }^{48}$ In this case the median elasticity becomes -4.0 and the standard deviation 8.5.
} 
Figure A1 shows the distribution of the shipping cost elasticity to distance $\rho_{k}$ obtained as a ratio between the distance and tariff coefficients in Equation 5. This can be compared to the shipping-cost elasticity estimated by Hummels (2007) on US imports at the SITC 5-digit level. The average $\rho$ in our data is 0.145 , to be compared to the figures of 0.151 for the 1974-2004 period for maritime transportation, and 0.160 in 2004 for air transportation in Hummels (2007). ${ }^{49}$

Overall, our estimations are successful: the median $t$-statistic is 3.2 , and $78 \%, 72 \%$ and $61 \%$ of the estimated $\beta_{k}$ 's are significant at the $10-, 5$ - and 1 -percent significance levels respectively. ${ }^{50}$ In the remainder of the paper, we will adopt the strictest statistical criterion and only comment on the values that are significant at the $1 \%$ level. For some HS-6 digit positions, the bilateral variability in tariffs is insufficient to estimate the parameter $\beta_{k}$ in Equation 5. Table 4 shows, for each HS section, the number of HS6 positions and the number of non-positive estimated elasticities $\varepsilon_{k}$ that are statistically significant at the $1 \%$ level. The (simple) average trade elasticity (across HS positions in each HS section) ranges from 4.75 for Footwear to 23.44 for Mineral products. ${ }^{51}$ The largest elasticity in each HS section is also indicated in Table 4, and high average figures can be driven by very large elasticities for some homogeneous products at the HS6 level (such as for Mineral products). In most of the sectors, our method successfully recovers trade elasticities for most of the products within an HS section. In five of the HS sections, all of the $\beta_{k}$ tariff elasticities are estimated. For Pulp of wood or other cellulosic materials, only two product-level elasticities are not identified out of 144 product categories; the same observation can be made for Articles of stone, plaster, ceramic and glass (1 out of 143). Section VI (Products of chemical industries) is a little more problematic, with $729 \beta_{k}$ coefficients estimated out of 789 product categories. The dispersion of estimated trade elasticities $\varepsilon_{k}$ within a sector can be further illustrated by focusing on the

\footnotetext{
${ }^{49}$ Note also that our estimates of distance elasticities $\gamma_{k}$ are distributed around -1 , in line with Head \& Mayer (2014).

${ }^{50}$ We can benchmark these figures with Kee et al. (2009), who also use HS6 data, although their estimation method and the period (1998-2001 instead of 2001-2016) differ. The corresponding figures are $71 \%, 66 \%$ and $57 \%$. Their median $t$-statistic is identical.

${ }^{51}$ This section contains our largest estimated elasticity, 123 for product code "270210" (Lignite; whether or not pulverised, but not agglomerated, excluding jet). Very large elasticities have been also obtained in previous papers. See for example the average elasticities in Broda, Greenfield \& Weinstein (2006) for the HS 3-digit product headings " 860 " and " 021 ".
} 
sector (Textiles) with the largest number of HS6 categories. ${ }^{52}$ The average dispersion across the 788 estimated trade elasticities (out of 801 product categories) is -8.36 . We show in Table A2 the average trade elasticities by HS2 within the Textile industry. The trade elasticity is very large for Man-made filaments and Man-made staple fibres (respectively -10.69 and -10.55), and much lower for 1) Apparel and clothing accessories not knitted or crocheted, 2) Textile, made up articles, sets, worn clothing and worn textile articles, and 3) Apparel and clothing accessories knitted or crocheted (at respectively $-5.02,-4.53$ and -3.00 ). ${ }^{53}$

\section{Figure 1 - The empirical distribution of trade elasticities $\varepsilon_{k}$ across all prod- ucts (PPML estimations).}

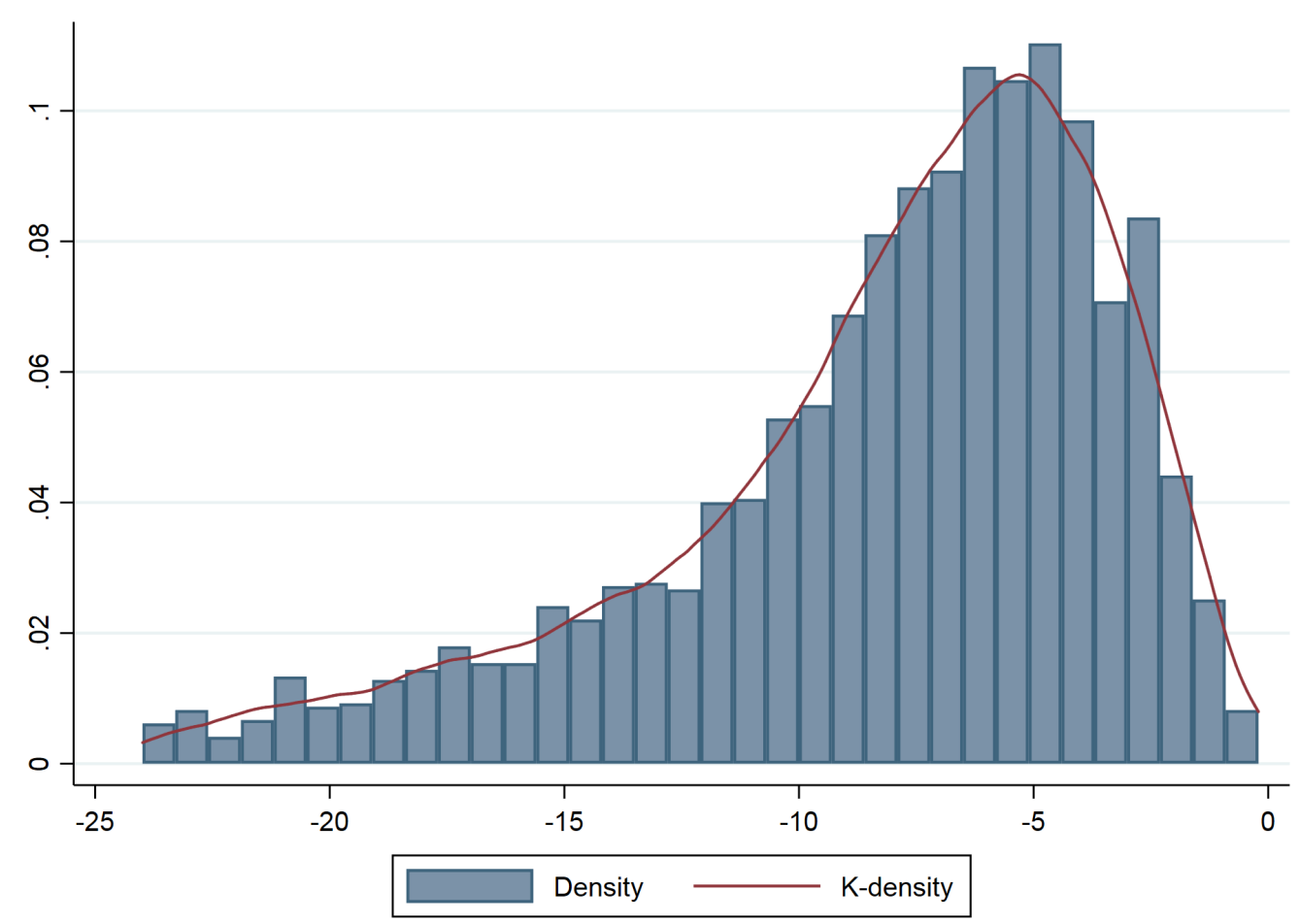

Note: This is the empirical distribution calculated for HS-6 products with $\varepsilon_{k}<0$. Source: Authors' calculations.

\footnotetext{
${ }^{52}$ For clarity of exposition, we keep textiles as an example. However product-specific trade elasticities are very heterogeneous in all of the product categories. The descriptive statistics on the trade elasticities for textile products exclude products with positive elasticities.

${ }^{53}$ Trade elasticities are heterogeneous and significantly-different among products of a given HS heading. In Online Appendix Figure G4 we show the trade-elasticity estimates along with their upper and lower bounds (plus/minus one standard error in the tariff coefficient). This figure shows the results for one heading (61) of the HS 2-digit classification, for clarity of exposition.
} 


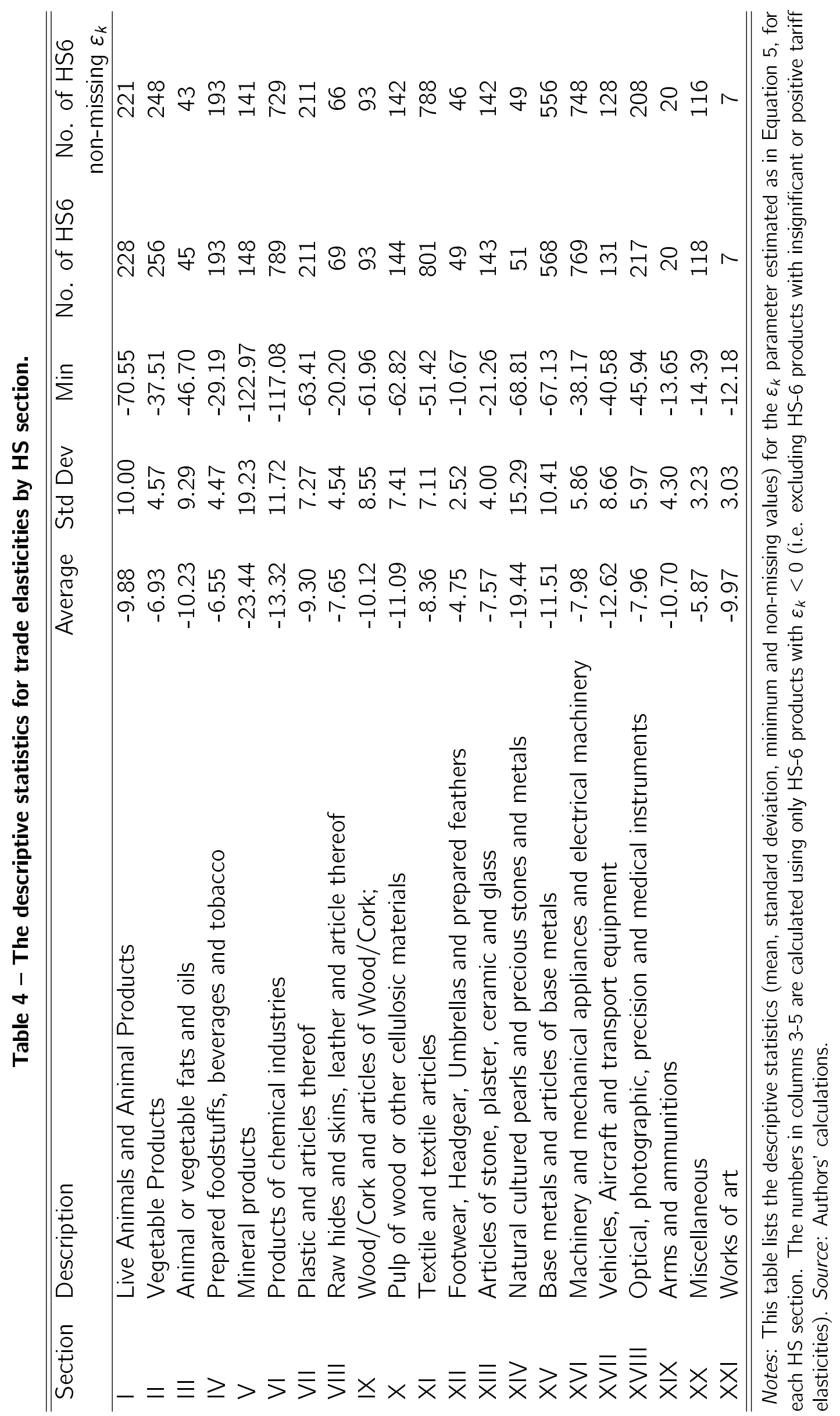


The average trade elasticities within the different HS sections in Table 4 take on reasonable values: for fairly-standardized products like Plastic and Rubber the average trade elasticity is close to -9 , while this is -4.7 in highly-differentiated products like Footwear. Regarding the macro-sector heterogeneity, trade elasticities $\varepsilon_{k}$ are more dispersed in Manufacturing than in Agriculture, although centered around the same value (see Appendix Figure A4). ${ }^{54}$ Another interesting characterization of trade elasticities by product type emerges from the Rauch classification of differentiated vs. homogeneous products. As expected, Figure A6 shows larger and more dispersed $\varepsilon_{k}$ coefficients for homogeneous than for differentiated products. This pattern is more formally tested in Table 5, where we explore some empirical regularities in the size of the absolute value of the estimated trade elasticity $\left|\varepsilon_{k}\right| .{ }^{55}$ There are two clear results. First, as expected, the trade elasticity is smaller for differentiated products. In line with columns $1-2$, we confirm in columns $3-5$ that the probability of obtaining very high trade elasticities (respectively above the $1^{\text {st }}, 5^{\text {th }}$ and $10^{\text {th }}$ percentile) is smaller for differentiated products. Second, within HS 2-digit chapters products covering (on average) a larger distance in the bilateral-trade matrix have smaller trade elasticities. This may reflect that products that are traded in spite of sizeable trade frictions (as reflected by distance) are less elastic to tariffs, or that only the most-productive firms manage to export to remote markets thanks to the inelastic demand for their products. This is in line with Spearot (2013), suggesting that high-revenue varieties (those exported to distant markets), are less affected by trade liberalization as they have lower demand elasticities. It also echoes the interpretation of the impact of composition effects on the aggregate trade elasticity to distance by Redding \& Weinstein (2019), along the lines of the "shipping the good apples out" statistical regularity (Hummels \& Skiba 2004).

One important question is the sensitivity of the estimated elasticities to the estimator used. Comparing the trade-elasticity distribution between PPML and OLS, we see that the zero

\footnotetext{
${ }^{54}$ Since specific tariffs (here transformed to their ad valorem equivalents) are often used for Agricultural products, in Online Appendix Figure G6 we plot the distribution of trade elasticities estimated by dropping the country pairs with a specific tariff for product $k$. The distribution remains qualitatively unchanged.

${ }^{55}$ We use the absolute value of trade elasticity to render the interpretation of the results easier, and only consider negative and statistically-significant tariff elasticities. The results in Table 5 are correlations and cannot be interpreted as causal.
} 


\section{Table 5 - OLS regression of the absolute value of the trade elasticity and probit regressions for the probability of very-high trade elasticity.}

\begin{tabular}{lcccccc}
\hline \hline Dep var: & \multicolumn{2}{c}{$\left|\varepsilon_{k}\right|$} & & \multicolumn{3}{c}{ Top-Elasticity dummy } \\
\cline { 2 - 3 } \cline { 5 - 7 } & $(1)$ & $(2)$ & & $(3)$ & $(4)$ & $(5)$ \\
\hline Av. dist. across ij $(\mathrm{In})$ & -0.786 & $-1.594^{* * *}$ & & -0.006 & 0.107 & -0.077 \\
& $(0.566)$ & $(0.606)$ & & $(0.337)$ & $(0.210)$ & $(0.144)$ \\
Differentiated & $-6.493^{* * *}$ & $-4.899^{* * *}$ & & $-0.938^{*}$ & $-0.855^{* * *}$ & $-0.685^{* * *}$ \\
& $(0.450)$ & $(0.600)$ & & $(0.505)$ & $(0.217)$ & $(0.141)$ \\
\hline Estimator & OLS & OLS & & Probit & Probit & Probit \\
\hline Top-Elast. dummy & & & & $\left|\varepsilon_{k}\right|>1 p c t$ & $\left|\varepsilon_{k}\right|>5 p c t$ & $\left|\varepsilon_{k}\right|>10 p c t$ \\
\hline HS1 fixed effects & yes & no & & no & no & no \\
HS2 fixed effects & no & yes & & yes & yes & yes \\
\hline Observations & 2,518 & 2,518 & & 2,518 & 2,518 & 2,518 \\
\hline \hline
\end{tabular}

Notes: The dependent variable in columns $1-2$ is the absolute value of the trade elasticity when negative $\left(\varepsilon_{k}<0\right.$ with $\beta_{k}<-1$ ). The dependent variable in columns $3-5$ is a dummy for the trade elasticity (when $\varepsilon_{k}<0$ and $\beta_{k}<-1$ ) being above the $1^{\text {st }}, 5^{\text {th }}$ and $10^{\text {th }}$ percentile of the distribution. Robust standard errors appear in parentheses. $* * * \quad p<0.01 ; * * p<0.05 ; * p<0.1$.

trade-flows problem (and heteroskedasticity) and the different weighting schemes in the two estimators produce a severe negative bias in the estimated trade elasticity (comparing the continuous to the dashed line in Figure A5). To isolate the role of the different weighting schemes, ${ }^{56}$ the dotted line in Figure A5 shows the trade-elasticity from PPML in a dataset without zero-trade flows (log-linear OLS estimates do not include zero-trade flows). By comparing the latter and the OLS distribution of $\varepsilon_{k}$ we can infer that, by giving more weight to country pairs with large trade flows, the PPML estimator produces on average larger (in absolute values) trade elasticities than does OLS. ${ }^{57}$

One of the main contributions of our work here is its use of the largest sample of importing countries to calculate product-level trade elasticities. It is therefore of interest to check whether countries at different levels of development have different trade elasticities. Heterogeneity in trade elasticity by degree of importing-country development is also of interest for researchers and policy makers who wish to evaluate the welfare impact of trade liberalization in developing countries. To proceed, we calculate the distribution of trade elasticity by importer income group (developed vs. developing). We slightly modify Equation 5 and interact

\footnotetext{
${ }^{56}$ Remember that the PPML estimator gives more weight to pairs with large trade flows. See Head \& Mayer (2014) for a detailed discussion of this point.

${ }^{57}$ The average trade elasticity under OLS is -0.97 .
} 
the tariff variable with respectively a developing and developed importing-country dummy. ${ }^{58}$ We then use the coefficient on the interaction with the developing-country dummy to infer the trade elasticity for low-income countries, and that on the interaction with developed countries for the high-income country trade elasticity. The results in Figure 2 clearly show a smaller average elasticity (in absolute value) for developing than for developed countries. The average trade elasticity (after excluding products with positive elasticities, and setting insignificant tariff elasticities to zero) is -8.05 and -5.66 respectively for developed and developing importers. ${ }^{59}$ Using developed-country trade elasticities produces negative bias in the calculation of the welfare gains from trade for developing importers.

Figure 2 - The empirical distribution of the trade elasticity $\varepsilon_{k}$
across all products: developed $v s$. developing importing countries.

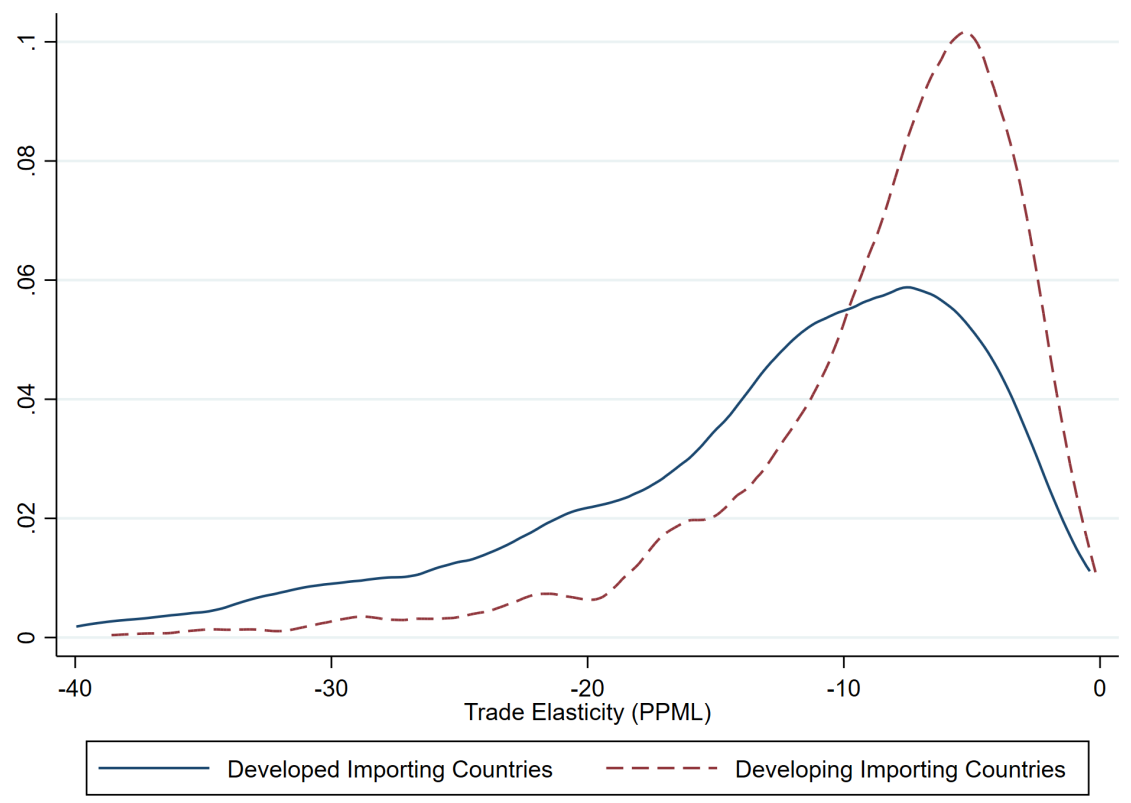

Note: The empirical distribution is calculated on HS-6 products with $\varepsilon_{k}<0$. Source: Authors' calculations.

\footnotetext{
${ }^{58}$ We adopt the 2010 World Bank classification of country income groups, and consider as "developed" high (OECD and non-OECD) and middle-upper income countries, and as "developing" low and middle-low income countries.

${ }^{59}$ Interestingly, the average standard error of the tariff coefficient is smaller for developing than for developed countries (3.14 and 7.49 respectively). This reflects the greater estimation precision in developing countries due the greater variation in tariffs there, as well as the largest number of observations for developing countries in our panel (41,037 on average for each $k$, against 21,638 for developed countries).
} 


\subsection{The accuracy of the estimated elasticities}

We have calculated trade elasticities for thousands of HS6 product categories. Although the distribution of these elasticities is centered around values that are in line with those in the literature, how can we ascertain that these elasticities are correctly distributed? This section aims to answer this question by comparing the variations in bilateral imports at the product level predicted by our product-specific elasticities to the actual variation in imports in response to a change in bilateral tariffs (an ex-post evaluation test). Appendix $C$ also compares our set of elasticities to estimates in previous work, and shows that they are positively correlated with those in the literature.

Our estimated elasticities can be used to calculate the predicted import growth following a reduction in preferential applied tariffs due to the signature of a Preferential Trade Agreement (PTA). This exercise mirrors exactly the spirit of our estimation strategy: the trade elasticities estimated here correspond to the substitution of imports from different origins, and this is what is captured by our strategy implemented at the bilateral level. The comparison between predicted and effectively-observed post-PTA import growth will help establish the reliability of our product-level elasticities. As a benchmark, we also compare the predicted import growth obtained using product-specific heterogeneous elasticities to that from a homogeneous (average) trade elasticity. ${ }^{60}$

We consider the US-Chile Preferential Trade Agreement that entered into force on January $1^{\text {st }} 2004$ to carry out this ex-post evaluation. ${ }^{61}$ Over the pre- and post- PTA period, the US represented on average almost one-fifth of total Chilean imports. Following the PTA (i.e. over the 2001-2004 period) Chile reduced its (average) preferential import tariff towards US products by $93 \%$ (from an average applied tariff of $6.9 \%$ to $0.5 \%$ ), with a peak of a $100 \%$ tariff cut (i.e. the complete removal of import tariffs) for many organic and inorganic

\footnotetext{
${ }^{60}$ To aggregate from HS 6-digit specific to a product-invariant (homogeneous) elasticity we rely on a weighted average (with the product export share over total 2001 exports as the weight). This is required when aggregating (by averaging) very different products. The results remain qualitatively unchanged if we use a simple average to approximate the homogeneous trade elasticity.

${ }^{61}$ More details on the US-Chile agreement can be found on the dedicated page https://ustr.gov/ trade-agreements/free-trade-agreements/chile-fta.
} 
chemical products (HS chapters 28 and 29) as well as for many plastic and rubber products (HS chapter 40). We run this ex-post evaluation focussing on products with (i) non-zero ad valorem tariffs in the pre-PTA period (year 2001), (ii) the same HS 6-digit classification over time (i.e. no contrasting revisions codes), (iii) an actual tariff cut in the 2001-2004 period and (iv) imports that rose over the post-PTA period. Sampling rules (i)-(iv) allow us to focus on products for which the ex-post PTA evaluation is economically relevant, and for which heterogeneous vs. homogeneous tariff elasticities matter for predicting import growth. ${ }^{62}$

Based on the observed tariff cut in percentage points, we calculate the predicted percentage change in Chilean imports from the US using heterogeneous vs. homogeneous tariff elasticities and correlate them with the post-PTA observed bilateral import growth (over the 2004-2007 period). ${ }^{63}$

The results appear in Table 6. The top part of the table shows the correlation between the observed post-liberalization Chilean import growth from the US (2004-2007) and predicted import growth using heterogeneous elasticities; the bottom part of the table carries out the same exercise using a homogeneous elasticity. We condition these correlations respectively on HS 1-digit section fixed effects (column 1), HS 2-digit chapter fixed effects (column 2) and HS 4-digit heading fixed effects to absorb any sector-specific factor that may have affected Chilean import growth independently of tariff cuts (i.e. some import-demand shock that is uncorrelated with tariff cuts).

The results show clear evidence of the accuracy of the product-specific tariff elasticities over the average (homogeneous) tariff elasticity in predicting import growth. Independently of the type of fixed effects, the predicted import growth with heterogeneous tariff elasticities is pos-

\footnotetext{
${ }^{62}$ For products with no tariff cut (i.e. those violating sampling rules $\mathrm{i}$ and iii), the predicted import growth with the heterogeneous vs. homogeneous tariff elasticity would be the same (zero). Products violating condition (iv) likely experienced an unobserved shock (import demand) that reduced imports at the same time as tariffs fell.

${ }^{63}$ Tariff cut is from the tariff data discussed in Appendix B. Homogeneous elasticities are a weighted average of our product-level elasticities. Predicted import growth is simply the product of the tariff elasticity $\beta_{k}$ in Equation 5 and the percentage tariff reduction implied by the PTA, here approximated by the change in tariffs between 2001 (pre-PTA) and 2004 (the year of entry into force of the PTA). As this exercise aims to evaluate the accuracy of the elasticities proposed here for model calibration, the ex-post evaluation exercise uses the values of the elasticities made available online: these come from the estimation of Equation 5 with positive and insignificant estimates replaced by the average HS-4 trade elasticities.
} 
itively and significantly correlated with the observed import growth, as opposed to the import growth that is predicted with a homogeneous elasticity. Figure 3 provides a graphical representation of the results, where we correlate post-PTA observed import growth (horizontal axis) to predicted import growth using heterogeneous (panel a) and homogeneous (panel b) tariff elasticities (vertical axis). Both observed and predicted import growth are conditioned on HS 1-digit section fixed effects. There is a strong positive correlation with heterogeneous elasticities (panel a), but no correlation with the homogeneous elasticity (panel b). Products with predicted large import growth but stable observed imports may reflect some HS 6-digit specific factors acting as a brake on imports despite the lower tariffs. This is, for example, the case of product HS "290516" (alcohols; saturated monohydric, octanol and isomers thereof), on which Chile applies a non-tariff measure restricting or preventing the use of certain substances contained in food and feed imports.

Overall, this exercise not only underlines the accuracy of our estimated tariff elasticities, it also highlights the potential bias in predicting import growth based on homogeneous (rather than heterogeneous) tariff elasticities. We will further discuss this last point in what follows.

Table 6 - The conditional correlation (OLS estimates) between observed and predicted Chilean growth in imports from the US in the post-PTA period (2004-2007).

\begin{tabular}{|c|c|c|c|}
\hline \multirow[t]{2}{*}{ Dep var: } & \multicolumn{3}{|c|}{$\begin{array}{l}\text { Observed Chilean imports, } \\
\text { growth rate } 2004-2007\end{array}$} \\
\hline & $(1)$ & $(2)$ & (3) \\
\hline Predicted imports using heterogeneous elasticity & $\begin{array}{c}2.040 * * * \\
(0.344)\end{array}$ & $\begin{array}{c}2.250 * * * \\
(0.397)\end{array}$ & $\begin{array}{l}1.845^{* *} \\
(0.753)\end{array}$ \\
\hline Predicted imports using homogeneous elasticity & $\begin{array}{c}0.537 \\
(1.178)\end{array}$ & $\begin{array}{c}0.033 \\
(1.429)\end{array}$ & $\begin{array}{c}0.247 \\
(1.865)\end{array}$ \\
\hline HS1 fixed effects & Yes & No & No \\
\hline HS2 fixed effects & No & Yes & No \\
\hline HS4 fixed effects & No & No & Yes \\
\hline Observations & 199 & 199 & 199 \\
\hline
\end{tabular}

Notes: There are 199 HS6 product categories that satisfy the sampling rules (i)-(iv) discussed in Section 3.2. Robust standard errors appear in parentheses. *** $p<0.01 ; * * p<0.05 ; * p<0.1$. 
Figure 3 - Observed $v s$. predicted Chilean US import growth over the post-PTA period (2004-2007).

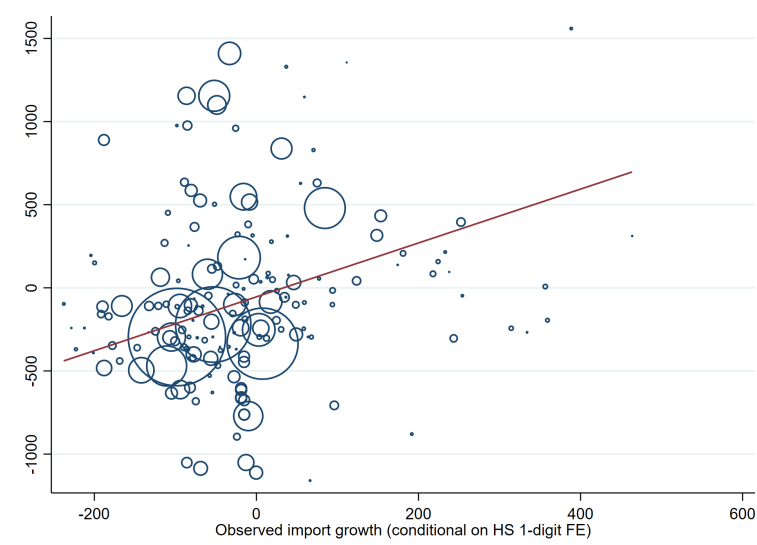

(a) Predicted import growth based on heterogeneous product-specific elasticities

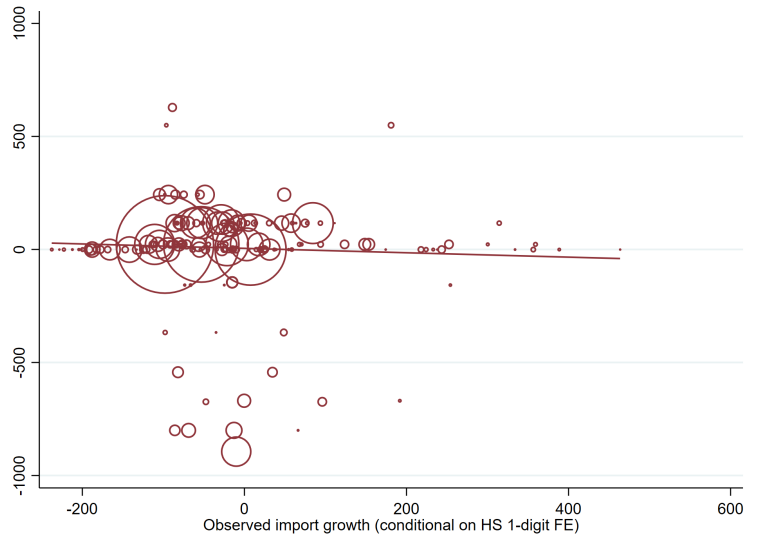

(b) Predicted import growth based on a homogeneous elasticity

Notes: The figures show predicted Chilean import growth in the post-PTA period based on heterogeneous (panel a) and homogeneous (panel b) trade elasticities on the vertical axis. Observed Chilean import growth in the post-PTA period is on the horizontal axis. Both predicted and observed import growth are conditional on HS 1-digit fixed effects. The unbroken lines in panels (a) and (b) shows the fitted values. The size of the circles reflects the level of Chilean imports from the US in 2004 (the starting year for the post-PTA period). Source: Authors' calculations on MAcMAP-HS6 and BACI (CEPII) data.

\subsection{Robustness checks}

We now carry out a series of robustness checks to (i) address the endogeneity of tariffs to import flows; (ii) check whether the estimated elasticities are sensitive to the productclassification aggregation level; (iii) establish whether/how the inclusion of a PTA dummy affects our results; (iv) analyze a more-homogeneous set of exporting countries to reduce concerns regarding selection into export markets; ( $v$ ) include in turn country-pair fixed effects and country-pair specific trends to control for unobservable time-invariant and trend-specific country-pair characteristics; and last (vi) estimate import-demand elasticities that are consistent with a non-CES demand system. In Appendix E we further test the robustness of our results by using cross-section rather than panel data to estimate trade elasticities.

\subsubsection{Endogeneity}

Section 2 discussed the main empirical issues that might bias our baseline results, and why we do not believe that these are first-order in our empirical setting. This sub-section first proposes a robustness check that addresses any residual endogeneity concerns, and then an 
IV strategy.

First, as liberalization episodes generally start by lowering tariffs for industries that are only slightly affected by foreign competition, or on a declining trend that induces rising import competition, tariff cuts may be only spuriously correlated with imports (via omitted variables). The lack of any pre-existing trend in Table 1 and the inclusion of country-year fixed effects (in product-specific regressions), controlling for any unobserved country-product-year specific factors, reduce considerably this omitted-variable worry.

The second issue is that the imposition of high tariffs on certain exporting countries and products may aim to extract rents from an exporter with considerable market power. The political economy of protection provides a similar rationale for endogenous tariffs: domestic industries affected by increasing import competition will lobby for protection. Accordingly, tariffs should vary with the inverse penetration ratio and the price elasticity of imports (Gawande \& Bandyopadhyay 2000). If an importing country sets tariff protection based on the level of imports from a specific exporter, imports and tariffs may appear to be positively correlated, so that the tariff coefficient $\beta_{k}$ is positively biased (via reverse causality).

At the level of detail considered here (HS6 products), the penetration ratio is not observable as we have no expenditure information in the importing country. This precludes any instrumentation based on this common theoretical argument, and we resort to lagged variables as in Shapiro (2016), who estimates trade elasticities for 13 sectors using shipping costs (and not trade policy). Figure A7 compares our baseline PPML trade-elasticity estimates to those using three-year lagged tariff information. ${ }^{64}$ The trade-elasticity distributions with contemporaneous and lagged tariffs are not notably different, reinforcing our conclusion that endogeneity due to potential reverse causality does not invalidate our results. As a further robustness check for reverse causality, Appendix D proposes an IV strategy, where we instrument the bilateral product-level tariff $\tau_{i j k t}$ with the average tariff imposed on similar products $s \neq k$ (with $s$ and $k$ belonging to the same HS 4-digit heading). The average trade elasticity from these 2SLS regressions is qualitatively similar to that from OLS (as 2SLS

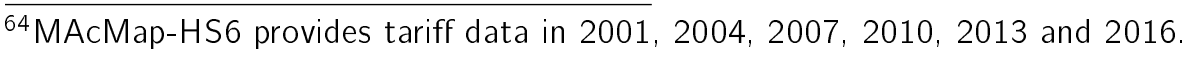


is a log-linear estimation, OLS is the right benchmark): on average reverse causality does not reduce the estimated tariff elasticity $\beta_{k}$. In other words, we find no evidence of reverse causality producing positively-biased OLS estimates. The lack of reverse-causality problems in OLS supports the absence of endogeneity bias in PPML estimations. Appendix D provides a detailed discussion of the exclusion-restriction assumption in our 2SLS estimations.

\subsubsection{Aggregation bias}

To what extent are these estimated elasticities sensitive to product aggregation? At a higher level of aggregation, elasticities are often estimated after summing the levels rather than the log level of trade, so that the consequent higher-level trade elasticity is affected by composition effects (Redding \& Weinstein 2019). Our preferred strategy to avoid these here is to use import and tariff data at the HS 6-digit level to produce trade elasticities: we thus benefit from the largest variation in tariffs (and so in estimated trade elasticities). ${ }^{65}$ However, it is important to check the implications of this choice. Figure A8 shows the distribution of trade elasticities when estimated at the HS 4-digit rather than 6-digit aggregation level. Namely, we pool all the HS 6-digit products within each HS 4-digit heading, and estimate the tariff and distance elasticities for each HS 4-digit heading: ${ }^{66}$

$$
X_{i j, H S 6, t}^{H S 4}=\theta_{i, H S 6, t}+\theta_{j, H S 6, t}+\beta_{k}^{H S 4} \ln \left(1+\tau_{i j, H S 6, t}\right)+\gamma_{k}^{H S 4} \ln \left(d_{i j}\right)+\mathbf{l}_{k}^{H S 4} \mathbf{Z}_{i j}+\epsilon_{i j, H S 6, t}
$$

The trade elasticities at the HS 4-digit level in Figure A8 have qualitatively the same empirical distribution as that of the baseline results in Figure $1 .{ }^{67}$ However, the overall empirical

\footnotetext{
${ }^{65}$ The firm-composition effect may still play a role, and by the same token the shape of the distribution of firm productivity, but we cannot control for these issues with our data.

${ }^{66}$ Country-product-year fixed effects fully absorb the multilateral resistance term. In an alternative robustness check we estimate HS 4-digit specific trade elasticities by using imports and tariff data at the HS 4-digit level. Namely, we aggregate imports summing across HS6 within-HS4 positions for each country-pair, and use the simple average tariff at the HS4 level for each importer-exporter pair (we aggregate by simple average in order to reduce endogeneity concerns). The distribution obtained with this method, available upon request, is qualitatively similar to that from estimating Equation 6 and is depicted in Figure A8.

${ }^{67}$ The final dataset of trade elasticities at the HS 4-digit level is available here: https://sites.google.com/ view/product-level-trade-elasticity/home.
} 
distribution may mask sector-specific aggregation bias (with large discrepancies between the HS 6-digit and 4-digit elasticities in certain HS4 sectors). Table A1 shows the ratio between the trade elasticities at the HS 6-digit and 4-digit levels (averaged across products within each HS 1 chapter). For the majority of HS 1-digit chapters, these ratios suggest a weak/zero aggregation bias, with the HS 6-digit elasticities being only slightly larger than their 4-digit counterparts. However, for sectors like Live Animal and Animal Products (chapter I), Base metals and articles of base metals (chapter XV) and Optical, photographic, precision and medical instruments (chapter XVIII), the bias from using more aggregated trade elasticities is substantial, with the HS 6-digit specific elasticities being (on average) almost twice as large as those at the HS 4-digit level. Overall, using detailed HS 6-digit bilateral trade and tariff data is useful as (i) it maximizes the variation in tariffs and hence makes the estimation of elasticities more precise, (ii) it maximizes the variance in elasticities across products, and (iii) it avoids the aggregation bias resulting from the use of more aggregated data.

\subsubsection{The role of PTA, selection and time-varying trade costs}

Our evidence so far is based on Equation 5, which does not control for the presence of PTAs between trade partners. In Table 2 we showed that up to one quarter of bilateral tariffs were different from the MFN. This is an important source of variation in our independent variable. Consequently, any preferential market access is then captured by the applied tariffs, and our tariff elasticity $\beta_{k}$ could simply reflect the impact of PTAs that may go beyond a simple market-access effect. PTAs are signal of good political and business relationships between the PTA partners, who are possibly engaged in the mutual recognition of standards and certification procedures, for example. This may affect bilateral trade, and so introduce omitted-variable bias in Equation 5. To address these potential concerns, Figure A9 compares the baseline distribution of $\varepsilon_{k}$ (the unbroken line) to the empirical distribution controlling for PTA presence (the dashed line) in Equation 5. The two distributions are very similar, suggesting that there is no systematic bias from PTA omission.

Another robustness test retains only exporting countries that exhibit enough variation in the 
tariffs faced at destination. Online Appendix Figure G5 shows the empirical distribution of trade elasticities from the sub-sample of exporting countries with over five trade partners (for a given product). By the same token, keeping the sub-sample of more-productive exporters (those exporting toward more than five destinations), we reduce selection bias in the tariffelasticity estimates by relying on a more-homogeneous set of exporters. Figure G5 shows that the main results are robust.

Tariff-elasticity estimations may be also affected by the omission of unobserved time-varying trade costs (such as changes in the cost of shipping goods between countries over time). To partially control for this omission, we include country-pair specific time trends in the baseline estimation. ${ }^{68}$ The results in Figure A10 show that controlling for these trends reduces the average trade elasticity a little. However, with country-pair trends the tariff elasticity is imprecisely estimated (statistically insignificant) for 3,495 HS6 products. The dotted line in Figure A10 shows the trade-elasticity distribution when we control for country-pair fixed effects (and not pair-specific trends) in Equation 5; the previous conclusions continue to hold, but here again with 3,548 statistically-insignificant elasticities. ${ }^{69}$

\subsubsection{Trade Elasticity with non-CES preferences: subconvex gravity}

At a very-disaggregated level, the perfectly equalized bilateral trade balance predicted by CES demand systems is rarely observed in the data (Davis \& Weinstein 2002, Allen et al. 2020). We therefore in this section follow Mrázová et al. (2020) and depart from the CES demand system to adopt a more general additively-separable preferences framework to estimate trade elasticities. ${ }^{70}$ Under this assumption the elasticity to trade cost (tariffs and/or distance) depends on the volume of trade, and under the subconvexity assumption in Mrázová et al. (2020) we expect tariff elasticities to fall (in absolute value) with trade volume. Empirically, this translates into the quantile estimation of Equation 5. Note that

\footnotetext{
${ }^{68}$ Alternatively, we can keep the same set of fixed effects as in Equation 5 and interact distance with year variables to control for (linearly) time-varying transportation costs. The average trade elasticity in that case is -8.2 .

${ }^{69}$ Estimations with country-pair fixed effects and country-pair specific trends produce missing tariff elasticities for respectively 19 and 113 HS 6-digit products.

${ }^{70}$ Note that additively-separable preferences nest the CES case.
} 
we are particularly interested here in the variation of the tariff elasticity across quantiles, as variations in the distance between $i$ and $j$ affect the volume of trade through a combination of the trade elasticity $(\varepsilon)$ and the elasticity of the shipping cost to distance $(\rho)$.

Each quantile $q \in(0,1)$ denotes the value ${ }^{71}$ of the dependent variable that partitions the distribution of product-specific bilateral imports $\left(X_{j i k, t}\right)$ into a proportion $q$ below and $1-q$ above. Our baseline equation can therefore be estimated for each quantile $q$ of imports. In doing so, we follow Machado \& Santos Silva (2019) and adopt the Method of MomentsQuantile Regression technique that allows the inclusion of the large sets of fixed effects in Equation 5. ${ }^{72}$ Unfortunately, available econometric software routines do not allow the application of quantile approaches to non-linear models (such as the PPML used in our baseline), so we here use a log-linear quantile estimator. ${ }^{73}$ As a compromise to minimize the bias from zero trade flows in the log-linear model, we limit the amount of zeros by (i) pooling all of the HS 6-digit products $k$ within a given HS 4-digit heading to obtain quantile $q$ different from zero ${ }^{74}$ and (ii) running log-linear models only for higher quantiles $(q \geq 25)$, where the problem of zeros is reduced. For each quantile $q \geq 25$ and HS 4-digit heading we then estimate the following regression (with distance $d_{i j}$ included in the set of controls $\tilde{\mathbf{Z}}_{i j}$ ):

$$
X_{i j k, t, q}^{H S 4}=\theta_{i t}+\theta_{j t}+\beta_{q}^{H S 4} \ln \left(1+\tau_{i j k, t}\right)+\mathbf{I} \tilde{\mathbf{Z}}_{i j}+\epsilon_{i j k, t, q}
$$

Equation 7 produces for each quantile $q$ a distribution of HS 4-digit specific trade elasticities. Figure 4 summarizes the moments of these quantile-specific trade-elasticity distributions, which we find to be statistically similar across quantiles. ${ }^{75}$ The median trade elasticity ap-

\footnotetext{
${ }^{71}$ As we have incomplete information on trade volumes (missing observations) we rely on trade values.

${ }^{72} \mathrm{In}$ STATA this is implemented by the xtqreg routine.

${ }^{73}$ The Method of Moments-Quantile Regression can be theoretically applied to a non-linear PPML model. See Machado \& Santos Silva (2019) Section 3.2 for a discussion of the quantile approach in non-linear models with large sets of fixed effects.

${ }^{74} \mathrm{By}$ applying the quantile approach to each specific HS 6-digit product, we would face a huge amount of zeros, implying many quantiles (up to the $50^{\text {th }}$ or $75^{\text {th }}$ in some cases) being zero, rendering impossible any meaningful quantile estimation.

${ }^{75}$ The median trade elasticity for quantile $q=25$ appears slightly lower than that for the other quantiles. However, the results for this bottom-end quantile must be taken cum grano salis as the presence of many zeros may produce biased point estimates.
} 
pears to only marginally increase in quantiles $q \geq 25$ (in absolute value), and the confidence intervals (the box borders at the 25th and 75th percentile of each quantile distribution) provide evidence in favor of a statistically-invariant trade-elasticity across quantiles. Table A4 shows the mean and standard deviation of the HS 4-digit specific trade elasticities for each quantile $q$. The confidence intervals of one standard deviation above or below the mean include all the trade-elasticity distributions across quantiles. Finding no statistically-significant difference in trade elasticities across quantiles suggests that the baseline results based on the CES demand system can be considered valid and unbiased.

Figure 4 - Moments of the empirical distributions of trade elasticities across HS4 products, for different quantiles of import values.

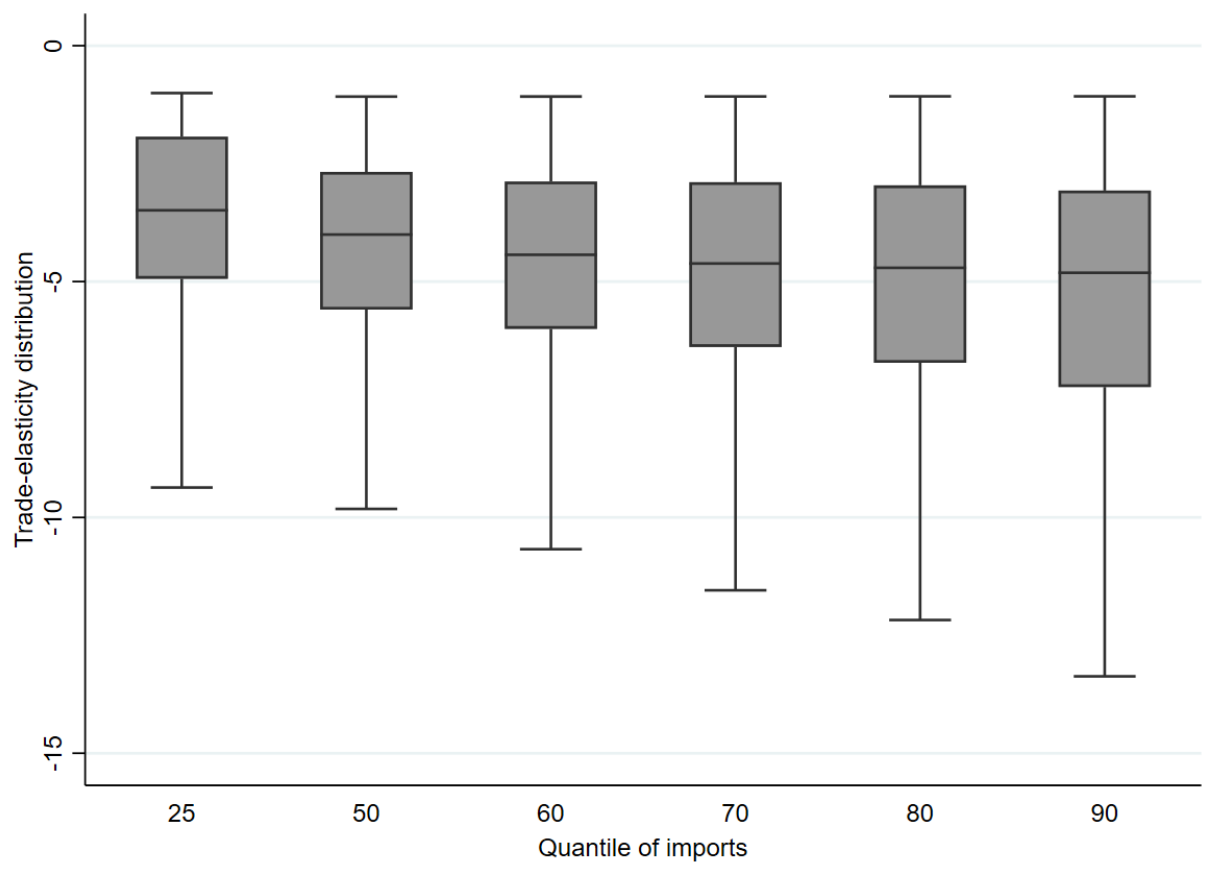

Notes: These results come from the Method of Moments-Quantile regressions discussed in Machado \& Santos Silva (2019). All regressions include exporter-year and importer-year fixed effects. Only HS 4-digit headings with tariff elasticities that are negative and significant at the $10 \%$ level across all quantiles are retained in this figure. The boxes are bordered at the 25 th and 75 th percentile of the quantile-specific tradeelasticity distribution (across HS 4-digit headings). The whiskers extend from the box to the upper and lower adjacent values. Outside values exceeding the adjacent are not shown. 


\section{The gains from trade with heterogeneous elasticities}

The considerable trade-elasticity heterogeneity that we have uncovered raises the question of how the use of sector-specific trade elasticities affects the evaluation of the gains from trade. Whether heterogeneous trade elasticities produce systematically higher gains from trade depends on the combination of these elasticities, the sectoral consumption share and sectoral import penetration. Ossa (2015) compares the welfare change from the simple ACR formula to that in a multi-sector economy with heterogenous sector-level elasticities. The punch-line is that the average of the inverse trade-weighted elasticities differs from the inverse of trade-weighted average elasticities when there are heterogeneous sector-level trade elasticities. Accounting for sectoral heterogeneity produced much larger welfare changes (e.g. twice as large for the US). Giri et al. (2020) demonstrate that other (possibly compensating) factors have to be considered, such as sectoral budget shares and the initial specialization of importers, and compare the gains obtained with and without heterogenous elasticities in a multi-sector economy. ${ }^{76}$

We then go one step further and ask whether the bias in welfare measurement from a homogeneous trade elasticity differs by country development levels. All else equal in terms of import penetration, a higher consumption share in sectors where the trade elasticity is lower than average magnifies the gains from trade. And for a given consumption share, higher import penetration in low-elasticity sectors raises the gains from trade. These simple mechanisms explain why the bias in welfare evaluation might differ across development levels. As the level of applied tariffs is correlated with the country's level of development, the introduction of heterogenous trade elasticities in calibrated models becomes particularly relevant in evaluating the welfare impacts of trade policies. Table 7 highlights the difference in the average applied tariffs between countries with different income levels (high, upper-middle, lower-middle and low): we adopt the classification provided by the World Bank in 2010. This

\footnotetext{
${ }^{76}$ The share of intermediate goods in production costs amplifies the gains from trade, while the share of nontraded services reduces them. Ossa (2015) shows that these two additional determinants are roughly offsetting when introduced in the calculation of the gains from trade. We here follow Costinot \& Rodriguez-Clare (2018), and consider the input-output structure of countries' production by using trade in value-added data. We consider the Manufacturing sector only, as we do not estimate trade elasticities for Services.
} 
confirms that low- and middle-income countries impose higher average import tariffs than do developed (rich) countries.

In this section we tentatively sort out these questions and evaluate the gains from trade obtained using (i) heterogeneous vs. homogeneous trade elasticities across sectors, ${ }^{77}$ and (ii) income-group specific vs. income-group invariant trade elasticities. ${ }^{78}$ To shed light on the impact of heterogenous trade elasticities across sectors, we first keep the same elasticity value for countries at all development levels and allow import-penetration and consumption shares to vary across countries (and hence for countries at different development levels). We next plug in different sectoral-trade elasticities for developing and developed economies.

Table 7 - Average applied import tariff by income group: high, upper-middle, lower-middle and low.

\begin{tabular}{ccccc}
\hline \hline & $\begin{array}{c}\text { High } \\
\text { income }\end{array}$ & $\begin{array}{c}\text { Upper-middle } \\
\text { income }\end{array}$ & $\begin{array}{c}\text { Lower-middle } \\
\text { income }\end{array}$ & $\begin{array}{c}\text { Low } \\
\text { income }\end{array}$ \\
\hline 2001 & 3.8 & 11.8 & 18.1 & 14.4 \\
2004 & 3.0 & 11.7 & 13.4 & 14 \\
2007 & 2.7 & 10.1 & 13.4 & 12.2 \\
2010 & 2.5 & 9.6 & 11.9 & 12.1 \\
2013 & 2.4 & 9.3 & 10.5 & 11.8 \\
2016 & 2.5 & 7.9 & 10.1 & 11.2 \\
\hline
\end{tabular}

Notes: This table lists the mean import tariff for countries in different income groups. The mean is calculated by averaging applied tariffs within a given importer-product combination (across exporters), averaging within importing country, and finally averaging by incomelevel group of the importer. The final averaging follows the usual "reference group approach". We use the World Bank classification of countries' income levels, and define poor and middle-income countries as "developing" while high-income countries are "developed".

To proceed, we closely follow Arkolakis et al. (2012) and calculate the gains from trade as the negative of moving to autarky, with heterogeneous trade elasticities across sectors. The change in real income is related to the total expenditure devoted to domestic production (the domestic market share) and the trade elasticity. We use TiVA (OECD) data to compute

\footnotetext{
${ }^{77}$ As noted above, we do not observe the variety of a product exported by each country (firm-specific exports). The same limitation pertains to the distribution of productivity of individual exporting firms. Departing from the assumption of an untruncated Pareto distribution for productivity would imply a variable trade elasticity, as opposed to the CES model underlying the ACR approach (Melitz \& Redding 2015).

${ }^{78} \mathrm{As}$ an ex-ante step, we applied the ACR formula abstracting from sector differentiation (i.e. calculating the share of total expenditure devoted to domestic production for the Manufacturing sector as a whole) and using the average trade elasticity. We obtain a $7.5 \%$ welfare gain from trade for the US.
} 
both the share of country j's total expenditure devoted to domestic production (i.e. $\lambda_{j j}$ in ACR) and country j's consumption share in sector $s$ (i.e. $\eta_{j s}$, the upper-tier in consumer utility in ACR). These shares are calculated using trade in value-added. ${ }^{79}$ We then compare the ex-ante evaluation of the welfare change with heterogeneous trade elasticities to that from a homogeneous elasticity across sectors (the sectoral weighted average of $\varepsilon_{k}$ ). ${ }^{80}$

The first step is to estimate tariff (and therefore trade) elasticities using the TiVA sector aggregation. To this end, we mimic the empirical approach discussed in Section 3.3.2 by pooling HS6 products within each TiVA sector and estimate the average tariff elasticity by macro TiVA sector. The empirical model used to obtain TiVA sector-specific trade elasticities is:

$$
X_{i j, H S 6, t}^{T i V A}=\theta_{i, H S 6, t}+\theta_{j, H S 6, t}+\beta_{k}^{T i V A} \ln \left(1+\tau_{i j, H S 6, t}\right)+\gamma_{k}^{T i V A} \ln \left(d_{i j}\right)+\mathbf{I}_{k}^{T i V A} \mathbf{Z}_{i j}+\epsilon_{i j, H S 6, t}
$$

We run Equation 8 for each TiVA sector to produce a sectoral tariff elasticity $\left(\beta_{k}^{T i V A}\right):{ }^{81}$ this is the average tariff elasticity across HS6 products within the same TiVA sector. The advantage of this approach is that it constrains the other parameters (e.g. distance) to be equal for all products in a given TiVA sector, and avoids the composition effect that arises in aggregate data by summing (averaging) imports (tariffs) across products within a TiVA sector (Redding \& Weinstein 2019). ${ }^{82}$ The results from this sector aggregation appear in Table A3. We exclude the pure Service-oriented sectors (such as Construction, Wholesale, Hotel and Restaurants) in the TiVA classification. ${ }^{83}$

\footnotetext{
${ }^{79}$ Costinot \& Rodriguez-Clare (2018) stress the importance of using value-added trade flows in calculating the welfare gains from trade, as gross trade flows systematically underestimate countries' import penetration.

${ }^{80}$ We use product export shares (over total World exports) as weights. In Online Appendix Figure G7, we alternatively use the simple average to approximate the homogeneous elasticity.

${ }^{81}$ All TiVA elasticities are negative and statistically significant, making possible the calculation of the ACR formula for all sectors (i.e. there is no indefinite exponential in the ACR formula).

${ }^{82} \mathrm{As}$ the specification is country pair-HS6-year specific, we include both exporter-HS6-year and importer-HS6year fixed effects to fully capture the multilateral resistance term.

${ }^{83}$ We use a similar empirical strategy to estimate trade elasticities at the level of the GTAP sector (revision 10). We consider GTAP sectors that include at least one HS6 product with non-missing tariffs. The results appear in Online Appendix Table G3.
} 
To give a sense of how using TiVA sector-specific elasticities versus an overall homogeneous elasticity affects the gains from trade by industry, we calculate: (i) the TiVA sector-specific elasticities as in Equation 8, and (ii) the homogeneous elasticity by calculating the overall weighted average across TiVA sector elasticities (using sectoral export shares as weights).

As an illustration, we use $\lambda_{j j}$ (the country-sector share of domestic expenditure, i.e. the inverse of the sectoral import-penetration ratio) in 2010 in the US economy and for each industry (the $\lambda_{j j}$ are based on trade in value-added flows, in line with Costinot and RodriguezClare 2018). We then calculate the ratio of the gains from trade with and without heterogeneous sector-level elasticities. Figure 5 correlates the size of the bias in welfare gains (the vertical axis) - calculated as the ratio of sectoral welfare change using respectively heterogeneous $(\widehat{W \text { Hetero }})$ and homogeneous $\left(\widehat{W_{\text {Homog }}}\right)$ trade elasticities - with the ratio of the elasticity estimated for the sector at stake to the average (homogeneous) trade elasticity (the horizontal axis). All else equal, welfare gains rise non-linearly in the dispersion of sectoral elasticities, as expected. For low-elasticity sectors (i.e. those whose actual trade elasticity is lower than the average), using the mean trade elasticity leads to an underestimation of the gain $\left(\widehat{\text { WHetero }} / \widehat{\text { WHomog }^{\prime}}>1\right)$, and vice-versa. ${ }^{84}$

However, the extent of the bias in the estimation of the welfare change also depends on the country's consumption shares for the different sectors. The welfare change $W_{j}$ then becomes:

$$
\widehat{W}_{j}=1-\prod_{s}^{S}\left(\lambda_{j j}^{s}\right)^{-\eta_{j s} / \varepsilon_{s}}
$$

where $\eta_{j s}$ is the consumption share of country $j$ in sector $s$. Equation (9) applies under either perfect competition or imperfect competition and restricted entry (Arkolakis et al. 2012). ${ }^{85}$ We now adopt this strategy to calculate the welfare gains from trade for the largest

\footnotetext{
${ }^{84}$ Note that this graphical illustration differs from that in Costinot \& Rodriguez-Clare (2018), who plot (see their Figure 5) the welfare changes for the US at different values, ranging from 2 to 12 , of the homogeneous trade elasticity.

${ }^{85}$ In monopolistic competition with free entry one more variable enters, namely the industry shares in employment. As this information is missing for a number of countries in TiVA, we did not use this approach.
} 
Figure 5 - The correlation between the bias in sectoral welfare gains (heteregeneous $v s$. homogeneous trade elasticities) and the ratio between heterogeneous and homogeneous trade elasticities. US in 2010.

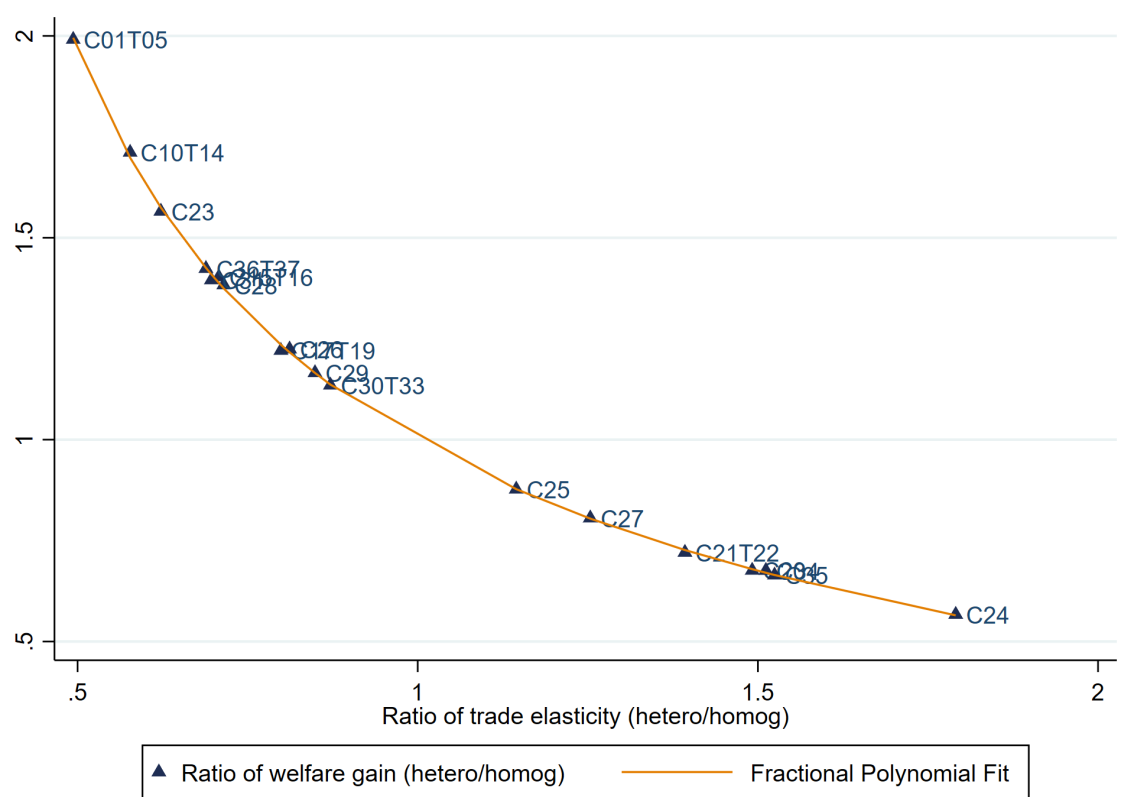

Notes: The vertical axis refers to the ratio between the welfare change computed using heterogeneous elasticity ( $\widehat{\text { WHetero }}$ ) and homogeneous elasticity $\left(\widehat{W^{H o m o g}}\right)$ based on the weighted average of $\varepsilon_{k}$ across TiVA sectors. The weights are the sectoral shares of exports. Source: Authors' calculations. 
set of countries available in TiVA. For this exercise we retain a common trade elasticity for countries at different levels of income per capita in order to isolate the impact of heterogenous elasticities across sectors.

Figure 6 depicts the extent of the bias in the welfare change calculated as discussed above (the vertical axis), ${ }^{86}$ ranking countries by (the logarithm of) per capita income in 2010 (the horizontal axis). First, the dispersion of observations in Figure 6 suggests that the bias is far from being systematic. At a given level of income per capita, using a homogeneous trade elasticity implies considerable underestimation of the gains in certain importing countries (e.g Japan), and a small/zero underestimation for others (e.g. Luxembourg). The dispersion of the bias is larger for high-income countries. In addition, Figure 6 reveals that the under-estimation of the welfare change using the average homogeneous trade elasticity falls with per-capita income: using homogeneous rather than "actual" sector-specific trade elasticities introduces a more-severe downward bias in the welfare-gain estimation for poor and developing countries.

In a robustness check in the Appendix, we compare our welfare-change statistics using a homogeneous trade elasticity to those from three benchmark papers: (i) Feenstra et al. (2018), finding an elasticity for the substitution between varieties of foreign goods of 4.4; (ii) Bas et al. (2017), who find an average elasticity of around 5; and (iii) Romalis (2007), where the elasticity is $8.5: 87$ see Appendix tables $A 5$ and $A 6 .^{88}$ The comparison of column 1 to the others shows how the ex-ante welfare-change evaluation depends on the trade elasticity. ${ }^{89}$

\footnotetext{
${ }^{86}$ The change in welfare with a homogeneous elasticity $\left(\widehat{W_{\text {Homog }}}\right)$ is based on the weighted average trade elasticity $(\varepsilon)$ obtained across TiVA sectors (i.e. 5.9). The results using the unweighted average trade elasticity (i.e. 5.6) are identical with a simple re-scaling of values in the vertical axis. See Figure $\mathrm{G} 7$ in the online appendix.

${ }^{87}$ Depending on the specification, Romalis (2007) finds elasticities of substitution spanning from 6 to 11 - see their Tables $3 \mathrm{~A}$ and $3 \mathrm{~B}$. We here take the average of these elasticities as a benchmark.

${ }^{88}$ Online Appendix Tables G4 and G5 compare the welfare gains from trade obtained using heterogeneous trade elasticities to those using a homogeneous elasticity approximated respectively by the weighted and unweighted average elasticity.

${ }^{89}$ The tariff elasticity cannot be estimated for pure Service sectors where there are no tariffs. As such, the welfare change evaluations reported here consider only TiVA Manufacturing sectors (see Table A3 for the list of elasticity parameters by TiVA sector). These results are therefore not fully comparable to a pure generalequilibrium exercise as in Arkolakis et al. (2012) that considers also Service sectors in the calculation of import penetration. In Arkolakis et al. (2012) the absence of an elasticity parameter for Service sectors is not an issue
} 
Figure 6 - The correlation between the bias in welfare-change evaluation (heteregeneous $v s$. homogeneous trade elasticities) and 2010 per capita GDP.

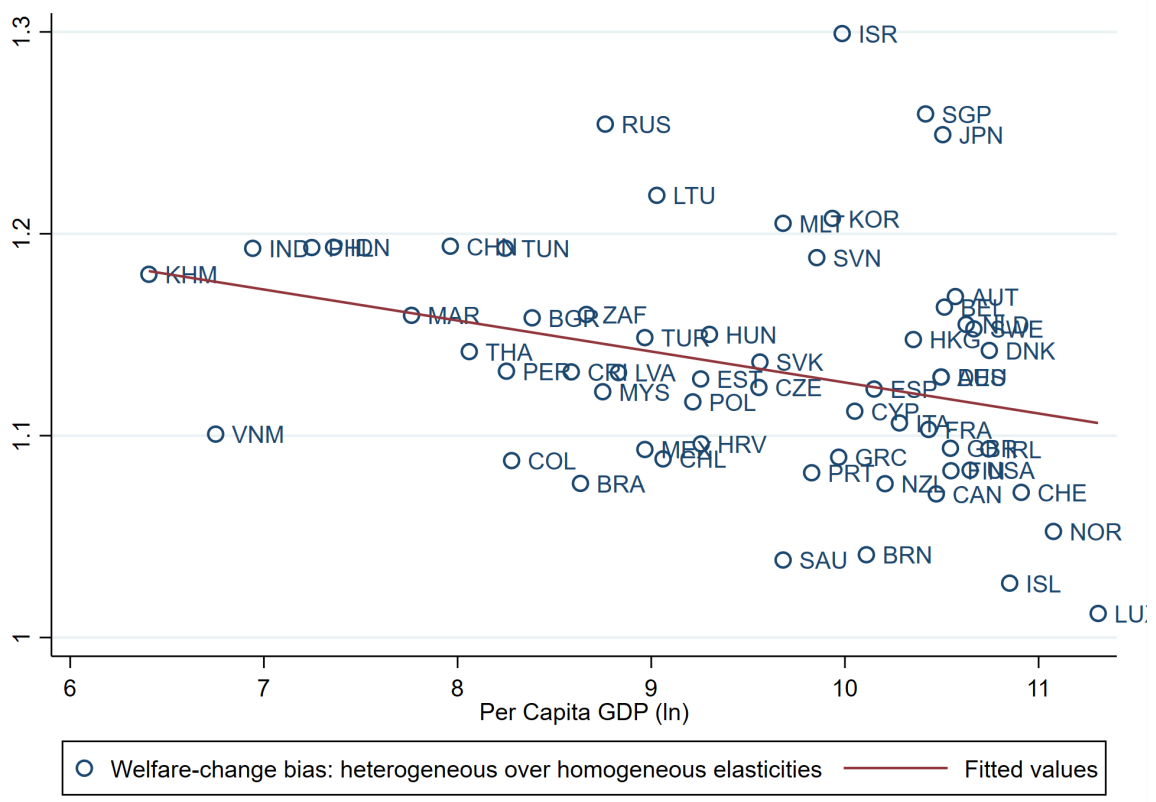

Notes: The vertical axis refers to the ratio of the welfare change calculated using heterogeneous elasticities $(\widehat{W \text { Hetero }})$ and a homogeneous (WHomog $)$ elasticity based on the weighted average of $\varepsilon_{k}$ across TiVA sectors. The weights are the sectoral export shares. The unbroken line shows the fitted values. Source: Authors' calculations. 
Two factors explain the large bias in the welfare change for poor and developing countries in Figure 6. First, these countries may have, on average, smaller trade elasticities than developed countries (as highlighted in Section 3.1). This would produce a negative (positive) bias in the welfare gains from trade for developing (developed) countries when using an average trade elasticity (between developing and developed countries) in the ACR formula. Second, developing countries may have low trade elasticities in sectors with smaller domestic expenditure shares (i.e. the welfare change is maximized when small $\varepsilon$ is found together with small $\left.\lambda_{j j}\right)$. This would again bias the welfare gains from trade when using a homogeneous trade elasticity across all sectors. Using these two arguments, we now delve deeper into the non-systematic bias in the welfare gains from trade across developing and developed countries.

We first show the consequences for the welfare gains from trade when income-group specific (rather than average) trade elasticities are used in the ACR method (in Section 3.1 we clearly showed that developing countries have, on average, smaller trade elasticities than developed countries). Figure 7 plots the welfare gains from trade with income-group specific (vertical axis) and country-invariant trade elasticities (horizontal axis). Both elasticities are sectorspecific, to isolate the effect of country-specific vs. invariant trade elasticities. Figure 7 clearly shows the negative (positive) bias in welfare gains for low- (high-) income countries when using the income-group invariant trade elasticity (a welfare gain above the 45-degree line for low-income countries).

as they consider a homogeneous elasticity parameter for all sectors (Manufacturing and Services). 
Figure 7 - The correlation between the bias in welfare-change evaluation: country-specific $v s$. invariant trade elasticities.

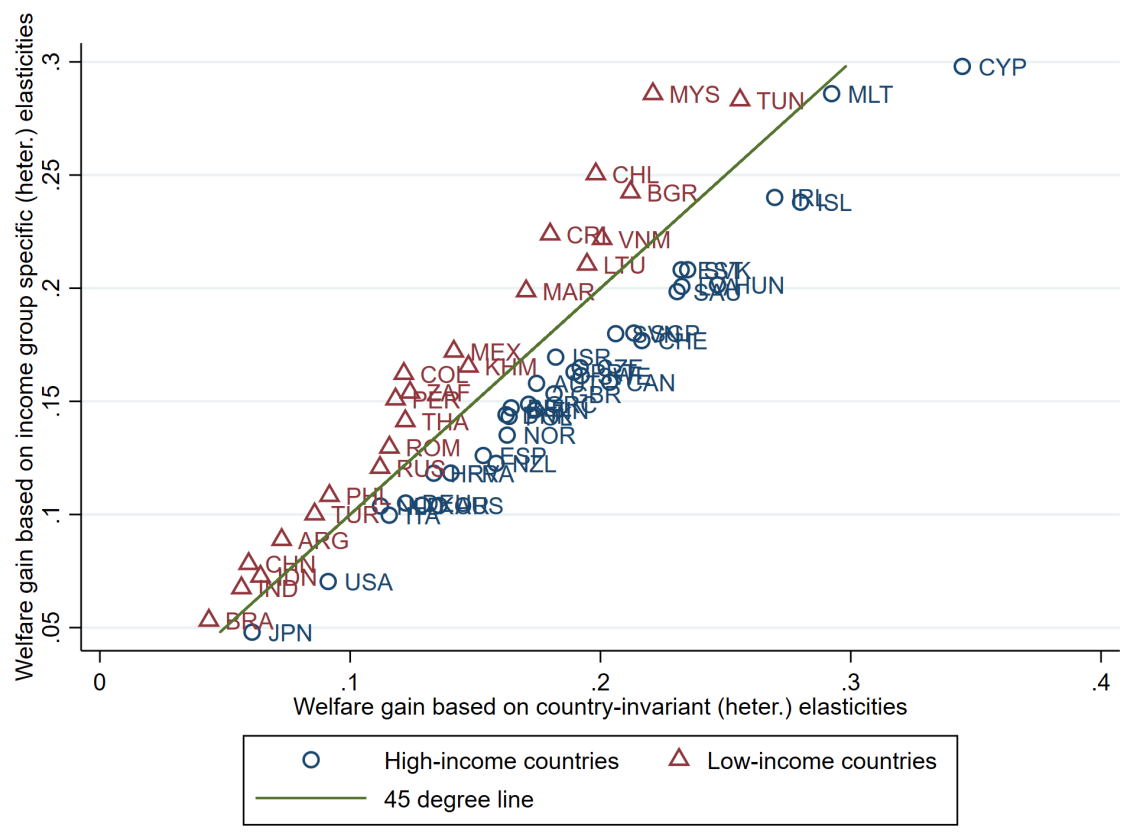

Notes: The vertical axis shows the welfare change with income groupspecific trade elasticities. The horizontal axis shows the same figure with income-group invariant elasticities. The unbroken line shows the 45-degree line. Luxembourg and Hong Kong are not plotted for the sake of readability (their value on the horizontal axis is over 0.5 ). Source: Authors' calculations. 
To further underline the role of homogeneous (rather than heterogeneous) trade elasticities in the negative bias in the welfare gains from trade for developing countries, we now use income-group specific elasticities (to address the bias discussed above) and calculate the ratio of welfare changes using sector heterogeneous over homogeneous trade elasticities. This ratio is used as the dependent variable in the regressions in Table 8, where using homogeneous rather than heterogeneous trade elasticities introduces a significant negative bias in the evaluation of the welfare gains from trade in developing countries (the positive coefficient on the developing-country dummy). Interestingly, the size of the bias from homogeneous trade elasticities is larger for countries whose domestic market share $\left(\lambda_{j j, k}\right)$ is lower in lesselastic sectors (i.e. for countries with a strong positive correlation between $\lambda_{j j, k}$ and $\varepsilon_{k}$ ). These are countries that would enjoy the largest welfare gains from trade liberalization, and whose welfare-gain estimations are strongly underestimated with homogeneous rather than heterogeneous trade elasticities. Figure 8 visualizes these results (for developing countries) by plotting the bias in the welfare-change evaluation from using a homogeneous trade elasticity (the vertical axis) against the correlation between $\lambda_{j j, k}$ and $\varepsilon_{k}$ (the horizontal axis). This confirms that homogeneous trade elasticities imply a negative bias in the welfare change for developing countries (the vertical axis is always greater than one), with this negative bias being larger for countries with domestic market shares that are highly-correlated with the trade elasticity. 
Table 8 - The bias in the welfare-change evaluation (heterogeneous $v s$. homogeneous trade elasticities) and the correlation between the domestic-expenditure share $\left(\lambda_{j j, k}\right)$ and trade elasticity $\left(\varepsilon_{k}\right)$. High- $v s$. low-income countries.

\begin{tabular}{|c|c|c|c|}
\hline Dep var: & \multicolumn{3}{|c|}{ 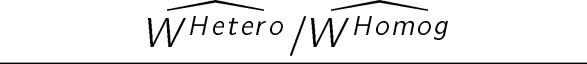 } \\
\hline Developing country (dummy) & $\begin{array}{c}0.312^{* * * *} \\
(0.019)\end{array}$ & & $\begin{array}{c}0.330 * * * \\
(0.026)\end{array}$ \\
\hline $\operatorname{Corr}\left(\lambda_{j j}^{s} ;\left|\varepsilon_{k}\right|\right)$ & & $\begin{array}{c}0.476^{* * *} \\
(0.054)\end{array}$ & $\begin{array}{l}-0.057 \\
(0.046)\end{array}$ \\
\hline $\operatorname{Corr}\left(\lambda_{j j}^{S} ;\left|\varepsilon_{k}\right|\right) \times$ Developing country (dummy) & & & $\begin{array}{c}0.232 * * \\
(0.093)\end{array}$ \\
\hline Observations & 62 & 62 & 62 \\
\hline R-squared & 0.820 & 0.446 & 0.829 \\
\hline
\end{tabular}

Notes: The dependent variable is the ratio in the welfare changes calculated using income-group specific heterogeneous elasticities $\left(\widehat{W^{\text {Hetero }}}\right)$ and a homogeneous elasticity $\left(\widehat{W^{H o m o g}}\right)$. We use the World Bank classification of country income levels, and define poor and middle-income countries as "developing", while high-income countries are "developed". Robust standard errors appear in parentheses. *** $p<0.01 ; * * p<0.05 ; * p<0.1$.

Figure 8 - The bias in welfare-change evaluation (heterogeneous $v s$. homogeneous trade elasticities) and the country's correlation between domestic-expenditure share and trade elasticity.

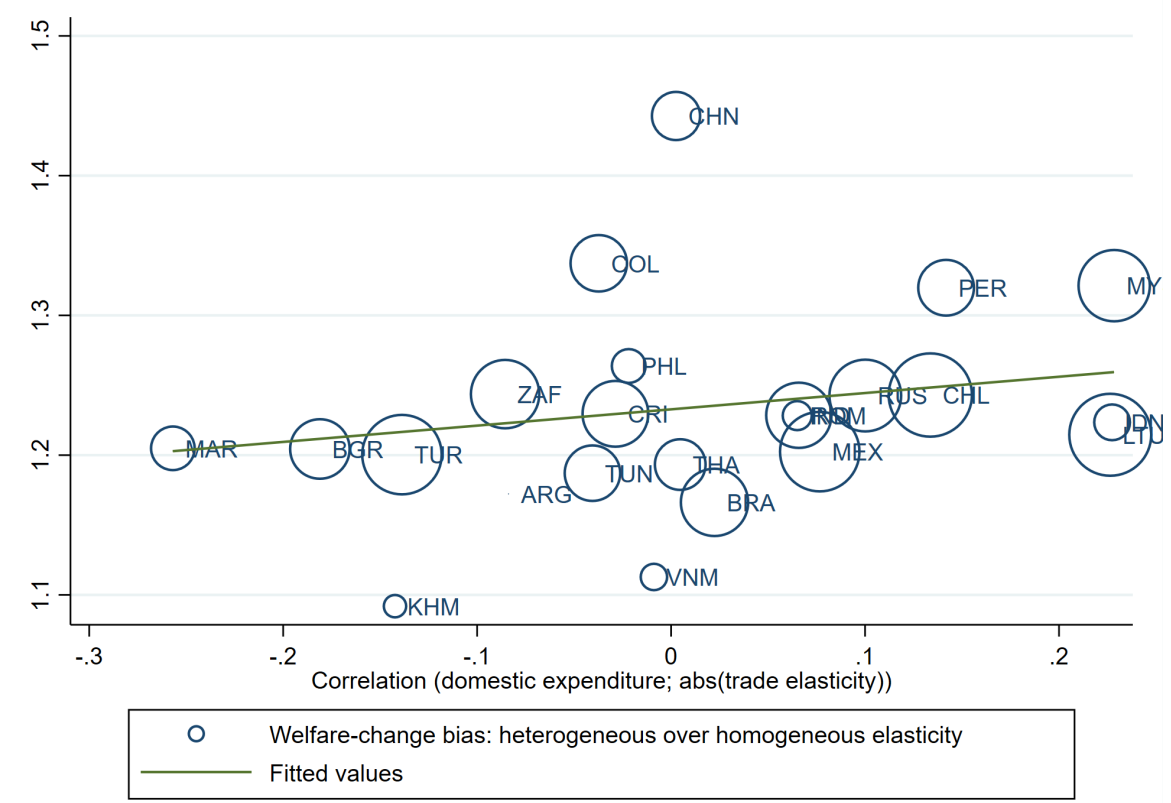

Notes: the vertical axis shows the ratio of the welfare change calculated using income-group specific heterogeneous elasticities $(\widehat{W \text { Hetero }})$ and a homogeneous elasticity $\left(\widehat{W^{H o m o g}}\right)$. The correlation between $\lambda_{j j, k}$ and $\varepsilon_{k}$ is on the horizontal axis. The size of the circles reflects country per capita GDP. The unbroken line shows the fitted values. Source: Authors' calculations. 


\section{Conclusion}

The first contribution of this paper is to provide estimates of trade elasticities at the product level, by exploiting the variation over the 2001-2016 period in bilateral applied tariffs (a variable trade cost) for each product category and the widest-possible set of importers, and so including countries at different level of development. We combine two databases covering the universe of exporters, importers and products at the finest level of disaggregation (the 6-digit level of the Harmonized System). Although we obtain an average trade elasticity in line with that in the literature, we shed light on the wide range around the value that is generally used to calibrate empirical exercises. This is the second contribution of our paper. We finally illustrate the impact of heterogeneous trade elasticities on the estimation of the welfare gains from trade for countries at different levels of development. This is carried out via a simple exercise in line with Arkolakis et al. (2012). We show that using homogeneous trade elasticities produces a downward bias in the estimation of the welfare gains from trade for developing countries, and in particular for those with considerable import penetration in less-elastic sectors. 


\section{Bibliography}

Adao, R., Costinot, A. \& Donaldson, D. (2017), 'Nonparametric counterfactual predictions in neoclassical models of international trade', American Economic Review 107(3), 633-89.

Allen, T., Arkolakis, C. \& Takahashi, Y. (2020), 'Universal Gravity', Journal of Political Economy 128(2), 393-433.

Amiti, M., Redding, S. J. \& Weinstein, D. E. (2019), 'The impact of the 2018 tariffs on prices and welfare', Journal of Economic Perspectives 33(4), 187-210.

Anderson, J. E. \& Yotov, Y. V. (2016), 'Terms of trade and global efficiency effects of free trade agreements 1990-2002', Journal of International Economics 99(C), 279-298.

Anderson, J., Larch, M. \& Yotov, Y. (2018), 'Estimating general equilibrium trade policy effects: GE PPML', The World Economy 41(10), 2750 - 2782.

Arkolakis, C., Costinot, A. \& Rodriguez-Clare, A. (2012), 'New trade models, same old gains?', American Economic Review 102(1), 94 - 130.

Armington, P. S. (1969), 'A theory of demand for products distinguished by place of production', Staff Papers 16(1), 159-178.

Atkeson, A. \& Burstein, A. (2008), 'Pricing-to-market, trade costs, and international relative prices', American Economic Review, 98(5), 1998-2031.

Bas, M., Mayer, T. \& Thoenig, M. (2017), 'From micro to macro: Demand, supply, and heterogeneity in the trade elasticity', Journal of International Economics 108(C), 1-19.

Bertoletti, P., Etro, F. \& Simonovska, I. (2018), 'International trade with indirect additivity', American Economic Journal: Microeconomics 10(2), 1-57.

Broda, C., Greenfield, J. \& Weinstein, D. (2006), From groundnuts to globalization: A structural estimate of trade and growth, Working Paper 12512, National Bureau of Economic Research.

Broda, C. \& Weinstein, D. (2006), 'Globalization and the gains from variety', Quarterly Journal of Economics 121(2).

Caliendo, L. \& Parro, F. (2015), 'Estimates of the trade and welfare effects of NAFTA', The Review of Economic Studies 82(1), 1-44.

Cavallo, A., Gopinath, G., Neiman, B. \& Tang, J. (2019), Tariff passthrough at the border and at the store: Evidence from US trade policy, Working Paper 26396, National Bureau of Economic Research.

Chaney, T. (2008), 'Distorted gravity: the intensive and extensive margins of international trade', American Economic Review 98(4), 1707-1721.

Costinot, A., Donaldson, D. \& Komunjer, I. (2012), 'What Goods Do Countries Trade? A Quantitative Exploration of Ricardo's Ideas', Review of Economic Studies 79(2), 581-608.

Costinot, A. \& Rodriguez-Clare, A. (2014), Trade theory with numbers: Quantifying the 
consequences of globalization, in 'Handbook of International Economics', Vol. 4, Elsevier, pp. 197-261.

Costinot, A. \& Rodriguez-Clare, A. (2018), 'The US gains from trade: Valuation using the demand for foreign factor services', Journal of Economic Perspectives 32(2), 3-24.

Davis, D. R. \& Weinstein, D. E. (2002), 'The Mystery of the Excess Trade (Balances)', American Economic Review 92(2), 170-174.

Dekle, R., Eaton, J. \& Kortum, S. (2008), 'Global rebalancing with gravity: Measuring the burden of adjustment', IMF Staff Papers 55(3), 511-540.

Eaton, J. \& Kortum, S. (2002), 'Technology, geography, and trade', Econometrica 70(5), 1741-1779.

Fajgelbaum, P. D., Goldberg, P. K., Kennedy, P. J. \& Khandelwal, A. K. (2020), 'The return to protectionism', Quarterly Journal of Economics 135(1), 1-55.

Fally, T. (2015), 'Structural gravity and fixed effects', Journal of International Economics 97(1), 76-85.

Fally, T. \& Sayre, J. (2018), Commodity trade matters, Working paper, National Bureau of Economic Research, Working Paper 24965.

Feenstra, R. C. (1994), 'New product varieties and the measurement of international prices', American Economic Review 84(1)(1), 157-177.

Feenstra, R. C., Luck, P., Obstfeld, M. \& Russ, K. N. (2018), 'In search of the Armington elasticity', Review of Economics and Statistics 100(1), 135-150.

Fontagné, L., Martin, P. \& Orefice, G. (2018), 'The international elasticity puzzle is worse than you think', Journal of International Economics 115, 115-129.

Fontagné, L. \& Orefice, G. (2018), ‘Let's try next door: Technical barriers to trade and multi-destination firms', European Economic Review 101, 643-663.

Freund, C. \& Ornelas, E. (2010), 'Regional trade agreements', Annual Review of Economics 2(1), 139-166.

Gawande, K. \& Bandyopadhyay, U. (2000), 'Is protection for sale? evidence on the Grossman-Helpman theory of endogenous protection', Review of Economics and Statistics 82(1), 139-152.

Giri, R., Yi, K.-M. \& Yilmazkuday, H. (2020), Gains from trade: Does sectoral heterogeneity matter?, Technical report, National Bureau of Economic Research Working Paper No. 26741.

Goldberg, P. K. \& Pavcnik, N. (2016), The effects of trade policy, in K. Bagwell \& R. Staiger, eds, 'Handbook of commercial policy', Vol. 1, Elsevier, pp. 161-206.

Head, K. \& Mayer, T. (2014), Gravity equations: Workhorse, toolkit, and cookbook, in 'Handbook of International Economics', Vol. 4, Handbook of International Economics, Gita Gopinath, Elhanan Helpman and Kenneth Rogoff editors, chapter 4. 
Head, K., Mayer, T. \& Ries, J. (2010), 'The erosion of colonial trade linkages after independence', Journal of International Economics 81(1), 1-14.

Head, K. \& Ries, J. (2001), 'Increasing returns versus national product differentiation as an explanation for the pattern of US-Canada trade', American Economic Review 91(4), 858876.

Hillberry, R. H., Anderson, M. A., Balistreri, E. J. \& Fox, A. K. (2005), 'Taste parameters as model residuals: assessing the fit of an Armington trade model', Review of International Economics 13(5), 973-984.

Hummels, D. (2007), 'Transportation costs and international trade in the second era of globalization', Journal of Economic perspectives 21(3), 131-154.

Hummels, D. \& Skiba, A. (2004), 'Shipping the good apples out? An empirical confirmation of the Alchian-Allen conjecture', Journal of Political Economy 112(6), 1384-1402.

Imbs, J. \& Mejean, I. (2015), ‘Elasticity Optimism', American Economic Journal: Macroeconomics 3(7), 43-83.

Kee, H. L., Nicita, A. \& Olarreaga, M. (2008), 'Import demand elasticities and trade distortions', Review of Economics and Statistics 90(4), 666-682.

Kee, H. L., Nicita, A. \& Olarreaga, M. (2009), 'Estimating Trade Restrictiveness Indices', Economic Journal 119(534), 172-199.

Machado, J. A. \& Santos Silva, J. (2019), 'Quantiles via moments', Journal of Econometrics 213(1), 145-173.

Markusen, J. R. (2013), 'Putting per-capita income back into trade theory', Journal of International Economics 90(2), 255-265.

Martin, P., Mayer, T. \& Thoenig, M. (2008), 'Make trade not war?', Review of Economic Studies 75(3), 865-900.

Melitz, M. J. \& Redding, S. J. (2015), 'New trade models, new welfare implications', American Economic Review 105(3), 1105-46.

Mrázová, M. \& Neary, P. (2017), 'Not so demanding: Demand structure and firm behavior', American Economic Review 107(12), 3835-74.

Mrázová, M., Neary, P. \& Carrere, C. (2020), 'Gravity without apologies: the science of elasticities, distance, and trade', Economic Journal forthcoming.

Ossa, R. (2014), 'Trade wars and trade talks with data', American Economic Review 104(12), 4104-46.

Ossa, R. (2015), 'Why trade matters after all', Journal of International Economics 97(2), 266-277.

Redding, S. J. \& Weinstein, D. E. (2019), Aggregation and the gravity equation, in 'AEA Papers and Proceedings', Vol. 109, pp. 450-55.

Romalis, J. (2007), 'NAFTA's and CUSFTA's impact on international trade', Review of 
Economics and Statistics 89(3), 416-435.

Santos-Silva, J. M. C. \& Tenreyro, S. (2006), 'The Log of Gravity', The Review of Economics and Statistics 88(4), 641-658.

Sequeira, S. (2016), 'Corruption, Trade Costs, and Gains from Tariff Liberalization: Evidence from Southern Africa', American Economic Review 106(10), 3029-3063.

Shapiro, J. S. (2016), 'Trade costs, CO2, and the environment', American Economic Journal: Economic Policy 8(4), 220-54.

Simonovska, I. \& Waugh, M. E. (2014a), 'The elasticity of trade: Estimates and evidence', Journal of International Economics 92(1), 34 - 50.

Soderbery, A. (2018), 'Trade elasticities, heterogeneity, and optimal tariffs', Journal of International Economics 114, 44-62.

Spearot, A. C. (2013), 'Variable demand elasticities and tariff liberalization', Journal of International Economics 89(1), 26-41. 


\section{Appendix}

\section{Appendices}

\section{A. Appendix tables and figures}

Table A1 - Ratio of HS 6-digit to 4-digit trade elasticities.

\begin{tabular}{llc}
\hline \hline Section & Description & $\varepsilon^{H S 6} / \varepsilon^{H S 4}$ \\
\hline I & Live Animals and Animal Products & 2.94 \\
II & Vegetable Products & 1.51 \\
III & Animal or vegetable fats and oils & 1.50 \\
IV & Prepared foodstuffs, beverages and tobacco & 1.28 \\
V & Mineral products & 1.26 \\
VI & Products of chemical industries & 1.44 \\
VII & Plastic and articles thereof & 1.13 \\
VIII & Raw hides and skins, leather and article thereof & 1.35 \\
IX & Wood/Cork and articles of Wood/Cork; & 1.00 \\
X & Pulp of wood or other cellulosic materials & 1.09 \\
XI & Textile and textile articles & 1.17 \\
XII & Footwear, Headgear, Umbrellas and prepared feathers & 0.95 \\
XIII & Articles of stone, plaster, ceramic and glass & 1.23 \\
XIV & Natural cultured pearls and precious stones and metals & 1.40 \\
XV & Base metals and articles of base metals & 2.21 \\
XVI & Machinery and mechanical appliances and electrical machinery & 1.74 \\
XVII & Vehicles, Aircraft and transport equipment & 1.12 \\
XVIII & Optical, photographic, precision and medical instruments & 1.79 \\
XIX & Arms and ammunitions & 1.27 \\
XX & Miscellaneous & 1.55 \\
XXI & Works of art & 1.00 \\
\hline
\end{tabular}

Notes: The figures in this table exclude positive trade elasticities. The HS 4-digit elasticities are obtained using the procedure described in Equation 6. 


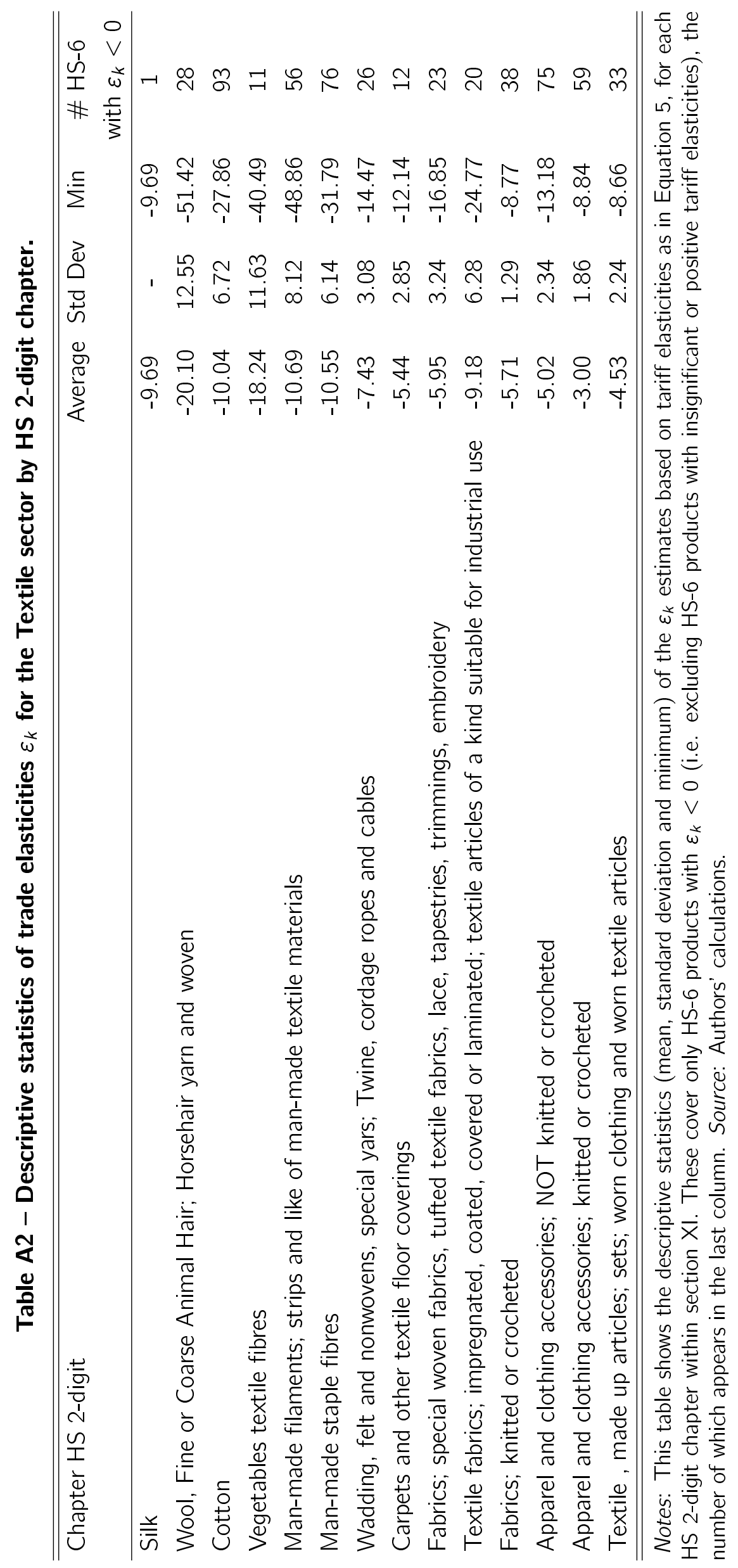


Table A3 - Trade elasticity $\varepsilon_{k}$ by TiVA 2016 sectors used to calculate the gains from trade in Section 3.

\begin{tabular}{llc}
\hline \hline TiVA Industry code & Heading & Elasticity $\varepsilon_{k}$ \\
\hline C01T05 & Agriculture, hunting, forestry and fishing & -2.91 \\
C10T14 & Mining and quarrying & -3.41 \\
C15T16 & Food products, beverages and tobacco & -4.17 \\
C17T19 & Textiles, textile products, leather and footwear & -4.71 \\
C20 & Wood and products of wood and cork & -8.80 \\
C21T22 & Pulp, paper, paper products, printing and publishing & -8.21 \\
C23 & Coke, refined petroleum products and nuclear fuel & -3.67 \\
C24 & Chemicals and chemical products & -10.56 \\
C25 & Rubber and plastics products & -6.75 \\
C26 & Other non-metallic mineral products & -4.79 \\
C27 & Basic metals & -7.39 \\
C28 & Fabricated metal products & -4.22 \\
C29 & Machinery and equipment, nec & -5.01 \\
C30T33X & Computer, electronic and optical equipment & -5.14 \\
C31 & Electrical machinery and apparatus, nec & -4.11 \\
C34 & Motor vehicles, trailers and semi-trailers & -8.92 \\
C35 & Other transport equipment & -8.99 \\
C36T37 & Manufacturing nec; recycling & -4.06 \\
C40T41 & Electricity, gas and water supply & NS \\
C73T74 & R\&D and other business activities & -5.90 \\
C90T93 & Other community, social and personal services & -8.35 \\
\hline
\end{tabular}

Note: We consider TiVA sectors that include at least one HS6 product with non-missing tariff information. 
Table A4 - Quantile regressions. Log-linear model results by quantile $q$.

\begin{tabular}{lccccc}
\hline \hline Quantile & $\begin{array}{c}\text { Average } \\
\text { elasticity } \varepsilon_{k}\end{array}$ & Std Dev & Min & Max & $\begin{array}{c}\text { No. HS 4-digit } \\
\text { headings }\end{array}$ \\
\hline $\mathrm{q}=25$ & -4.07 & 2.98 & -22.55 & -1.00 & 371 \\
$\mathrm{q}=50$ & -4.62 & 2.84 & -18.28 & -1.08 & 371 \\
$\mathrm{q}=60$ & -4.94 & 3.01 & -21.08 & -1.08 & 371 \\
$\mathrm{q}=70$ & -5.16 & 3.17 & -23.47 & -1.07 & 371 \\
$\mathrm{q}=80$ & -5.36 & 3.33 & -25.37 & -1.07 & 371 \\
$\mathrm{q}=90$ & -5.60 & 3.58 & -27.85 & -1.07 & 371 \\
\hline
\end{tabular}

Notes: These results come from the Method of Moments-Quantile regression discussed in Machado \& Santos Silva (2019). All regressions include exporter-year and importer-year fixed effects. Only HS 4-digit headings with negative and significant at 10\% tariff elasticities across all quantiles appear in the statistics listed in this table. 
Table A5 - Ex-ante welfare evaluation: moving to autarky. The change in log real income across non-OECD countries using the ACR formula with a homogeneous trade elasticity (weighted average across HS 6-digit specific elasticities) compared to those in previous works.

\begin{tabular}{|c|c|c|c|c|}
\hline & \multicolumn{4}{|c|}{ Homogeneous elasticity across sectors: } \\
\hline & Average & Feenstra & Bas & Romalis \\
\hline & $(1-\sigma)$ & et al (2014) & et al.(2017) & $(2007)$ \\
\hline Argentina & 0.071 & 0.094 & 0.083 & 0.050 \\
\hline Brazil & 0.043 & 0.058 & 0.051 & 0.030 \\
\hline Bulgaria & 0.188 & 0.244 & 0.218 & 0.135 \\
\hline Cambodia & 0.179 & 0.232 & 0.208 & 0.128 \\
\hline China & 0.050 & 0.067 & 0.059 & 0.035 \\
\hline Colombia & 0.110 & 0.144 & 0.128 & 0.078 \\
\hline Costa Rica & 0.181 & 0.234 & 0.209 & 0.129 \\
\hline Croatia & 0.127 & 0.166 & 0.148 & 0.090 \\
\hline Cyprus & 0.380 & 0.473 & 0.431 & 0.282 \\
\hline India & 0.056 & 0.075 & 0.066 & 0.039 \\
\hline Indonesia & 0.056 & 0.074 & 0.066 & 0.039 \\
\hline Malaysia & 0.191 & 0.247 & 0.221 & 0.137 \\
\hline Malta & 0.290 & 0.368 & 0.332 & 0.211 \\
\hline Morocco & 0.162 & 0.211 & 0.188 & 0.115 \\
\hline Peru & 0.104 & 0.137 & 0.122 & 0.073 \\
\hline Philippines & 0.083 & 0.110 & 0.097 & 0.058 \\
\hline Romania & 0.110 & 0.145 & 0.129 & 0.078 \\
\hline Russia & 0.090 & 0.119 & 0.105 & 0.063 \\
\hline Saudi Arabia & 0.203 & 0.263 & 0.235 & 0.146 \\
\hline Singapore & 0.265 & 0.338 & 0.305 & 0.193 \\
\hline South Africa & 0.120 & 0.158 & 0.140 & 0.085 \\
\hline Taiwan & 0.165 & 0.214 & 0.191 & 0.117 \\
\hline Thailand & 0.111 & 0.146 & 0.130 & 0.079 \\
\hline Tunisia & 0.236 & 0.303 & 0.272 & 0.170 \\
\hline Vietnam & 0.185 & 0.240 & 0.214 & 0.132 \\
\hline
\end{tabular}

Notes: In calculating the cost of autarky we follow ACR(2010) Sections 3.3 and 5.1. To calculate the change in welfare using the elasticities in Feenstra et al. (2014), Bas et al. (2017) and Romalis (2007) we used $(1-\sigma)$ values of $4.4,5$ and 8.5 respectively. The welfare change is calculated using Manufacturing sectors only (due to data availability). Source: Authors' calculations. 
Table A6 - Ex ante welfare evaluation: moving to autarky. The change in log real income across OECD countries using the ACR formula with homogeneous trade elasticity (weighted average across HS 6-digit specific elasticities) compared to those in previous works.

\begin{tabular}{|c|c|c|c|c|}
\hline & \multicolumn{4}{|c|}{ Homogeneous elasticity across sectors: } \\
\hline & $\begin{array}{l}\text { Average } \\
(1-\sigma)\end{array}$ & $\begin{array}{c}\text { Feenstra } \\
\text { et al (2014) }\end{array}$ & $\begin{array}{c}\text { Bas } \\
\text { et al.(2017) }\end{array}$ & $\begin{array}{c}\text { Romalis } \\
\text { (2007) }\end{array}$ \\
\hline Australia & 0.132 & 0.173 & 0.154 & 0.094 \\
\hline Austria & 0.166 & 0.216 & 0.193 & 0.118 \\
\hline Belgium & 0.152 & 0.198 & 0.177 & 0.108 \\
\hline Canada & 0.181 & 0.235 & 0.210 & 0.130 \\
\hline Chile & 0.186 & 0.241 & 0.215 & 0.133 \\
\hline Czech Republic & 0.180 & 0.234 & 0.209 & 0.129 \\
\hline Denmark & 0.154 & 0.200 & 0.179 & 0.109 \\
\hline Estonia & 0.212 & 0.273 & 0.244 & 0.152 \\
\hline Finland & 0.172 & 0.224 & 0.200 & 0.123 \\
\hline France & 0.137 & 0.180 & 0.160 & 0.098 \\
\hline Germany & 0.119 & 0.156 & 0.139 & 0.084 \\
\hline Greece & 0.169 & 0.219 & 0.196 & 0.120 \\
\hline Hungary & 0.228 & 0.293 & 0.263 & 0.165 \\
\hline Iceland & 0.306 & 0.387 & 0.350 & 0.224 \\
\hline Ireland & 0.262 & 0.334 & 0.301 & 0.190 \\
\hline Israel & 0.204 & 0.263 & 0.236 & 0.146 \\
\hline Italy & 0.115 & 0.151 & 0.134 & 0.081 \\
\hline Japan & 0.057 & 0.075 & 0.067 & 0.040 \\
\hline Latvia & 0.222 & 0.286 & 0.256 & 0.160 \\
\hline Lithuania & 0.161 & 0.210 & 0.187 & 0.115 \\
\hline Luxembourg & 0.506 & 0.611 & 0.564 & 0.387 \\
\hline Mexico & 0.127 & 0.167 & 0.148 & 0.090 \\
\hline Netherlands & 0.105 & 0.139 & 0.123 & 0.074 \\
\hline New Zealand & 0.145 & 0.190 & 0.169 & 0.103 \\
\hline Norway & 0.135 & 0.176 & 0.157 & 0.096 \\
\hline Poland & 0.149 & 0.195 & 0.173 & 0.106 \\
\hline Portugal & 0.190 & 0.246 & 0.220 & 0.136 \\
\hline Slovakia & 0.220 & 0.283 & 0.254 & 0.158 \\
\hline Slovenia & 0.232 & 0.299 & 0.268 & 0.168 \\
\hline South Korea & 0.122 & 0.160 & 0.143 & 0.087 \\
\hline Spain & 0.150 & 0.196 & 0.175 & 0.107 \\
\hline Sweden & 0.179 & 0.232 & 0.207 & 0.128 \\
\hline Switzerland & 0.211 & 0.272 & 0.244 & 0.151 \\
\hline Turkey & 0.080 & 0.106 & 0.094 & 0.057 \\
\hline United Kingdom & 0.173 & 0.224 & 0.200 & 0.123 \\
\hline United States & 0.086 & 0.114 & 0.101 & 0.061 \\
\hline
\end{tabular}

Notes: In calculating the cost of autarky we follow ACR(2010) Sections 3.3 and 5.1. To calculate the change in welfare using the elasticities in Feenstra et al. (2014), Bas et al. (2017) and Romalis (2007) we used $(1-\sigma)$ respectively of $4.4,5$ and 8.5 . The welfare change is calculated using Manufacturing sectors only (due to data availability). Source: Authors' calculations. 
Figure A1 - The product-specific empirical distribution of the shipping-cost elasticity to distance (i.e. $\rho_{k}=\gamma_{k} / \beta_{k}$ ).

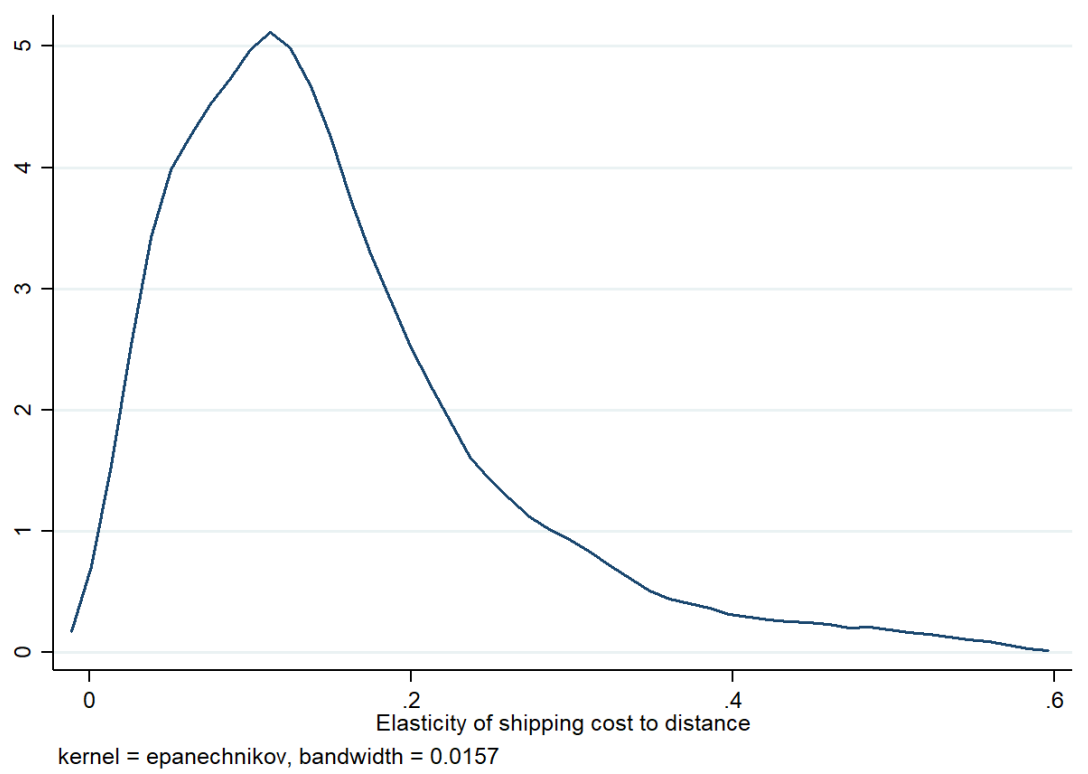

Notes: The empirical distribution is calculated on HS-6 products with negative distance to tariff elasticities. Source: Authors' calculations. 
Figure A2 - The empirical distribution of trade elasticities. Comparison of the baseline results to those obtained by constraining other trade-cost elasticities to be constant within the HS 4-digit heading.

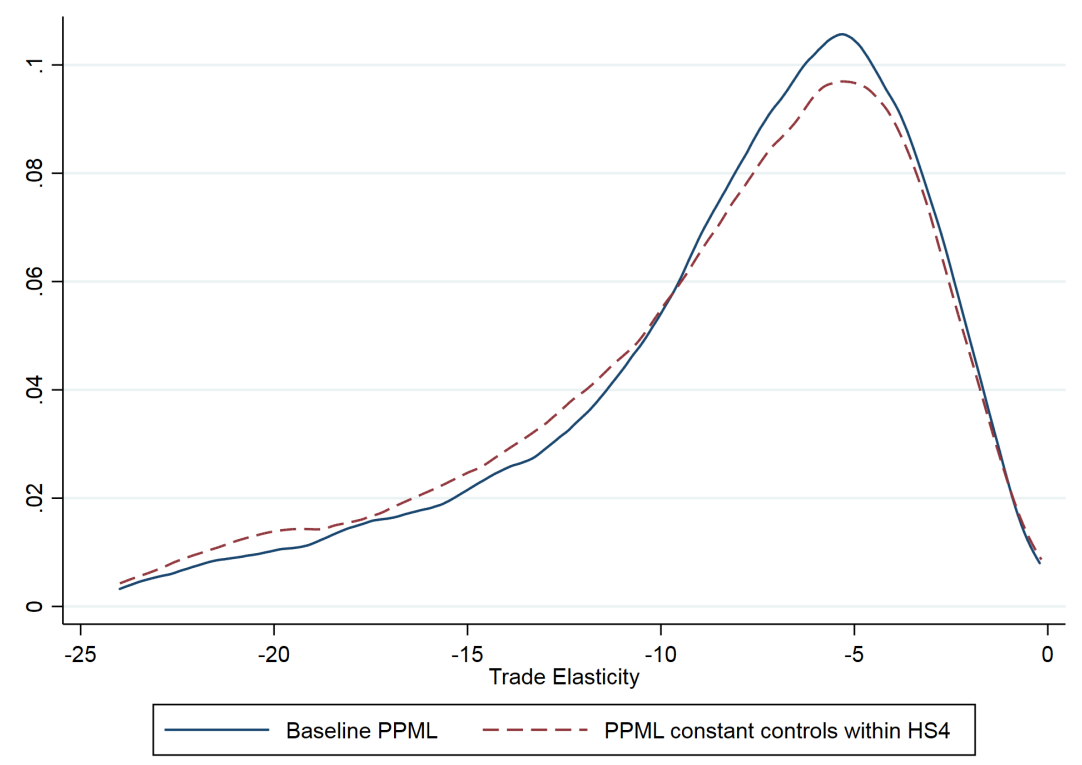

Note: The empirical distribution is calculated on HS-6 products with negative distance elasticities. Source: Authors' calculations.

Figure A3 - The empirical distribution of trade elasticities across all products. Comparison between the trade-elasticity distributions obtained with $99 \%$ and $95 \%$ statistical significance.

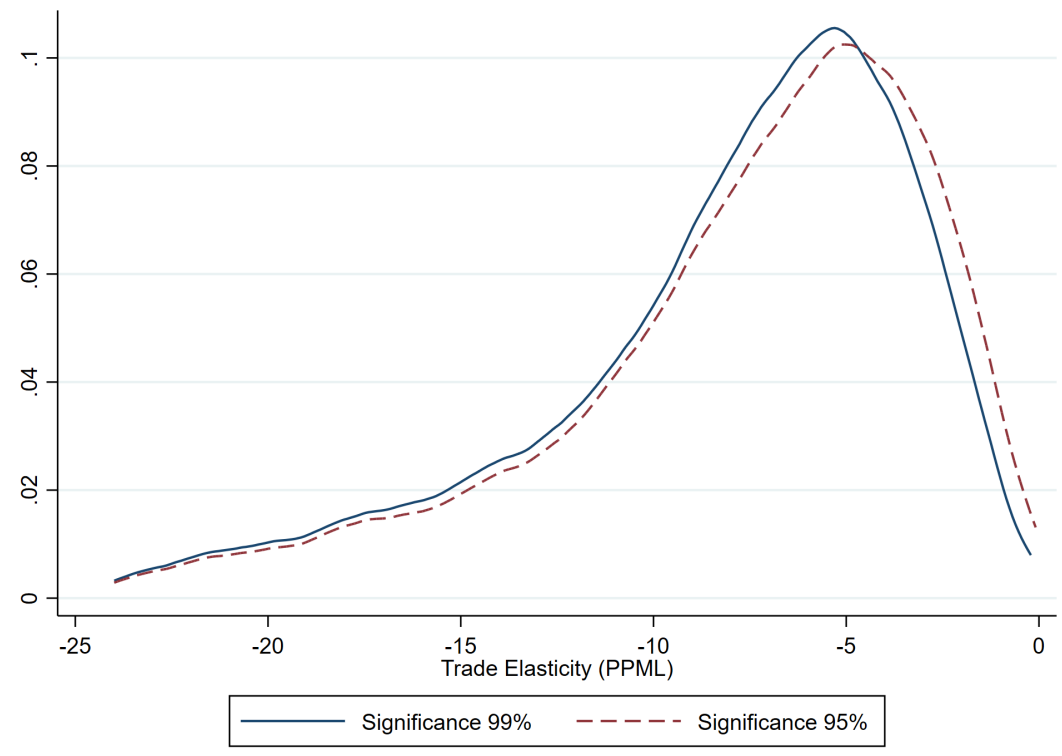

Note: The empirical distribution is calculated on HS-6 products with $\varepsilon_{k}<0$. Source: Authors' calculations. 
Figure A4 - The empirical distribution of trade elasticities. Manufacturing $v s$. Agriculture.

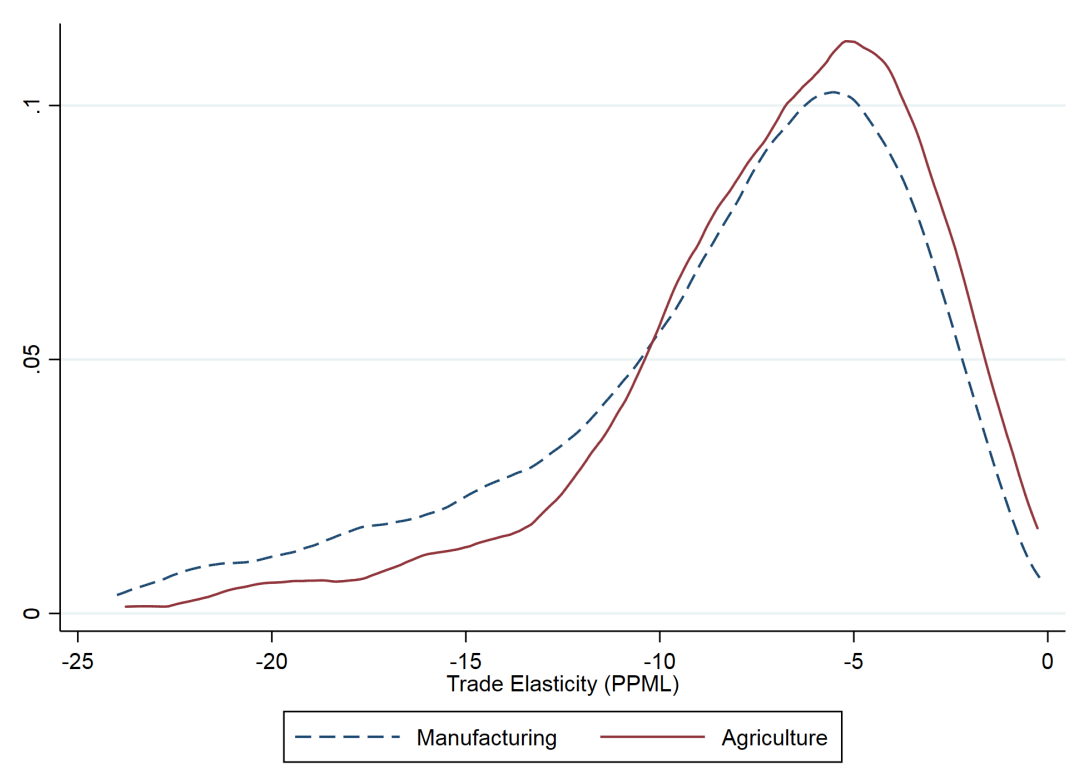

Note: The empirical distribution is calculated on HS-6 products with $\varepsilon_{k}<0$. Source: Authors' calculations.

Figure A5 - The empirical distribution of trade elasticities across all products. OLS vs. PPML estimations.

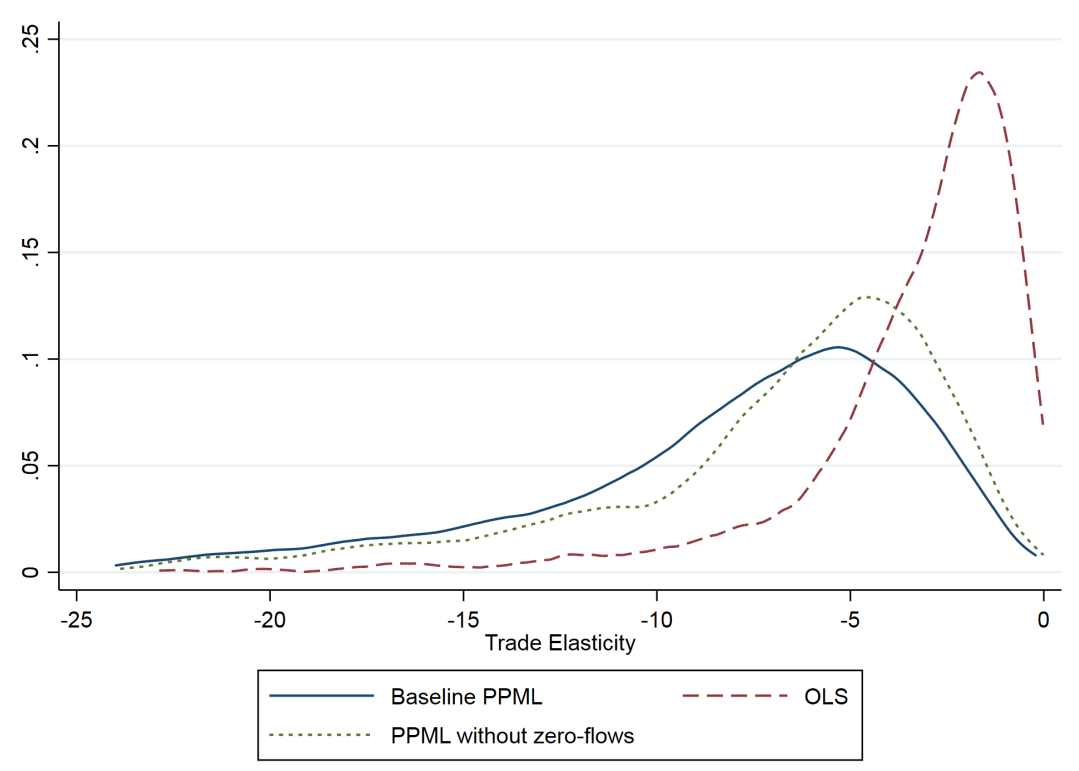

Notes: The empirical distribution is calculated on HS-6 products with $\varepsilon_{k}<0$. For the correct comparison of the OLS and PPML estimations, and focusing on the bias implied by the different weighting schemes (i.e. abstracting from the problem of the inclusion of zeros), both estimators are applied to datasets without zero trade flows. Source: Authors' calculations. 
Figure A6 - The empirical distribution of trade elasticities. Homogeneous $v s$. Differentiated products (based on the Rauch classification).

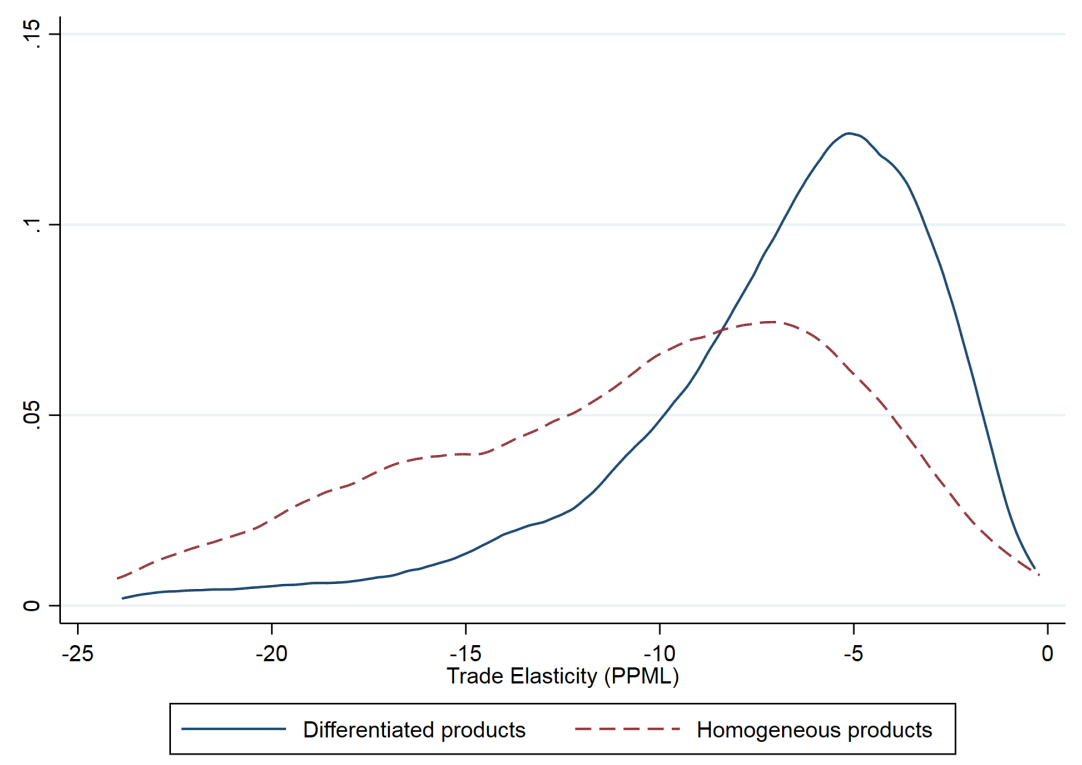

Note: The empirical distribution is calculated on HS-6 products with $\varepsilon_{k}<0$. Source: Authors' calculations.

Figure A7 - The empirical distribution of trade elasticities. Contemporaneous $v S$. lagged tariff estimations.

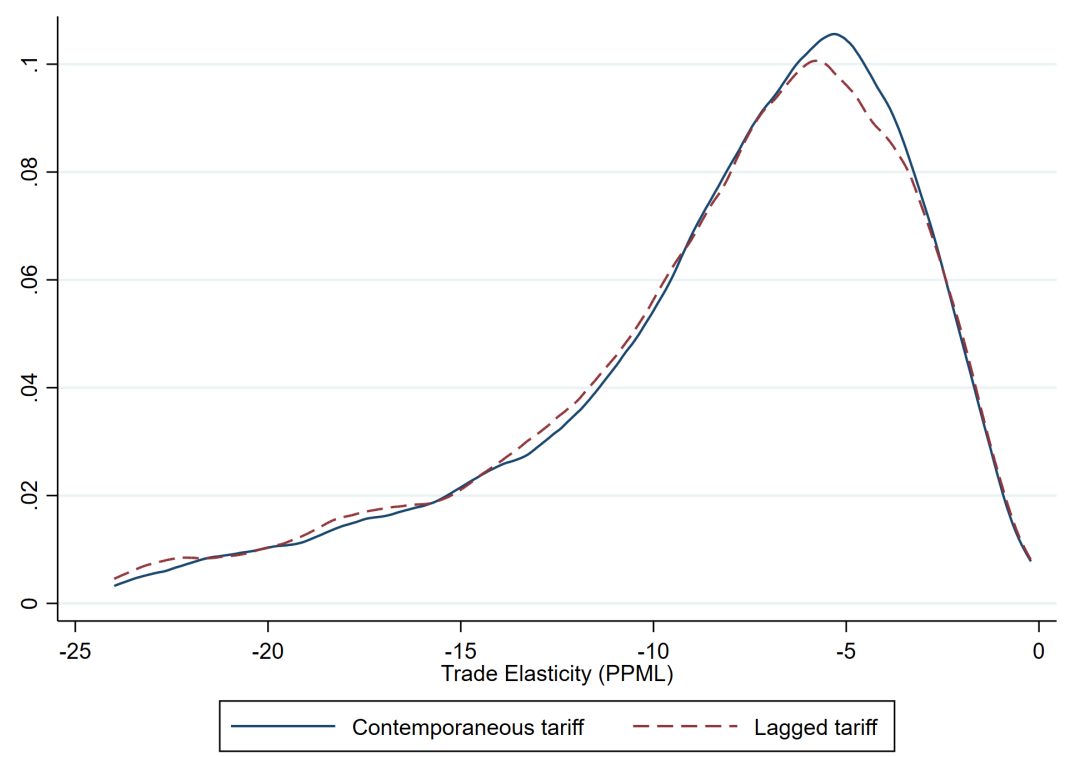

Note: The empirical distribution is calculated on HS-6 products with $\varepsilon_{k}<0$. Source: Authors' calculations. 
Figure A8 - The empirical distribution of trade elasticities across all HS 4-digit headings.

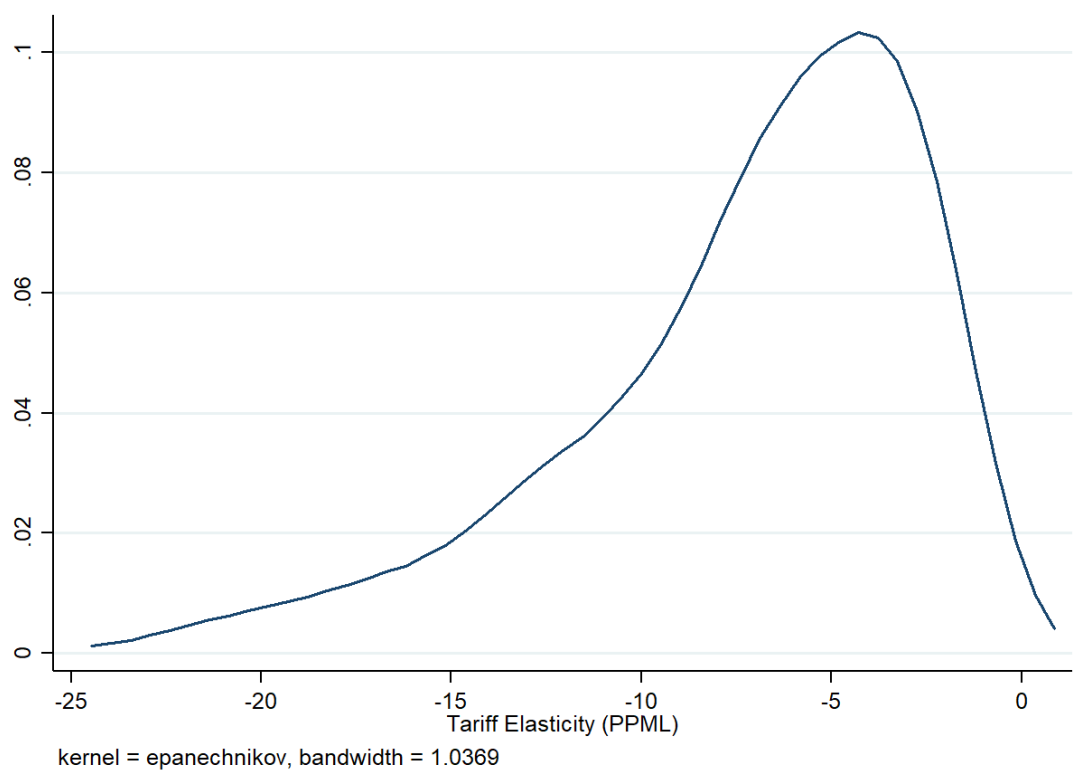

Note: The empirical distribution is calculated on HS-4 headings with $\varepsilon_{k}<0$. Source: Authors' calculations.

Figure A9 - The empirical distribution of trade elasticities: (i) baseline and (ii) conditional on a PTA dummy.

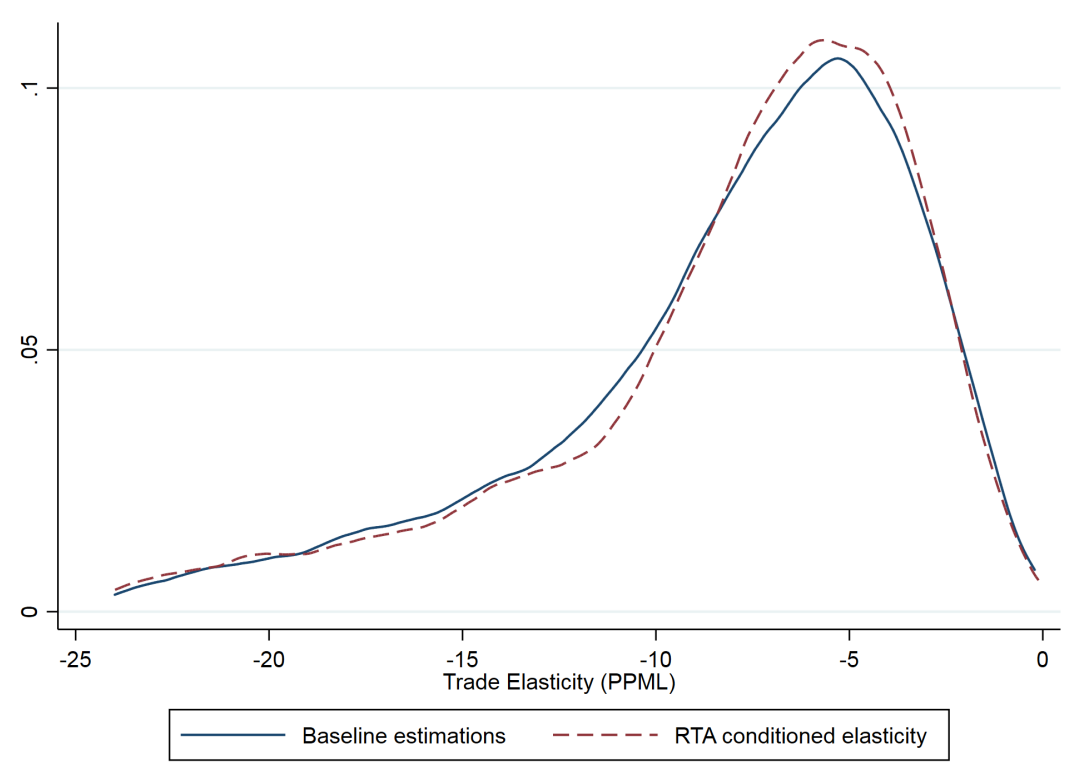

Note: The empirical distribution is calculated on HS-6 products with $\varepsilon_{k}<0$. Source: Authors' calculations. 
Figure A10 - The empirical distribution of trade elasticities: (i) baseline, (ii) conditional on country-pair fixed effects and (iii) conditional on country-pair specific trends.

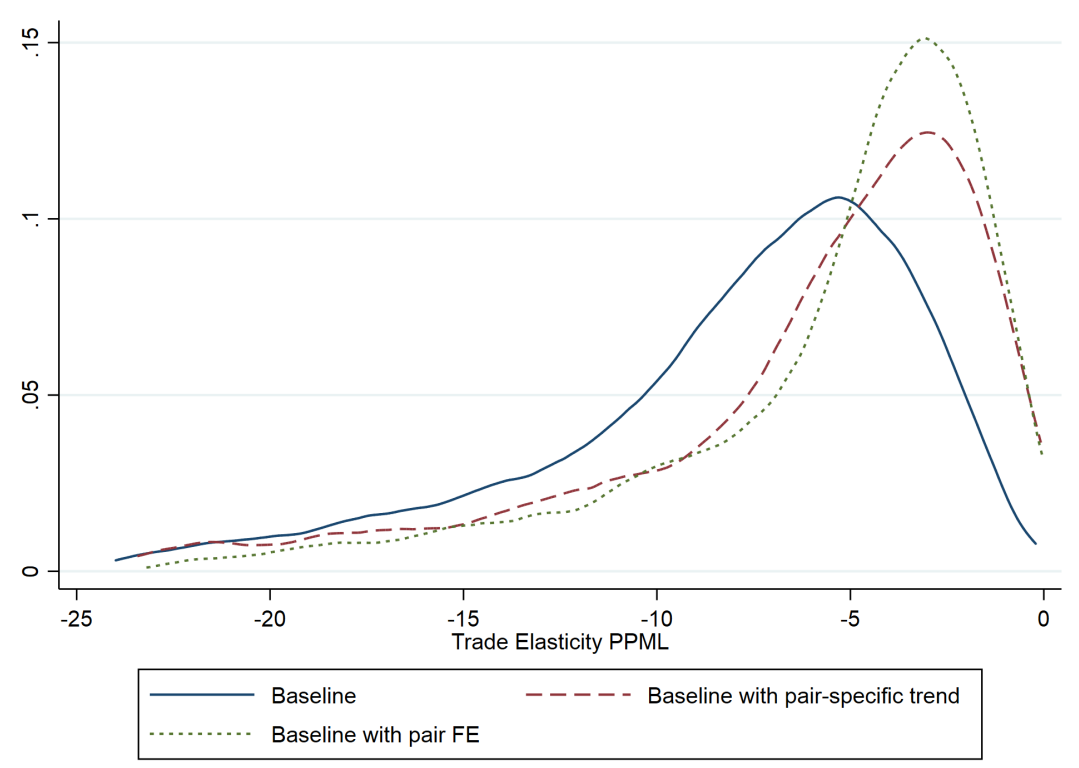

Note: The empirical distribution is calculated on HS-6 products with $\varepsilon_{k}<0$. Source: Authors' calculations. 


\section{B. Data}

We employ three main data sources in our analysis: (i) trade data from the $B A C I$ (CEPII) database on Worldwide bilateral trade flows, (ii) tariff data from the MAcMap - HS6 database on applied bilateral tariffs for 2001, 2004, 2007, 2010, 2013 and 2016; and (iii) gravity control variables introduced in the estimations (such as distance and common colony) from the CEPII gravity database.

Trade data. For a full matrix of importer and exporter countries, we use the $\mathrm{BACl}$ database. This provides information on bilateral trade flows (FOB), in current US Dollars, over the 1996-2016 period at the HS6 level. Based on COMTRADE, BACl has three particular features that are useful for our exercise. First, BACl fills empty cells in the World trade matrix using mirror trade flows. Second, BACl reconciles reported values between exporter $i$ and importer $j$ in a given product category $k$ and year $t$ pair: we can use either exports $X_{i, j, k, t}$ or imports $M_{j, i, k, t}$ as the figures are identical. ${ }^{90}$ Third, and importantly, $\mathrm{BACl}$ provides import values net of transport costs (hence FOB): transport and insurance rates were estimated by regressing the observed CIF/FOB ratio for a given flow on gravity variables and a productspecific World median unit value. More information is available as follows:

- Documentation: Gaulier, G. \& Zignago, S. (2010), Baci: International Trade Database at the Product-level. the 1994-2007 version, Working Paper 2010-23, CEPII.

- Access: http://www.cepii.fr/cepii/en/bdd_modele/presentation.asp?id=37.

Tariff data. To estimate the elasticity of import values to tariffs we need information on bilateral applied tariffs for all importers and exporters and all products. This information is provided by MAcMap-HS6, which is an aggregation of the tariff-line level instruments provided by the International Trade Center (ITC, UNCTAD-WTO) and made available to the CEPII. For each product and each country pair, MAcMap-HS6 provides the applied tariff inclusive of ad valorem equivalents of tariff quotas and specific tariffs. The method is the same over the different waves of data. An important feature of the database is that it $\overline{{ }^{90}}$ The reliability of reporting countries is used as a weight to reconcile bilateral trade flows. 
takes into account specific duties (transformed into ad valorem terms) as well as Tariff Rate Quotas. Filling rates are used to choose between the inside and outside tariff, when dealing with a tariff rate quota. Contingent protection is not included. More information is available as follows:

- Documentation: Guimbard, H., Jean, S., Mimouni, M. \& Pichot, X. (2012), MAcMapHS6 2007, an Exhaustive and Consistent Measure of Applied Protection in 2007, International Economics (130): 99-122.

- Access: http://www.cepii.fr/cepii/en/bdd_modele/presentation.aspid=12.

Gravity variables. The common gravity variables such as bilateral distance, common language, border and colony dummies are taken from the Gravity CEPII database available on line.

- Documentation: Head, K., Mayer, T. \& Ries, J. (2010), The Erosion of Colonial Trade Linkages after Independence, Journal of International Economics, 81(1):1-14

- Access: http://www.cepii.fr/cepii/en/bdd_modele/presentation.asp?id=8.

Construction of the estimation sample. MAcMap-HS6 covers 159 importers for 2001. Subsequent releases have increased coverage, with the exception of 2010 for which we have only 152 importers. We therefore retain the sample of the 152 importers that are present in all of the releases of MAcMap-HS6 (the list of importing countries appears in Table B1). On the exporting side the constraint is less binding, and we keep exporters that have been present in $\mathrm{BACl}$ since 2001. Ultimately, we have 189 exporters to 152 destinations in each year, and therefore potentially a fully-balanced dataset. However, at the HS6 level the Worldwide fullybalanced matrix of bilateral trade comprises many zeros, many of which are not relevant for the identification of the tariff coefficient. In particular, if a given exporting country $i$ never exports a specific product $k$, this would be perfectly predicted by the exporter-year fixed effects that always appear in Equation 5. We therefore carry out a fill-in of the World trade matrix with zeros only when country $i$ exports product $k$ to at least one destination over the period. 
Table B1 - The list of importing countries included in the estimation of Equation 5.

\begin{tabular}{|c|c|c|c|}
\hline Albania & Dominica & Latvia & Saint Lucia \\
\hline Algeria & Dominican Republic & Lebanon & Saint Vincent and the Grenadines \\
\hline Antigua and Barbuda & Ecuador & Libya & Saudi Arabia \\
\hline Argentina & Egypt & Lithuania & Senegal \\
\hline Armenia & El Salvador & Macedonia & Seychelles \\
\hline Australia & Equatorial Guinea & Madagascar & Singapore \\
\hline Austria & Eritrea & Malawi & Slovakia \\
\hline Azerbaijan & Estonia & Malaysia & Slovenia \\
\hline Bahamas & Ethiopia & Maldives & Solomon Islands \\
\hline Bahrain & Finland & Mali & South Africa \\
\hline Bangladesh & France & Malta & South Korea \\
\hline Barbados & Gabon & Mauritania & Spain \\
\hline Belarus & Georgia & Mauritius & Sri Lanka \\
\hline Belize & Germany & Mexico & Sudan \\
\hline Benin & Ghana & Moldova & Suriname \\
\hline Bermuda & Greece & Morocco & Sweden \\
\hline Bhutan & Grenada & Mozambique & Switzerland \\
\hline Bolivia & Guatemala & Myanmar & Syria \\
\hline Bosnia and Herzegovina & Guinea Bissau & Nepal & Tajikistan \\
\hline Brazil & Guyana & Netherlands & Tanzania \\
\hline Brunei Darussalam & Honduras & New Zealand & Thailand \\
\hline Burkina Faso & Hong Kong & Nicaragua & Togo \\
\hline Cambodia & Hungary & Niger & Trinidad and Tobago \\
\hline Cameroon & Iceland & Nigeria & Tunisia \\
\hline Canada & India & Norway & Turkey \\
\hline Central African Rep. & Indonesia & Oman & Uganda \\
\hline Chad & Iran & Pakistan & Ukraine \\
\hline Chile & Ireland & Panama & United Arab Emirates \\
\hline China & Israel & Papua New Guinea & United Kingdom \\
\hline Colombia & Italy & Paraguay & United States of America \\
\hline Congo & Jamaica & Peru & Uruguay \\
\hline Costa Rica & Japan & Philippines & Uzbekistan \\
\hline CÃtte d'Ivoire & Jordan & Poland & Vanuatu \\
\hline Croatia & Kazakhstan & Portugal & Venezuela \\
\hline Cuba & Kenya & Qatar & Vietnam \\
\hline Cyprus & Kuwait & Russia & Yemen \\
\hline Czech Republic & Kyrgyzstan & Rwanda & Zambia \\
\hline Denmark & Laos & Saint Kitts and Nevis & Zimbabwe \\
\hline
\end{tabular}




\section{The comparison to previous estimates of trade elasticities.}

As discussed in the introduction, this is not the first paper to provide trade elasticities (although we are the first to rely on the systematic coverage of exporters and importers at such a detailed level of product disaggregation). While the distribution of the productlevel elasticities obtained here is centered around values that are in line with those in the literature, the comparison shows more differences when aggregating these elasticities up to the classifications used in other papers. We now compare our trade-elasticity estimates to those in (i) Caliendo \& Parro (2015), ${ }^{91}$ (ii) Ossa (2015), ${ }^{92}$ (iii) Broda et al. (2006) $)^{93}$ and (iv) Kee et al. (2009). We aggregate our trade elasticities at the HS 3-digit level to compare with those in Broda et al. (2006) and Kee et al. (2009), at the SITC rev. 3 sector level to compare with Ossa (2015), and at the ISIC 2-digit level to compare with Caliendo \& Parro (2015). We calculate a weighted average of HS6 trade elasticities, using product-export shares (over World exports) in 2001 as the weights. For the correct comparison with other existing sets of elasticities, insignificant and missing elasticities have been replaced by the average HS 4-digit specific elasticity. The same strategy is adopted for the dataset of HS6 elasticities from this paper that has been made available online.

Table $\mathrm{C} 1$ shows the simple correlation indices and rank correlations between our estimated elasticities and those from the four benchmark papers above. Our elasticities are positively (although weakly) correlated with those in Broda et al. (2006), Caliendo \& Parro (2015) and Kee et al. (2009), and essentially uncorrelated with those in Ossa (2015). Our empirical method differs considerably from that in Broda et al. (2006), Kee et al. (2009) and Ossa (2015), but more importantly averaging product-level elasticities to produce sectorlevel elasticities is very sensitive to the weighting scheme: a simple average would produce a correlation of 0.8 with Caliendo \& Parro (2015). This is why we rely in the text on a more accurate strategy: TiVA (and other sector aggregations) elasticities are computed by pooling HS6 products within the TiVA sectors and estimating our equation sector by sector.

\footnotetext{
${ }^{91}$ See Table 1 in Caliendo \& Parro (2015).

${ }^{92}$ https: //docs. google.com/viewer?a=v\&pid=sites\&srcid=ZGVmYXVsdGRvbWFpbnXwcm9mb3NzYXV6aHxneDpiYTU3NmMxZ

${ }^{93}$ http: //www. columbia.edu/ dew35/TradeElasticities/TradeElasticities.html.
} 
Table C1 - The correlation index and Spearman rank correlation index between the tariff elasticities estimated here and those in (i) Caliendo \& Parro (2015), (ii) Ossa (2015), (iii) Broda et al. (2006) and (iv) Kee et al. (2009).

\begin{tabular}{|c|c|c|c|c|}
\hline Reference: & Sector Classification & Correlation & Rank Correlation & Obs. \\
\hline Broda et al. (2006) & HS 3 digit & 0.11 & 0.14 & 170 \\
\hline Ossa (2015) & SITC 3 digit & -0.05 & -0.19 & 248 \\
\hline Caliendo \& Parro (2015) & ISIC 2 digit & 0.26 & 0.07 & 15 \\
\hline Kee et al. (2009) & HS 3 digit & 0.20 & 0.07 & 169 \\
\hline
\end{tabular}

Notes: This table shows the simple and rank correlations between the trade elasticities estimated here and those in previous work. The aggregation of the trade elasticities from the HS 6-digit level to the sector classification adopted in previous papers is carried out as a weighted average. 


\section{An Instrumental-Variable approach}

The introduction of country-year fixed effects, along with gravity controls and the pre-existing trend test in Section 2 considerably reduce any endogeneity concerns, so that we consider our baseline PPML trade-elasticity estimates to be unbiased. This section aims to eliminate any residual endogeneity concerns by proposing a 2SLS approach. We instrument the bilateral HS 6-digit specific tariff with the average tariff imposed on other similar products (i.e. other HS 6-digit products within the same HS 4-digit heading). This is highly correlated with the bilateral product specific tariff $\tau_{i j k t}$ (IV relevance) and does not directly affect the bilateral imports of country $j$ from $i$ in product $k$ (IV validity). Our instrument for the bilateral product-specific tariff $\tau_{i j k t}$ is therefore the average tariff imposed by country $j$ on $i$ on other products $s \neq k$ :

$$
\tau_{i j k t}^{I V}=\frac{1}{S} \sum_{s \neq k} \tau_{i j s t}
$$

with $s$ and $k$ belonging to the same HS 4-digit heading and $S$ being the total (minus 1 ) number of HS 6-digit items within a given 4-digit heading. This instrumental variable has the same variability as the bilateral tariff $\tau_{i j k t}$ and allows us to retain the specification in Equation 5. This IV will be valid if (i) the level of imports of country $j$ from $i$ of product $k$ does not affect the tariff imposed on a different products $s$, and (ii) the tariff imposed on product $s$ affects the imports of $k$ only through its effect on the bilateral tariff $\tau_{i j k t}$. The exclusion restriction (i) is supported by the political-economy argument suggesting that the importer country reacts to import shocks (if any reaction happens) by protecting the specific product $k$. The exclusion restriction (ii) is plausibly satisfied as products belonging to a given 4-digit heading are only imperfectly-substitutable for each other, and any change in $k$-specific tariffs will likely re-direct the import demand of country $j$ toward an alternative supplier $i$ for the same $k$, rather than to another product $s$ (note that any $j k t$-specific diversion effect from a change in the tariff on product $k$ is captured by $j k t$ fixed effects). 
The trade elasticities from 2SLS estimation appear in Figure D1 as the dashed line, and are qualitatively the same as those from OLS estimation (the dotted line). This is the correct comparison as 2SLS is a log-linear model that does not consider zeros (the same as OLS). This (indirectly) shows the absence of endogeneity bias in our baseline PPML estimations. Were reverse causality to play a role in our log-linear estimations (OLS), then controlling for this via 2SLS should have produced larger tariff elasticities (more negative) and therefore higher trade elasticities. As the trade elasticities obtained via OLS and 2SLS are qualitatively the same, we conclude that there are no endogeneity concerns. In other words, we can reject the hypothesis that bilateral tariffs are endogenously set as a response to the competitive pressure of the exporter country (as also suggested by our pre-trend test in Table 1), so that our baseline PPML estimations are not biased. The relevance of our IV is supported by the statistical significance of the first-stage coefficient and their point estimates, which are on average around one (see Appendix Figure D2).

Figure D1 - The empirical distribution of trade elasticities. PPML, 2SLS and OLS estimations. IV based on the bilateral tariff imposed on similar products.

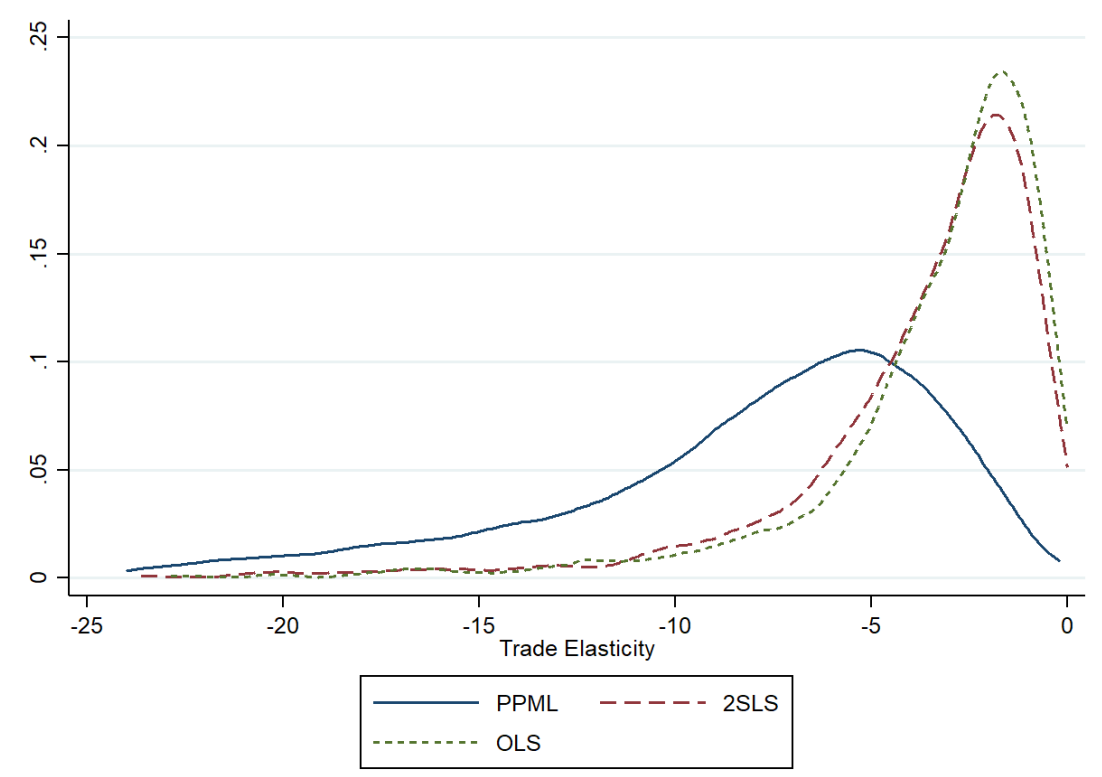

Note: The empirical distribution is calculated on HS-6 products with $\varepsilon_{k}<0$. Source: Authors' calculations. 
Figure D2 - The empirical distribution of the first-stage coefficient, i.e. the coefficient on $\tau_{i j k t}^{I V}$ in the first-stage regression.

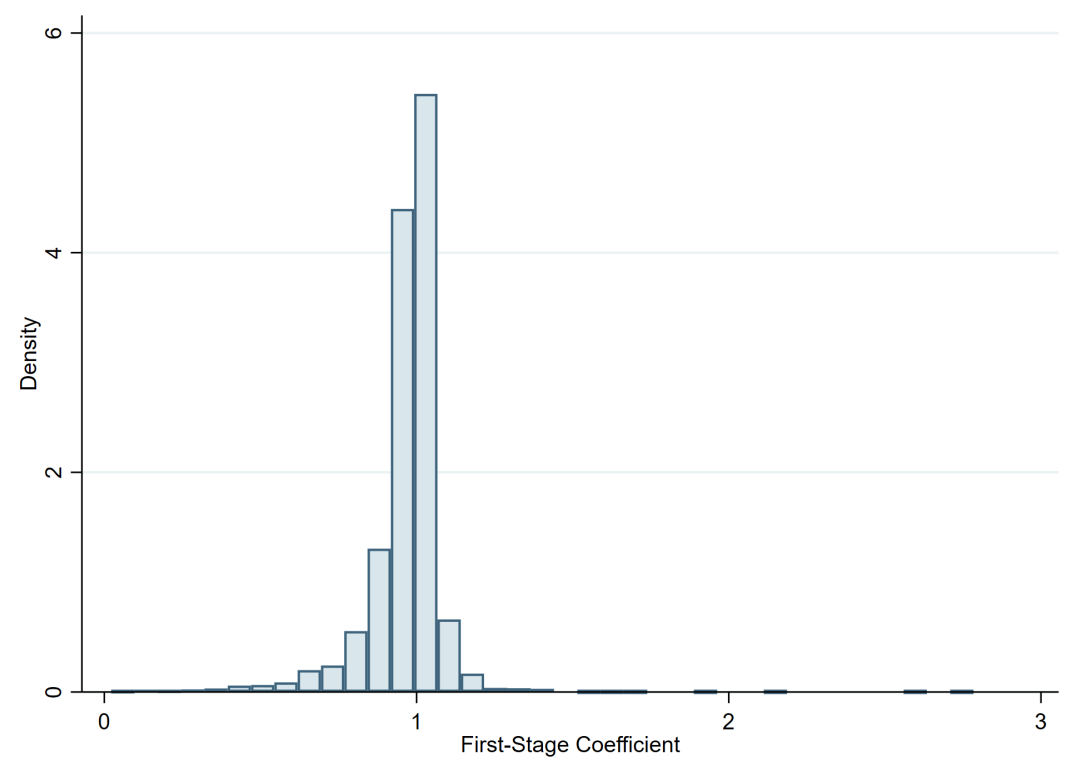

Source: Authors' calculations. 


\section{E. Panel versus Cross-section estimates}

Considering the small within-variation in tariffs (see Table 3), our baseline identification strategy relies on the cross-country variation in import tariffs (for a given importer-yearproduct). This strategy exploits the panel dimension of the bilateral trade and tariff data in order to be fully consistent with a structural gravity approach. Accordingly, our baseline equation is estimated for each product, over the whole period considered here, and includes exporter-time and importer-time fixed effects. This strategy raises two issues addressed in this sub-section. First, we may ask whether trade elasticities are stable over time. The pre- and post-2008 trade crisis periods might produce different elasticity patterns, or (more generally) tariff elasticities may not be constant over time. To address this first issue we estimate our set of elasticities separately for the two sub-periods, keeping our baseline specification, and restrict our attention to a sector where there is considerable variation in tariffs: the extreme case of Textiles. The second issue relates to the preferable approach to estimating trade elasticities (panel vs. cross-section). Are elasticities from repeated cross-section data on average consistent with those in panel data? Would it make sense to rely on cross-sectional estimations of elasticities in sectors where there is sufficient within variation in tariffs? As noted, there is non-negligible time variation in tariffs (the within component) for some HS sections, such as Textiles (HS section XI), Vegetable products (HS section II) and Prepared foodstuffs (HS section IV).

We address the first issue in Figure E1, where we correlate the product-level trade elasticities from Equation 5 in 2001-2007 (the horizontal axis) with those in 2010-2017 (the vertical axis). With some exceptions, the observations lie around the 45-degree line (with a correlation coefficient of 0.74 ), showing that estimated elasticities is qualitatively-insensitive to the time period analyzed (which is unsurprising, considering the set of time-specific fixed effects included in Equation 5).

To address the second issue, we adopt a repeated cross-section approach and estimate Equation 5 for each (product and) year separately, adjusting the set of fixed effects accordingly. ${ }^{94}$

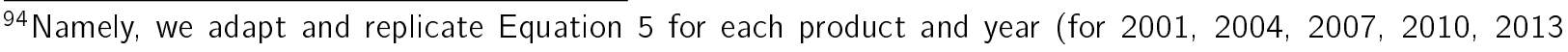


Figure E2 correlates the baseline elasticities obtained by estimating Equation 5 on a panel dataset (as described in Section 2.2) with the average elasticity (across years) obtained using the cross-section approach. Although (as expected) the correlation is strongly positive, with the majority of product elasticities lying around the 45-degree line, for certain product categories (in particular in the Mineral and Chemical sectors, HS chapters 26, 27 and 29) the trade elasticities from the two approaches differ considerably. Note that there is no systematic under- or over-estimation from the panel (with outliers on both sides of the 45-degree line).

We last focus again on the HS 2-digit chapter composing the Textile Section XI in Figure E3. The box plot shows boxes bordered at the 25th and 75 th percentiles of the time distribution of (the average) HS 2-digit trade elasticity, along with the median line and whiskers corresponding to the minimum and maximum elasticities. From Figure E3 there is a clear large gap in trade elasticities estimated by cross-section at different points in time for certain product categories (see for example the Wool, Vegetable and Textile sectors).

The evidence in Figures E2 and E3 suggests that, although the two empirical approaches produce on average qualitatively-similar results, there are notable exceptions. This reflects that the $\operatorname{Cov}\left(X_{j i t}-X_{. j t}, Y_{j i t}-Y_{. j t}\right)$ underlying the panel estimate with fixed effects in Equation 5 is different from the average $\operatorname{Cov}\left(X_{j i}-X_{. j}, Y_{j i}-Y_{. j}\right)$ used in the cross-section estimate. From a structural interpretation point of view, these exceptions stress that the cross-section approach, by abstracting from the time dimension, does not properly capture any exporter (or importer) specific time-varying shocks. For this reason the baseline panel approach is preferred in the paper.

and 2017). Considering the cross-section nature of these estimations, we include exporter and imported fixed effects only. 
Figure E1 - The correlation between the baseline HS6 trade elasticities estimated in the 2001-2007 and 2010-2017 sub-periods (Textile sector, HS section $\mathrm{XI}$ ).

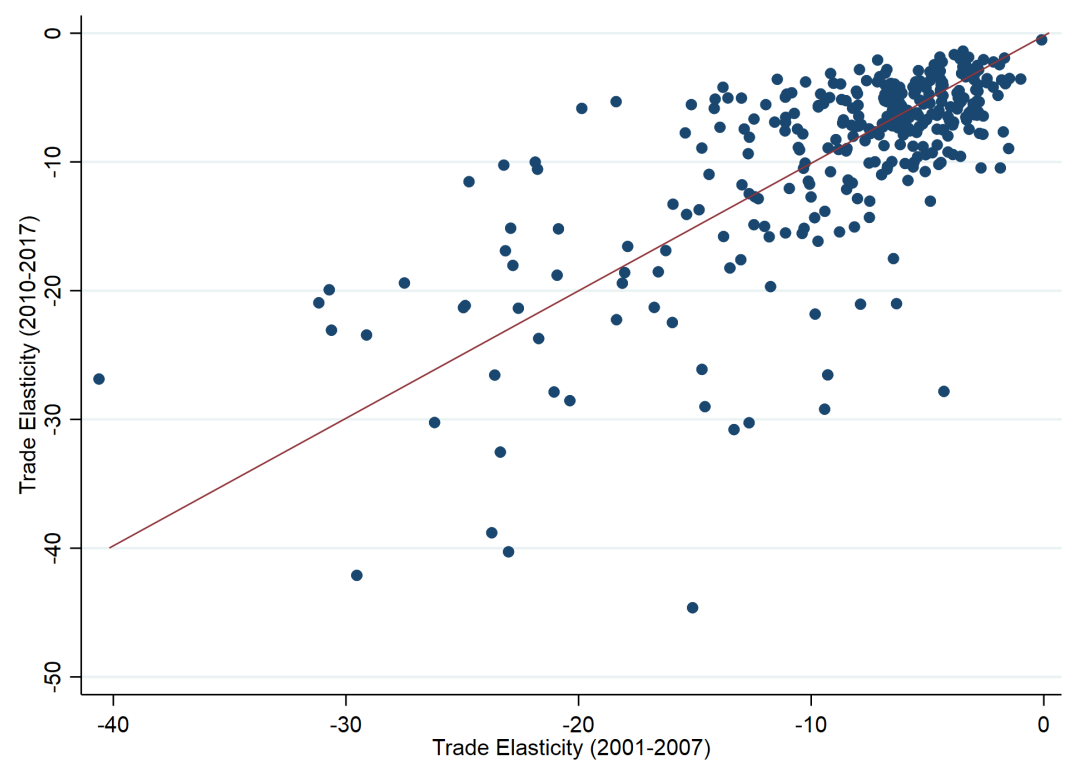

Notes: The empirical distribution is calculated on HS-6 products with $\varepsilon_{k}<0$. Trade elasticities under $\mathbf{- 5 0}$ are not shown for readability. Source: Authors' calculations.

Figure E2 - The correlation between the baseline trade elasticity estimations (PPML, panel) and the trade elasticity obtained by averaging HS6 elasticities across years (PPML, cross section).

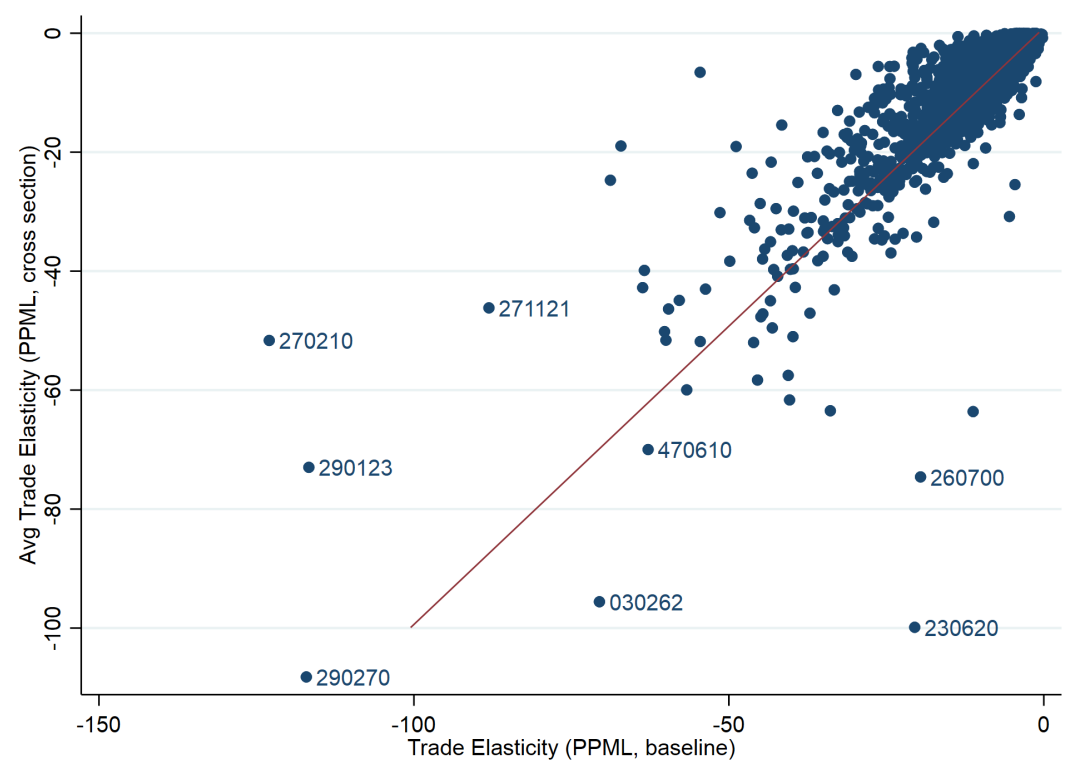

Note: The empirical distribution is calculated on HS-6 products with $\varepsilon_{k}<0$. Source: Authors' calculations. 
Figure E3 - Time variation in trade elasticities by HS 2-digit chapters of the Textile sector (HS section $\mathrm{XI}$ ).

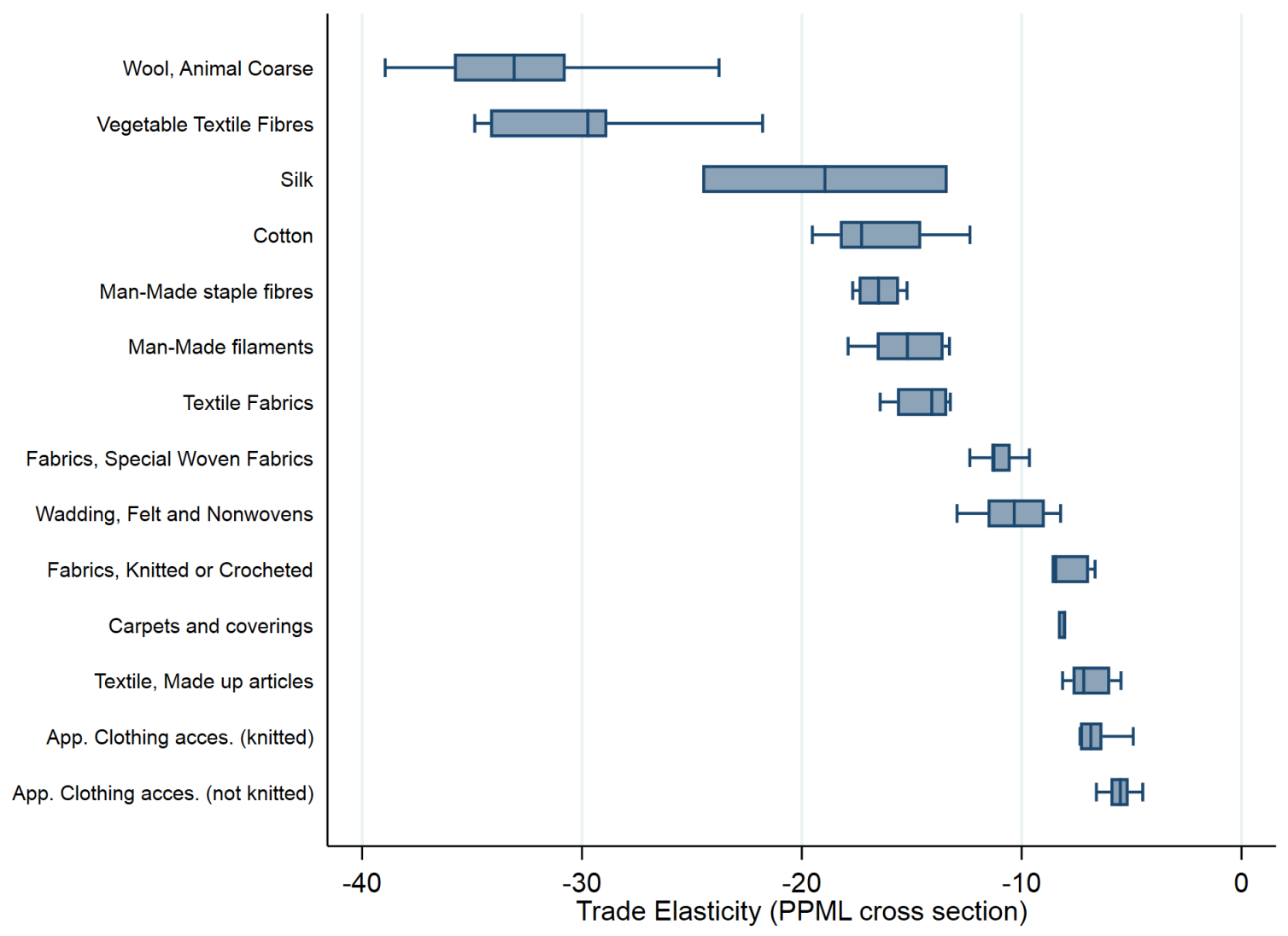

Notes: For each HS 2-digit chapter the borders of the box represent the 25th and 75th percentile in the time distribution of the HS 2-specific trade elasticity (obtained by averaging HS6-specific elasticities within an HS2). The whiskers correspond to the minimum and maximum. These statistics are calculated for HS- 6 products with $\varepsilon_{k}<0$. Source: Authors' calculations. 


\section{F. Interpreting positive and insignificant trade elasticities}

This section tentatively explains why certain elasticities were not precisely estimated. When estimating Equation 5 for each of the 5,050 HS-6 product lines using the PPML estimator, we obtain a small number of positive and some insignificant elasticities. These might appear puzzling at first glance, and we here propose some potential explanations.

Interpreting positive trade elasticities. We obtain positive $\beta_{k}$ parameters for certain products, implying positive trade elasticities $\varepsilon_{k} \cdot{ }^{95}$ Table F1 shows the descriptive statistics of the share of positive estimated $\varepsilon_{k}$ parameters that are statistically significant at the $1 \%$ level. This applies to $2.5 \%$ of the estimated $\varepsilon_{k},{ }^{96}$ and these are concentrated in a few veryparticular HS 2-digit chapters. Table F1 lists the HS 2-digit chapters in which the frequency of positive $\varepsilon_{k}$ coefficients is above the mean. Organic chemicals, Inorganic chemicals, and Nuclear reactors represent almost half of the total number of positive $\varepsilon_{k}$ elasticities in this Table. ${ }^{97}$ While in certain sectors, such as Nuclear reactors, we may not expect the usual market forces to apply, in others, like Chemicals, these positive trade elasticities deserve further scrutiny. When prices do not determine quantities, we should consider departures from monopolistically-competitive equilibrium. But here a lack of competition does not suffice to explain the reversal of the sign of the trade elasticity. We therefore consider an alternative explanation based on a general-equilibrium argument.

Let us first focus on market structures as an explanation for positive elasticities. Although these only represent $2.5 \%$ of the total sample of significant elasticities, we would like to

\footnotetext{
${ }^{95} \mathrm{~A}$ positive trade elasticity may also come about with small tariff elasticities, i.e. $-1<\beta_{k}<0$. However, this is only the case for one HS6 product.

${ }^{96}$ This figure rises to $4.3 \%$ and $6 \%$ respectively at the $5 \%$ and $10 \%$ significance levels. In the analysis that follows, and in the dataset we provide, we keep $1 \%$ significant $\varepsilon_{k}$ only. The trade elasticities with insignificant tariff coefficients are set to zero (as they are statistically not different from zero). In the published version of the database, each positive HS6 $\varepsilon_{k}$ coefficient is replaced by the average $\varepsilon_{k}$ of its HS-4 heading (the average across negative HS-6 specific $\varepsilon_{k}$ within the HS4). The products concerned are flagged. The database therefore contains five variables: (i) the HS6 product category, (ii) the value of the trade elasticity $\varepsilon_{k}$, (iii) a dummy for the $\varepsilon_{k}$ coefficient from the original estimation actually being one (i.e. an insignificant tariff elasticity), (iv) a dummy for the $\varepsilon_{k}$ from the original estimation being positive or ( $\mathrm{v}$ ) missing.

${ }^{97}$ The presence of numerous anti-dumping duties for Organic and Inorganic chemicals may help explain this outcome: in the presence of a binding overhang, imposing countries may increase their applied tariff up to the bound tariff in order to compensate for the phasing out of the anti-dumping duty, hence generating simultaneous rises in tariff and imports.
} 
characterize the product categories concerned. We thus adopt a purely heuristic approach and run a probit regression for having a positive trade elasticity (when the underlying tariff coefficient is positive) $-\mathbb{P}\left[\varepsilon_{k}>\left.0\right|_{\beta_{k}>0}\right]$ - using market-structure proxies:

$$
\mathbb{P}\left[\varepsilon_{k}>\left.0\right|_{\beta_{k}>0}\right]=\delta_{1} \mathbf{X}_{k}+\delta_{2} \mathbf{M}_{k}+\delta_{3} \mathbf{X} \mathbf{M}_{k}+\delta_{4} \mathbf{K}_{k}+\epsilon_{k}
$$

In Equation 11 the probability of a positive and significant (at the $1 \%$ level) trade elasticity for a given product $k$ from Equation 5 depends on four sets of covariates: (i) exporters' characteristics in the international trade of product $k\left(\mathbf{X}_{k}\right)$; (ii) importers' characteristics $\left(\mathbf{M}_{k}\right)$; (iii) country-pair characteristics in the international trade of product $k\left(\mathbf{X} \mathbf{M}_{k}\right)$; and (iv) product-specific characteristics $\left(\mathbf{K}_{k}\right)$. The set of covariates $\mathbf{X}_{k}$ includes the number of exporting countries in a specific $k$, their concentration (measured by a Herfindahl-Hirschmann index), and the average per capita GDP (weighted by total exports) of the exporter - here intended as a proxy for the technical level/quality of the exported products. Symmetrically, the set of covariates $\mathbf{M}_{k}$ includes the same variables but from the perspective of the importing countries. The vector $\mathbf{X} \mathbf{M}_{k}$ includes the number of exporter-importer pairs with zero-trade flows for a given $k$, and the average exporter-importer distance covered by a product in its international trade matrix (tentatively accounting for sorting effects in relation to trade costs). ${ }^{98}$ Last, the set of product-specific covariates $\mathbf{K}_{k}$ includes a dummy for differentiated vs. homogeneous products and, importantly, the average HS 4-digit applied worldwide bilateral tariff. ${ }^{99}$

The results in Table F2 show the empirical regularities behind the observed deviations from the monopolistically-competitive equilibrium for certain product categories. First, products $k$ with a highly-concentrated set of exporters and/or importers (as revealed by the $\mathrm{HH}$ index) are more likely to have positive tariff elasticities, and therefore trade elasticities $\varepsilon_{k}>0$. With

\footnotetext{
${ }^{98}$ We consider here the average distance across country-pairs in a given product $k$, weighted by trade flows. As the estimated elasticity $\varepsilon$ does not vary over time, all of the explanatory variables have been expressed as averages over the time period.

${ }^{99}$ Given the large chunk of positive trade elasticities in the Nuclear-reactors sector (HS 84), we re-estimated Equation 11 excluding HS chapter 84: the results do not change.
} 
substantial market concentration, higher tariffs at destination may lead to unexpected results: the deterioration of market access at destination may push incumbent exporters to exert even greater effort to secure their presence at destination. In a model of imperfect competition and variable markups, firms reduce their markups and thus export prices when they lose market share (Atkeson \& Burstein 2008). This yields a negative relationship between tariffs and export prices (see Fontagné et al. 2018), which may partially offset the direct negative tariff effect on exports. A second regularity in Table F2 is the positive correlation between the average income of exporters and importers and the probability of obtaining positive trade (and tariff) elasticities. On the exporter side this mirrors the technological level of goods, while on the importing side this is in line with the recent literature on non-homothetic preferences (Markusen 2013), in which markups rise with destination per capita income (Bertoletti, Etro \& Simonovska 2018). But again, this would not explain the positive impact of tariffs on demand for a given quality of the imported good. Some unobserved general-equilibrium effect is likely at play. In order to address this general-equilibrium issue, we observe the impact of tariffs on other goods within the same broad category. We obtain a positive (although weakly-significant) coefficient on average HS 4-digit tariffs: as the tariff on another similar product $s \neq k$ increases (here captured by the average tariff in the HS4 chapter), imports of $j$ may rise even though $j$ 's import tariff is higher as a result of the substitution of $j$ with $s .{ }^{100}$

Interpreting insignificant trade elasticities. The same proxies for market structure used to estimate Equation 11 may also explain our insignificant tariff coefficients. Columns 3-4 of Table F2 show the results from Equation 11, where the dependent variable is the probability of an insignificant underlying tariff elasticity, i.e. $\mathbb{P}\left[\beta_{k}=0\right]$.

Columns (3)-(4) of Table F2 reveal a positive correlation between insignificant tariff elasticities and the average income of exporting and importing countries. Similarly, there is a

\footnotetext{
${ }^{100}$ This argument should not be confused with the IV exclusion-restriction assumption discussed in Section D. For the validity of our IV we (plausibly) assume the absence of substitution effect across HS6 products (of a given HS4 heading) within the $i j$ trade relationship: when country $j$ raises its tariff on product $k$ exported by $i$, the demand for $k$ will then likely be diverted towards a new supplier $n \neq i$ of that product (rather than towards some imperfect substitute for $k$ produced by $i$ ). Here, as a potential explanation for the lack of reaction of the demand for product $k$ to a change in tariffs, we assume that there is substitutability between the HS6 products in a given HS4 heading. As such, when the average tariff on some HS6 product over all ij country pairs rises, the demand for this product switches to another product within the same HS4 heading.
} 
positive correlation between the average distance covered by a product and the probability of an insignificant tariff elasticity. Although these results are consistent with high-quality products often being characterized by low elasticities of substitution (Hummels \& Skiba 2004) they might also reflect a statistical problem: developed countries have low tariffs on average and little variation in these tariffs, making it difficult to estimate the tariff coefficient. Also, in line with intuition, columns (3)-(4) reveal that the demand for differentiated products is relatively insensitive to tariffs, as shown here by the positive and significant impact of differentiation on the probability of an insignificant $\beta_{k}$ estimate on the tariff variable in our baseline equation.

Last, columns (3) and (4) of Table F2 illustrate the intrinsic difficulties of trade-elasticity estimation based on tariff changes. First, we observe that the presence of zero trade flows for a given product (and so limited variation in the dependent variable) increases the probability of an insignificant $\beta_{k}$ estimate. Second, this probability falls with the number of exporting countries of a given product. This is consistent, as we exploit the variation in the bilateral tariff imposed by importers on the different exporters of the product: all else equal, the variation in the tariff is expected to rise in the number of exporters, making it easier to estimate precisely the parameter of interest. Despite these intrinsic obstacles, our estimations perform fairly well, as testified by the only small number of positive or insignificant $\beta_{k}$ estimates. 


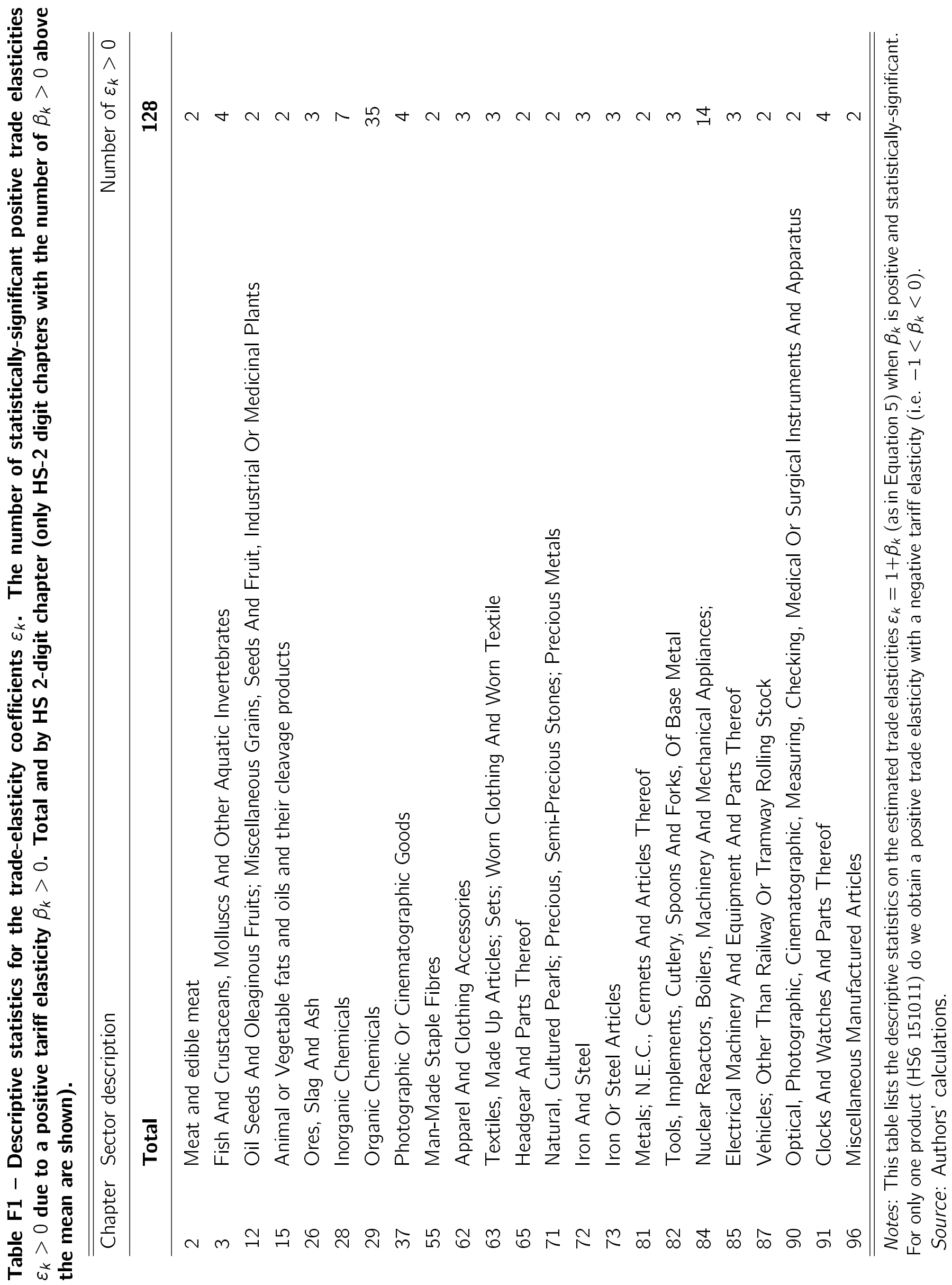


Table F2 - Probit regression of the probability of obtaining (i) a positive trade elasticity (when the tariff elasticity is positive) and (ii) an insignificant trade elasticity.

\begin{tabular}{|c|c|c|c|c|}
\hline \multirow[t]{2}{*}{ Dep var: } & \multicolumn{2}{|c|}{$\mathbb{P}\left[\varepsilon_{k}>\left.0\right|_{\beta_{k}>0}\right]$} & \multicolumn{2}{|c|}{$\mathbb{P}\left[\beta_{k}=0\right]$} \\
\hline & $(1)$ & $(2)$ & (3) & $(4)$ \\
\hline Concentration exporters ( $\mathrm{HH}$ index) & $\begin{array}{c}1.217^{* * *} \\
(0.382)\end{array}$ & $\begin{array}{c}1.519 * * * \\
(0.472)\end{array}$ & $\begin{array}{l}-0.274 \\
(0.250)\end{array}$ & $\begin{array}{l}-0.349 \\
(0.268)\end{array}$ \\
\hline Concentration importers ( $\mathrm{HH}$ index) & $\begin{array}{c}2.126 * * * \\
(0.600)\end{array}$ & $\begin{array}{c}2.139 * * * \\
(0.687)\end{array}$ & $\begin{array}{c}0.243 \\
(0.384)\end{array}$ & $\begin{array}{c}0.107 \\
(0.408)\end{array}$ \\
\hline Average per capita GDP exporters (In) & $\begin{array}{c}0.260 * * \\
(0.121)\end{array}$ & $\begin{array}{l}0.256^{*} \\
(0.144)\end{array}$ & $\begin{array}{c}0.0608 \\
(0.0638)\end{array}$ & $\begin{array}{l}0.167 * * \\
(0.0716)\end{array}$ \\
\hline Average per capita GDP importers (In) & $\begin{array}{c}0.565^{* * *} \\
(0.179)\end{array}$ & $\begin{array}{c}0.521^{* *} \\
(0.209)\end{array}$ & $\begin{array}{c}0.275^{* * *} \\
(0.0818)\end{array}$ & $\begin{array}{l}0.220 * * \\
(0.0965)\end{array}$ \\
\hline Average distance across country-pairs (In) & $\begin{array}{c}0.183 \\
(0.139)\end{array}$ & $\begin{array}{c}0.123 \\
(0.164)\end{array}$ & $\begin{array}{c}0.645^{* * *} \\
(0.0750)\end{array}$ & $\begin{array}{c}0.628 * * * \\
(0.0829)\end{array}$ \\
\hline Number of zero-trade flows $(\ln )$ & $\begin{array}{c}4.834 * * \\
(2.434)\end{array}$ & $\begin{array}{l}5.861^{*} \\
(3.250)\end{array}$ & $\begin{array}{c}8.869 * * * \\
(1.135)\end{array}$ & $\begin{array}{c}8.997 * * * \\
(1.250)\end{array}$ \\
\hline Number of exporting countries (In) & $\begin{array}{c}-4.770 * * \\
(2.319)\end{array}$ & $\begin{array}{c}-5.468 * \\
(3.107)\end{array}$ & $\begin{array}{c}-9.148 * * * \\
(1.058)\end{array}$ & $\begin{array}{c}-9.222 * * * \\
(1.166)\end{array}$ \\
\hline Number of importing countries (In) & $\begin{array}{l}-34.42 \\
(42.56)\end{array}$ & $\begin{array}{c}27.09 \\
(64.31)\end{array}$ & $\begin{array}{l}-10.93 \\
(24.52)\end{array}$ & $\begin{array}{l}-24.11 \\
(29.91)\end{array}$ \\
\hline Differentiated & $\begin{array}{r}-0.0189 \\
(0.121)\end{array}$ & $\begin{array}{c}0.117 \\
(0.170)\end{array}$ & $\begin{array}{c}0.229 * * * \\
(0.0553)\end{array}$ & $\begin{array}{c}0.207^{* * *} \\
(0.0755)\end{array}$ \\
\hline Average HS4 tariff & $\begin{array}{c}3.828 * * \\
(1.796)\end{array}$ & $\begin{array}{l}5.084 * \\
(2.955) \\
\end{array}$ & $\begin{array}{l}-0.113 \\
(1.003) \\
\end{array}$ & $\begin{array}{c}2.489 * \\
(1.471) \\
\end{array}$ \\
\hline HS 1-digit Fixed effects & Yes & No & Yes & No \\
\hline HS 2-digit Fixed effects & No & Yes & No & Yes \\
\hline Observations & 3,930 & 2,925 & 4,339 & 4,301 \\
\hline
\end{tabular}

Notes: The dependent variable in columns $1-2$ is a dummy for the estimated trade elasticity $\varepsilon_{k}=1+\beta_{k}$ in Equation 5 being positive and significant at the $1 \%$ level with an underlying positive tariff elasticity. The dependent variable in columns 3-4 is a dummy for the estimated trade elasticity $\varepsilon_{k}=1+\beta_{k}$ in Equation 5 being statistically insignificant at the $1 \%$ level (due to an insignificant tariff elasticity). Robust standard errors appear in parentheses. $* * * p<0.01 ; * * p<0.05 ; * p<0.1$. The number of observations falls across specifications 1 and 2, 3 and 4, as the inclusion of HS 1-digit and 2-digit fixed effects implies the dropping of chapters and sectors having only negative trade elasticities (i.e. $\mathbb{P}\left[\varepsilon_{k}>\left.0\right|_{\beta_{k}>0}\right]=0$ ) in all $k$ within a HS1 and HS2 chapter) or always non-zero. 


\section{G. Online Appendix}

Table G1 - Descriptive statistics. Average tariff by HS section and year.

\begin{tabular}{llcccccc}
\hline \hline Section & Description & 2001 & 2004 & 2007 & 2010 & 2013 & 2016 \\
\hline I & Live Animals and Animal Products & 17.4 & 17.6 & 16.4 & 15.5 & 14.8 & 14.2 \\
II & Vegetable Products & 15.3 & 15.2 & 13.5 & 13.0 & 12.5 & 11.7 \\
III & Animal or vegetable fats and oils & 13.6 & 13.6 & 12.0 & 11.0 & 10.6 & 10.4 \\
IV & Prepared foodstuffs, beverages and tobacco & 21.4 & 21.6 & 19.8 & 18.9 & 17.5 & 16.9 \\
V & Mineral products & 5.5 & 5.3 & 4.7 & 4.4 & 4.2 & 3.9 \\
VI & Products of chemical industries & 6.3 & 6.1 & 5.0 & 4.7 & 4.5 & 4.3 \\
VII & Plastic and articles thereof & 9.3 & 9.0 & 7.6 & 7.2 & 7.0 & 6.7 \\
VIII & Raw hides and skins, leather and article thereof & 11.2 & 11.0 & 9.7 & 9.5 & 9.1 & 8.6 \\
IX & Wood/Cork and articles of Wood/Cork; & 11.0 & 10.8 & 9.2 & 8.9 & 8.5 & 8.0 \\
X & Pulp of wood or other cellulose materials & 8.3 & 8.2 & 7.2 & 7.0 & 6.6 & 6.2 \\
XI & Textile and textile articles & 14.6 & 13.1 & 11.8 & 11.4 & 10.9 & 10.5 \\
XII & Footwear, Headgear, Umbrellas and prepared feathers & 16.6 & 16.2 & 14.4 & 14.0 & 13.3 & 12.6 \\
XIII & Articles of stone, plaster, ceramic and glass & 11.8 & 11.5 & 10.3 & 9.9 & 9.6 & 9.2 \\
XIV & Natural cultured pearls and precious stones and metals & 11.4 & 11.0 & 9.5 & 9.5 & 9.0 & 8.5 \\
XV & Base metals and articles of base metals & 8.3 & 8.1 & 7.1 & 6.8 & 6.5 & 6.2 \\
XVI & Machinery and mechanical appl. and electrical machinery & 6.9 & 6.8 & 5.8 & 5.4 & 5.1 & 4.9 \\
XVII & Vehicles, Aircraft and transport equipment & 9.7 & 9.4 & 8.1 & 7.6 & 7.1 & 6.8 \\
XVIII & Optical, photographic, precision and medical instruments & 8.6 & 8.5 & 7.3 & 6.9 & 6.6 & 6.3 \\
XIX & Arms and ammunitions & 18.2 & 18.2 & 16.5 & 15.9 & 15.1 & 13.5 \\
XX & Miscellaneous & 14.2 & 13.9 & 12.3 & 12.1 & 11.6 & 11.3 \\
XXI & Works of art & 10.8 & 10.5 & 9.4 & 9.4 & 9.0 & 8.5 \\
\hline \hline
\end{tabular}

Note: This table shows the simple average tariffs by HS section and year. Source: MAcMap-HS6, authors' calculations. 
Table G2 - Descriptive statistics. The standard deviation of tariffs by HS section and year.

\begin{tabular}{llcccccc}
\hline \hline Section & Description & 2001 & 2004 & 2007 & 2010 & 2013 & 2016 \\
\hline I & Live Animals and Animal Products & 28.9 & 31.4 & 31.8 & 28.0 & 27.4 & 26.2 \\
II & Vegetable Products & 29.2 & 30.3 & 26.2 & 24.6 & 23.3 & 23.1 \\
III & Animal or vegetable fats and oils & 17.8 & 19.2 & 17.5 & 16.1 & 16.1 & 16.1 \\
IV & Prepared foodstuffs, beverages and tobacco & 41.4 & 46.9 & 47.8 & 45.6 & 39.9 & 38.6 \\
V & Mineral products & 7.4 & 7.5 & 6.7 & 6.7 & 11.3 & 6.4 \\
VI & Products of chemical industries & 9.2 & 10.0 & 8.6 & 8.5 & 8.2 & 7.4 \\
VII & Plastic and articles thereof & 10.5 & 11.1 & 9.6 & 9.5 & 9.6 & 8.9 \\
VIII & Raw hides and skins, leather and article thereof & 13.5 & 14.0 & 13.0 & 13.1 & 12.9 & 11.3 \\
IX & Wood/Cork and articles of Wood/Cork; & 16.4 & 16.7 & 10.8 & 10.7 & 10.4 & 9.8 \\
X & Pulp of wood or other cellulose materials & 9.6 & 10.7 & 9.3 & 9.3 & 8.8 & 8.5 \\
XI & Textile and textile articles & 34.6 & 14.3 & 13.9 & 13.3 & 13.3 & 13.1 \\
XII & Footwear, Headgear, Umbrellas and prepared feathers & 15.6 & 16.8 & 14.7 & 14.4 & 13.9 & 13.3 \\
XIII & Articles of stone, plaster, ceramic and glass & 11.9 & 12.9 & 11.3 & 11.2 & 11.0 & 10.7 \\
XIV & Natural cultured pearls and precious stones and metals & 13.8 & 13.7 & 12.2 & 12.4 & 12.0 & 11.6 \\
XV & Base metals and articles of base metals & 9.2 & 10.4 & 8.8 & 8.9 & 8.6 & 8.3 \\
XVI & Machinery and mechanical appl. and electrical machinery & 8.5 & 10.2 & 8.1 & 8.1 & 7.8 & 7.6 \\
XVII & Vehicles, Aircraft and transport equipment & 14.6 & 15.1 & 12.5 & 11.9 & 11.5 & 10.5 \\
XVIII & Optical, photographic, precision and medical instruments & 10.2 & 11.7 & 9.5 & 9.5 & 9.2 & 9.0 \\
XIX & Arms and ammunitions & 26.1 & 27.0 & 25.4 & 24.9 & 21.2 & 15.1 \\
XX & Miscellaneous & 12.8 & 13.7 & 12.2 & 12.1 & 11.9 & 11.6 \\
XXI & Works of art & 12.6 & 12.5 & 11.3 & 11.4 & 11.2 & 11.0 \\
\hline
\end{tabular}

Note: This table shows the standard deviation of tariffs by HS section and year. Source: MAcMap-HS6, authors' calculations. 
Table G3 - The trade elasticity by GTAP revision 10 sectors.

\begin{tabular}{|c|c|c|}
\hline GTAP code & Sector description & Trade elasticity $\varepsilon$ \\
\hline oap & Animal Products n.e.c. & -4.29 \\
\hline b_t & Beverages and Tobacco products & -2.73 \\
\hline c_b & Cane and Beet: sugar crops & -2.33 \\
\hline $\mathrm{ctl}$ & Cattle: bovine animals, live, other ruminants & -6.39 \\
\hline $\mathrm{chm}$ & Chemicals and chemical products & -7.79 \\
\hline $\mathrm{coa}$ & Coal: mining and agglomeration of hard coal & NS \\
\hline ele & Computer, electronic and optical products & -5.26 \\
\hline ocr & Crops n.e.c. & -2.87 \\
\hline eeq & Electrical equipment & -4.63 \\
\hline ely & Electricity; steam and air conditioning supply & NS \\
\hline $\mathrm{pfb}$ & Fibres crops & -12.05 \\
\hline fsh & Fishing and hunting (including related service activities) & -5.04 \\
\hline ofd & Food products n.e.c. & -4.71 \\
\hline frs & Forestry: forestry, logging and related service activities & -2.53 \\
\hline gdt & Gas manufacture, distribution & NS \\
\hline gas & Gas: extraction of natural gas (including related activities) & NS \\
\hline i_s & Iron and Steel: basic production and casting & -3.45 \\
\hline lea & Leather and related products & -6.00 \\
\hline ome & Machinery and equipment n.e.c. & -4.13 \\
\hline omt & Meat products n.e.c & -5.17 \\
\hline $\mathrm{cmt}$ & Meat: fresh or chilled & -4.04 \\
\hline fmp & Metal products, except machinery and equipment & -4.22 \\
\hline mil & Milk and dairy products & -4.77 \\
\hline mvh & Motor vehicles, trailers and semi-trailers & -8.98 \\
\hline $\mathrm{nfm}$ & Non-Ferrous Metals & -13.09 \\
\hline osd & Oil Seeds: oil seeds and oleaginous fruit & -2.05 \\
\hline oil & Oil: extraction of crude petroleum (including related activities) & -10.89 \\
\hline gro & Other Grains (maize, sorghum, barley, rye, oats, millets) & NS \\
\hline omf & Other Manufacturing (includes furniture) & -4.89 \\
\hline oxt & Other Mining Extraction & -8.23 \\
\hline $\mathrm{nmm}$ & Other non-metallic mineral products & -4.82 \\
\hline otn & Other transport equipment & -7.98 \\
\hline ppp & Paper and Paper Products & -8.18 \\
\hline p_c & Petroleum and Coke & -3.64 \\
\hline bph & Pharmaceuticals, medicinal chemical and botanical products & -8.35 \\
\hline pcr & Processed Rice: semi- or wholly milled, or husked & -6.46 \\
\hline pdr & Rice: seed, paddy (not husked) & -7.63 \\
\hline rpp & Rubber and plastics products & -7.04 \\
\hline sgr & Sugar and molasses & -3.76 \\
\hline tex & Textiles & -6.03 \\
\hline vol & Vegetable Oils and fats & -2.75 \\
\hline$v_{-} f$ & Vegetables and Fruits (including nuts and edible roots) & -4.02 \\
\hline wap & Wearing apparel & -3.84 \\
\hline wht & Wheat: seed, other & -2.61 \\
\hline lum & Wood, products of wood, cork (except furniture) and straw & -8.69 \\
\hline wol & Wool, silk, and other raw animal materials used in textile & -7.28 \\
\hline
\end{tabular}

Notes: Estimations based on the HS (rev 2007)-GTAP conversion table available online (https: //www .gtap. agecon. purdue.edu/resources/res_display. asp?RecordID=5111) as of March $31^{\text {st }}$ 2020. Source: Authors' calculations. 
Figure G1 - The empirical distribution of trade elasticities $\varepsilon_{k}$ (PPML estimations) based on 5\% significant tariff elasticities.

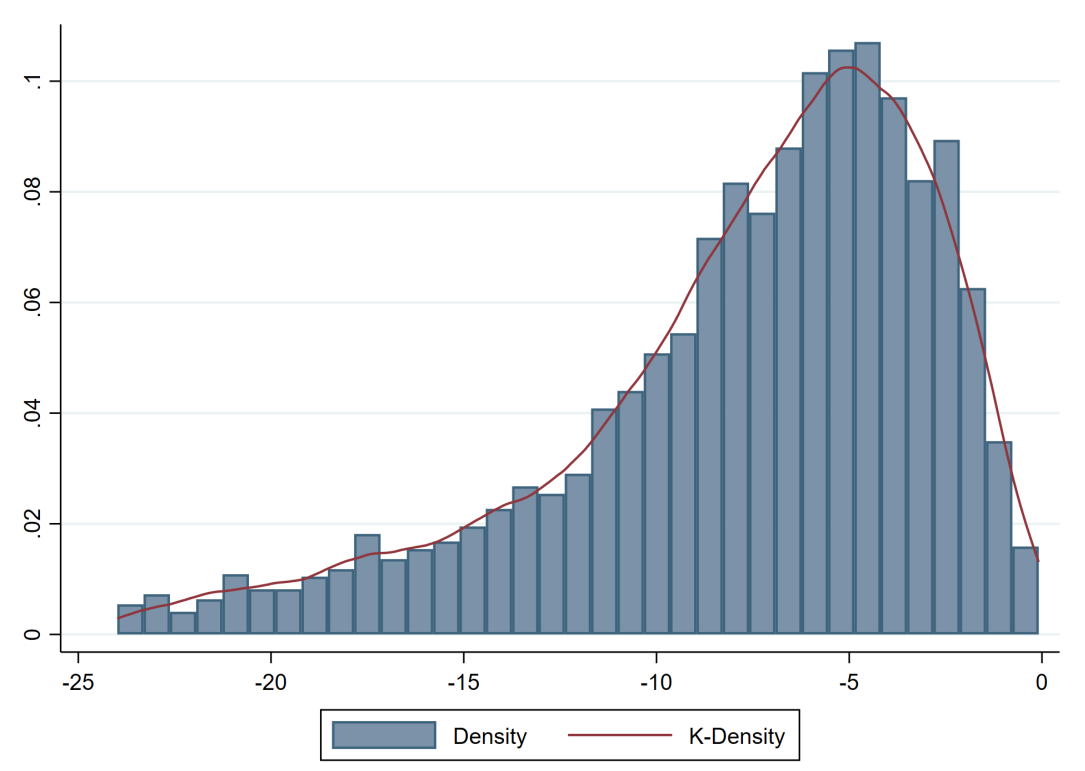

Note: The empirical distribution is calculated on HS-6 products with $\varepsilon_{k}<0$. Source: Authors' calculations.

Figure G2 - The empirical distribution of trade elasticities $\varepsilon_{k}$ (PPML estimations) based on $10 \%$ significant tariff elasticities.

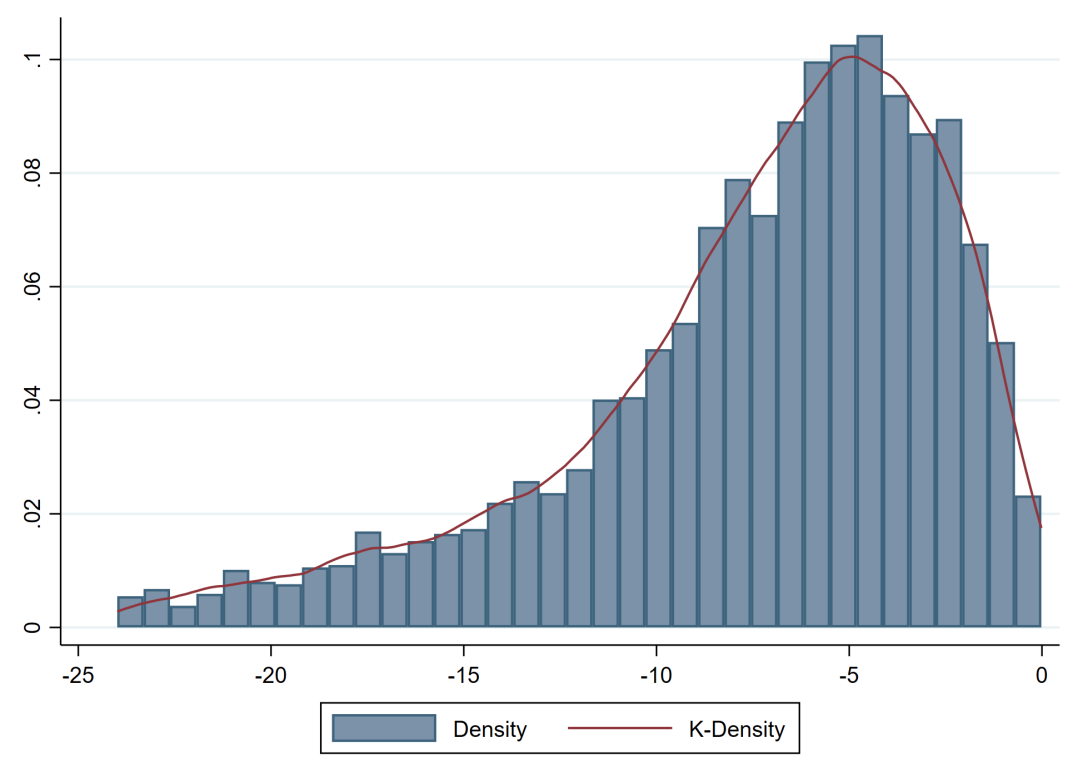

Note: The empirical distribution is calculated on HS-6 products with $\varepsilon_{k}<0$. Source: Authors' calculations. 
Figure G3 - The empirical distribution of trade elasticities $\varepsilon_{k}$ (PPML estimations) abstracting from the statistical significance of tariff elasticities.

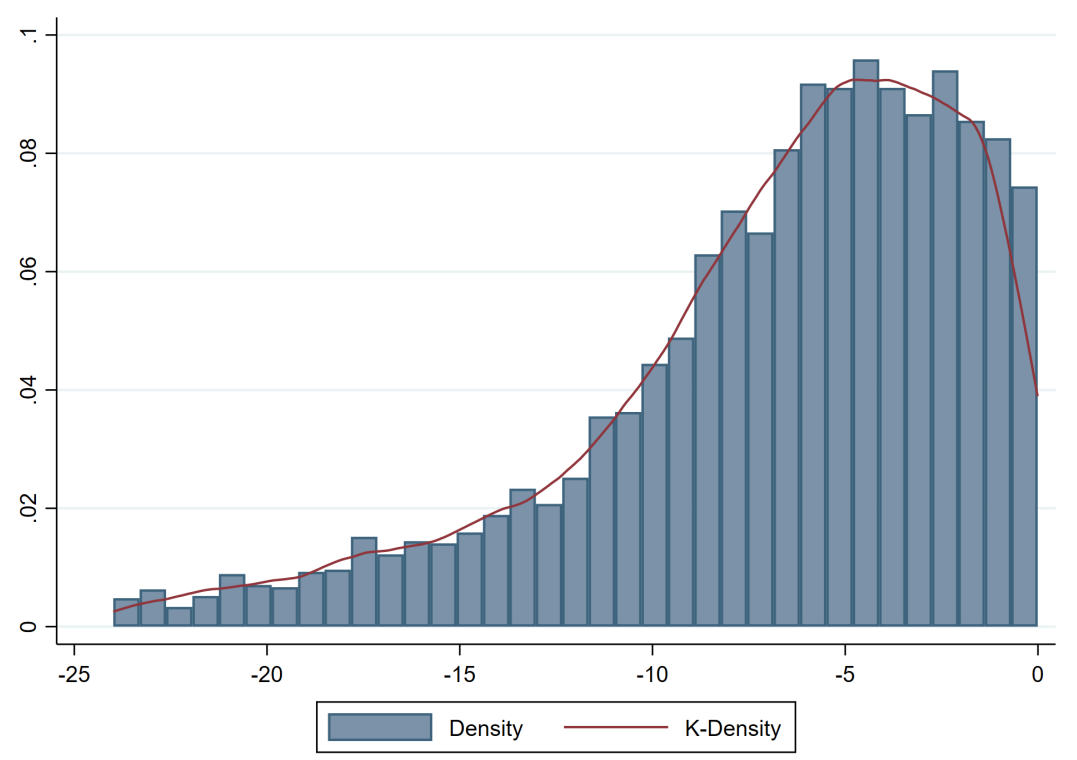

Note: The empirical distribution is calculated on HS-6 products with $\varepsilon_{k}<0$. Source: Authors' calculations.

Figure G4 - Differences in trade elasticities among HS 4-digit chapters of the same HS 2-digit heading: the example of Apparel and Clothing Accessories (HS 61).

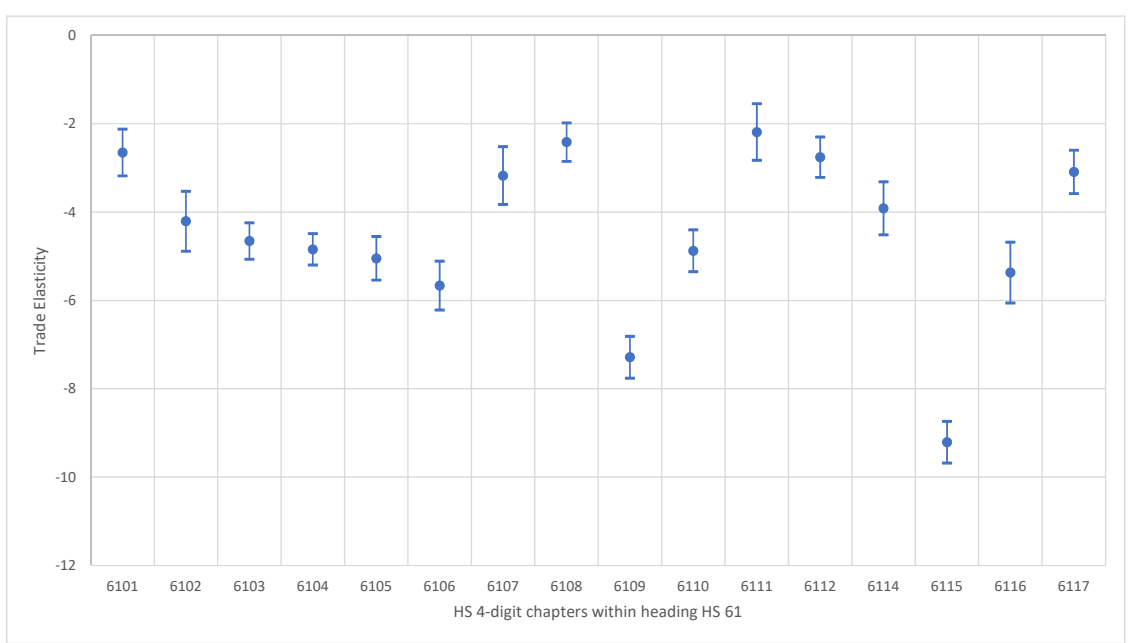

Notes: The whiskers correspond to the upper and lower values of the trade elasticity for a given HS 4-digit chapter (i.e. trade elasticity values plus/minus one standard error). Source: Authors' calculations. 
Figure G5 - The empirical distribution of trade elasticities $\varepsilon_{k}$ : (i) baseline, and (ii) conditional on having more than five trade partners.

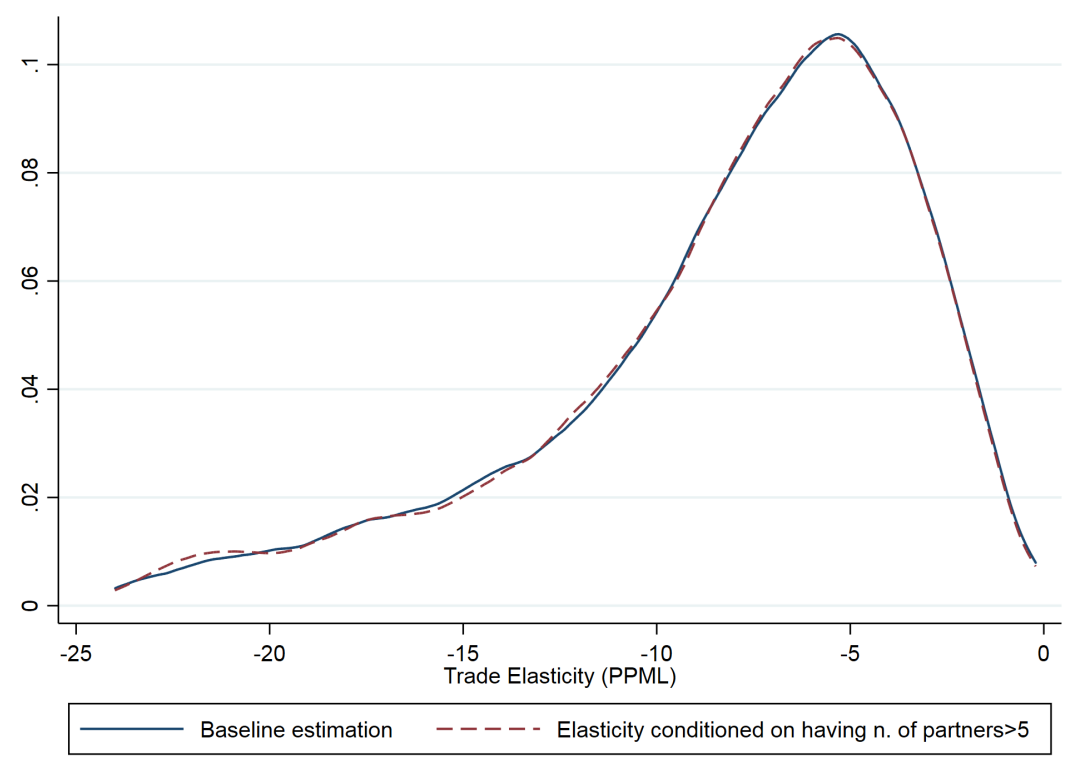

Note: The empirical distribution is calculated on HS-6 products with $\varepsilon_{k}<0$. Source: Authors' calculations.

Figure G6 - The empirical distribution of trade elasticities $\varepsilon_{k}$ : (i) baseline, and (ii) excluding country-pairs with specific tariffs.

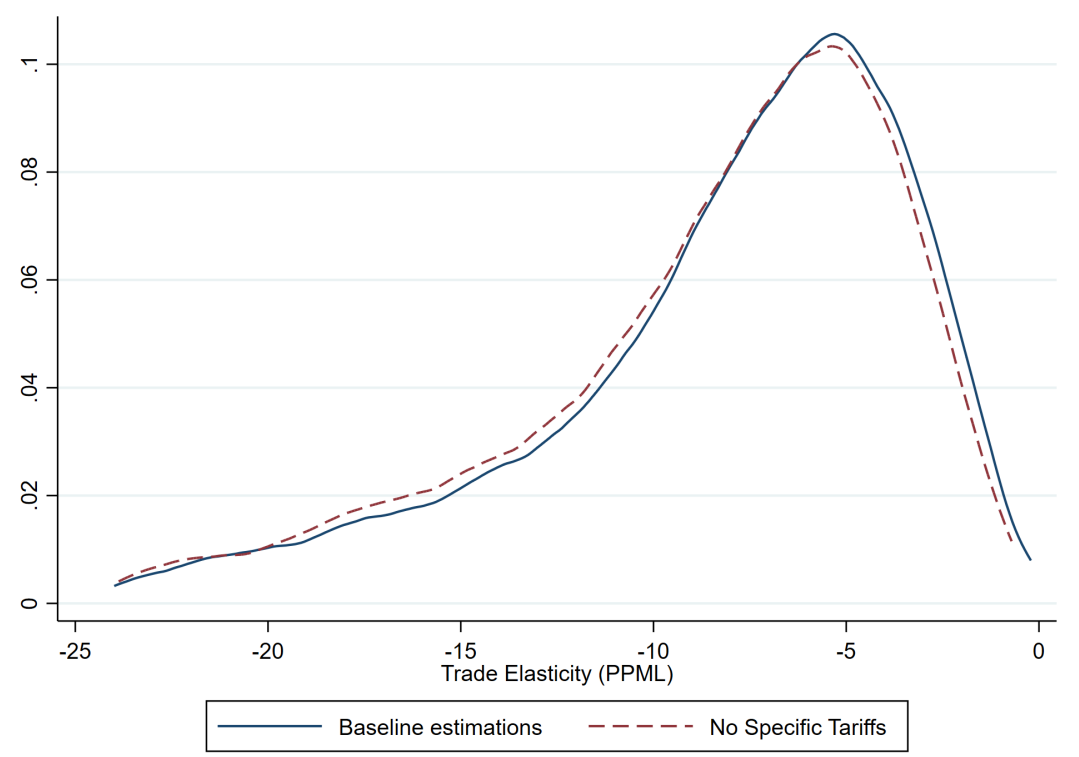

Note: The empirical distribution is calculated on HS-6 products with $\varepsilon_{k}<0$. Source: Authors' calculations. 
Figure G7 - The correlation between the bias in welfare-change evaluation (heteregeneous $v s$. homogeneous trade elasticities) and per capita GDP in 2010 . The homogeneous trade elasticity is a simple average (unweighted).

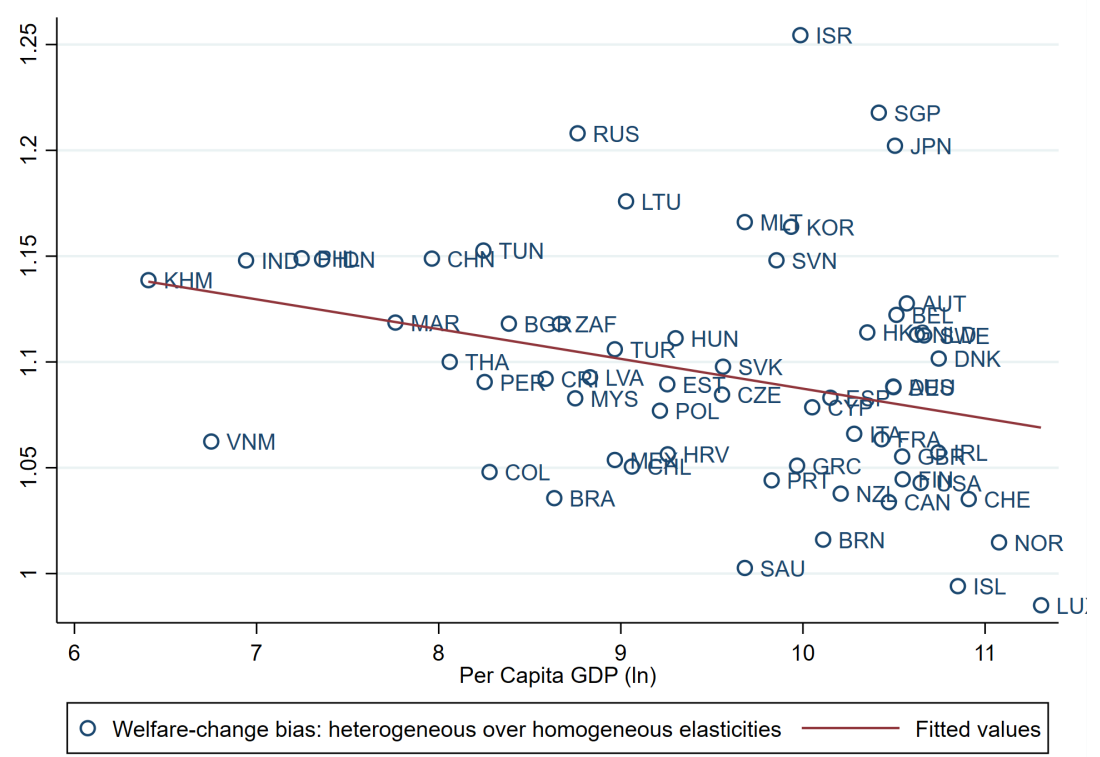

Notes: The vertical axis shows the ratio of the welfare changes calculated using heterogeneous $(\widehat{W \text { Hetero }})$ and homogeneous $(\widehat{W \text { Homog }})$ elasticities, with the latter being the unweighted average $\varepsilon$ across products in our dataset. Source: Authors' calculations. 
Table G4 - Ex-ante welfare evaluation: moving to autarky. The change in log real income across non-OECD countries using the ACR formula with heterogeneous $v s$. homogeneous trade elasticities (simple and weighted averages).

\begin{tabular}{|c|c|c|c|}
\hline & \multirow[t]{2}{*}{ Heterogeneous } & \multicolumn{2}{|c|}{ Homogeneous elasticity } \\
\hline & & simple avg & weight. avg \\
\hline Argentina & 0.077 & 0.074 & 0.071 \\
\hline Brazil & 0.047 & 0.045 & 0.043 \\
\hline Bulgaria & 0.218 & 0.195 & 0.188 \\
\hline Cambodia & 0.211 & 0.185 & 0.179 \\
\hline China & 0.060 & 0.052 & 0.050 \\
\hline Colombia & 0.119 & 0.114 & 0.110 \\
\hline Costa Rica & 0.204 & 0.187 & 0.181 \\
\hline Croatia & 0.139 & 0.131 & 0.127 \\
\hline Cyprus & 0.422 & 0.392 & 0.380 \\
\hline India & 0.067 & 0.059 & 0.056 \\
\hline Indonesia & 0.067 & 0.058 & 0.056 \\
\hline Malaysia & 0.214 & 0.198 & 0.191 \\
\hline Malta & 0.349 & 0.299 & 0.290 \\
\hline Morocco & 0.188 & 0.168 & 0.162 \\
\hline Peru & 0.118 & 0.108 & 0.104 \\
\hline Philippines & 0.099 & 0.086 & 0.083 \\
\hline Romania & 0.137 & 0.114 & 0.110 \\
\hline Russia & 0.113 & 0.093 & 0.090 \\
\hline Saudi Arabia & 0.211 & 0.211 & 0.203 \\
\hline Singapore & 0.334 & 0.274 & 0.265 \\
\hline South Africa & 0.140 & 0.125 & 0.120 \\
\hline Taiwan & 0.194 & 0.171 & 0.165 \\
\hline Thailand & 0.127 & 0.116 & 0.111 \\
\hline Tunisia & 0.281 & 0.244 & 0.236 \\
\hline Vietnam & 0.204 & 0.192 & 0.185 \\
\hline
\end{tabular}

Notes: In calculating the cost of autarky we follow ACR(2010) Sections 3.3 and 5.1. The simple and weighted average elasticities are respectively 5.6 and 5.9. Source: Authors' calculations. 
Table G5 - Ex-ante welfare evaluation: moving to autarky. The change in log real income across OECD countries using the ACR formula with heterogeneous $v s$. homogeneous trade elasticities (simple and weighted averages).

\begin{tabular}{|c|c|c|c|}
\hline & \multirow[t]{2}{*}{ Heterogeneous } & \multicolumn{2}{|c|}{ Homogeneous elasticity: } \\
\hline & & simple avg & weight. avg \\
\hline Australia & 0.149 & 0.137 & 0.132 \\
\hline Austria & 0.194 & 0.172 & 0.166 \\
\hline Belgium & 0.177 & 0.158 & 0.152 \\
\hline Canada & 0.194 & 0.188 & 0.181 \\
\hline Chile & 0.202 & 0.193 & 0.186 \\
\hline Czech Republic & 0.202 & 0.187 & 0.180 \\
\hline Denmark & 0.175 & 0.159 & 0.154 \\
\hline Estonia & 0.239 & 0.219 & 0.212 \\
\hline Finland & 0.186 & 0.178 & 0.172 \\
\hline France & 0.152 & 0.143 & 0.137 \\
\hline Germany & 0.134 & 0.123 & 0.119 \\
\hline Greece & 0.184 & 0.175 & 0.169 \\
\hline Hungary & 0.263 & 0.236 & 0.228 \\
\hline Iceland & 0.314 & 0.316 & 0.306 \\
\hline Ireland & 0.286 & 0.271 & 0.262 \\
\hline Israel & 0.265 & 0.211 & 0.204 \\
\hline Italy & 0.127 & 0.119 & 0.115 \\
\hline Japan & 0.071 & 0.059 & 0.057 \\
\hline Latvia & 0.251 & 0.230 & 0.222 \\
\hline Lithuania & 0.196 & 0.167 & 0.161 \\
\hline Luxembourg & 0.512 & 0.519 & 0.506 \\
\hline Mexico & 0.139 & 0.132 & 0.127 \\
\hline Netherlands & 0.122 & 0.109 & 0.105 \\
\hline New Zealand & 0.156 & 0.150 & 0.145 \\
\hline Norway & 0.142 & 0.140 & 0.135 \\
\hline Poland & 0.167 & 0.155 & 0.149 \\
\hline Portugal & 0.205 & 0.197 & 0.190 \\
\hline Slovakia & 0.250 & 0.227 & 0.220 \\
\hline Slovenia & 0.276 & 0.241 & 0.232 \\
\hline South Korea & 0.148 & 0.127 & 0.122 \\
\hline Spain & 0.169 & 0.156 & 0.150 \\
\hline Sweden & 0.206 & 0.185 & 0.179 \\
\hline Switzerland & 0.226 & 0.218 & 0.211 \\
\hline Turkey & 0.092 & 0.084 & 0.080 \\
\hline United Kingdom & 0.189 & 0.179 & 0.173 \\
\hline United States & 0.094 & 0.090 & 0.086 \\
\hline
\end{tabular}

Notes: In calculating the cost of autarky we follow ACR(2010) Sections 3.3 and 5.1. The simple and weighted average elasticities are respectively 5.6 and 5.9. Source: Authors' calculations. 